Georgia State University

ScholarWorks @ Georgia State University

\title{
Understanding of Earth and Space Science Concepts: Strategies for Concept Building in Elementary Teacher Preparation
}

Nermin Bulunuz

Follow this and additional works at: https://scholarworks.gsu.edu/ece_diss

\section{Recommended Citation}

Bulunuz, Nermin, "Understanding of Earth and Space Science Concepts: Strategies for Concept Building in Elementary Teacher Preparation." Dissertation, Georgia State University, 2007.

doi: https://doi.org/10.57709/1059133

This Dissertation is brought to you for free and open access by the Early Childhood and Elementary Education Department at ScholarWorks @ Georgia State University. It has been accepted for inclusion in Early Childhood and Elementary Education Dissertations by an authorized administrator of ScholarWorks @ Georgia State University. For more information, please contact scholarworks@gsu.edu. 


\section{ACCEPTANCE}

This dissertation, UNDERSTANDING OF EARTH AND SPACE SCIENCE CONCEPTS: STRATEGIES FOR CONCEPT BUILDING IN ELEMENTARY TEACHER PREPARATION by NERMIN BULUNUZ was prepared under the direction of the candidate's Dissertation Committee. It is accepted by the committee members in partial fulfillment of the requirements for the degree Doctor of Philosophy in the College of Education, Georgia State University.

The Dissertation Advisory Committee and the student's Department Chair, as representatives of the faculty, certify that this dissertation has met all standards of excellence and scholarship as determined by the faculty. The Dean of the College of Education concurs.

Olga S. Jarrett, Ph. D.

Committee Chair

Geeta Verma, Ph.D.

Committee Member

Date

Barbara Meyers, Ph.D.

Chair, Department of Early Childhood Education
Barbara Meyers, Ph.D.

Committee Member

Committee Member

Ronald P. Colarusso, Ed.D.

Dean, College of Education 


\begin{abstract}
AUTHOR'S STATEMENT
By presenting this dissertation as a partial fulfillment of the requirements for the advanced degree from Georgia State University, I agree that the library of Georgia State University shall make it available for inspection and circulation in accordance with its regulations governing materials of this type. I agree that permission to quote, to copy from, or to publish this dissertation mat be granted by the professor under whose direction it was written, by the College of Education' s director of graduate studies and research, or by me. Such quoting, copying, or publishing must be solely for scholarly purposes and will not involve potential financial gain. It is understood that any copying from or publication of this dissertation which involves potential financial gain will not be allowed without my written permission.
\end{abstract}

Nermin Bulunuz 


\title{
NOTICE TO BORROWERS
}

All dissertation deposited in the Georgia State University library must be used in accordance with the stipulations prescribed by the author in the preceding statement. The author of this dissertation is:

\author{
Nermin Bulunuz \\ 758 Derrydown Way \\ Decatur, GA 30030
}

The director of this dissertation is:

Dr. Olga S. Jarrett

Department of Early Childhood Education

College of Education

Georgia State University

Atlanta, GA 30303-3083 
VITA

Nermin Bulunuz

ADDRESS:

758 Derrydown Way

Decatur, GA 30030

EDUCATION:

$\begin{array}{ccl}\text { Ph.D. } & 2006 & \begin{array}{l}\text { Georgia State University } \\ \text { Early Childhood Education }\end{array} \\ \text { M.Ed. } & 2000 & \begin{array}{l}\text { Uludağ University } \\ \text { Elementary Education Department } \\ \text { Middle East Technical University } \\ \text { Biology Education }\end{array} \\ \text { B.A. } & 1995 & \end{array}$

PROFESSIONAL EXPERIENCE:

2003-Present

1999-2003

1997-1999

1995-1997
Graduate Research Assistant

Georgia State University, Early Childhood Education Department

Research Assistant

Uludağ University, Elementary Education Department

Science Teacher

Mudanya Anadolu Lisesi

Biology Teacher

Malatya Hüseyin Kölük

Anadolu Ticaret Meslek Lisesi

PROFESSIONAL SOCIETIES AND ORGANIZATIONS:

2005- Present

The National Association for Research in Science Teaching NARST

SELECTED PRESENTATION AND PUBLICATIONS:

Jarrett, O., Kimbro, P., Higdon, L., Bulunuz, M., \& Bulunuz, N. (2006, May). Teachers' effects on block and dramatic play: Video analysis of pre-K. Paper presented at the annual conference of The Association for the Study of Play, Brock University, St. Catharines, Ontario.

Bulunuz, N., \& Jarrett, O. (2006, February). Basic earth and space science concepts: Building elementary teacher understanding, Paper presented at the annual meeting of the Georgia Science Teachers Association, Colombus, GA. 
Jarrett, O., French-Lee, S., Bulunuz, M., Kimbro, P., \& Bulunuz, N. (2005, February).

Play in the Block and Pretend Play Areas: Context for Developing Positive Approaches to Learning. Paper presented at the annual conference of The Association for the Study of Play, Santa Fe, NM.

Bulunuz, N., Jarrett, O., \& Bulunuz, M. (2005, April). Fifth-grade Turkish elementary school students' conceptions and misconceptions about the fungus kingdom.

Paper presented at the annual conference of the National Association for Research in Science Teaching, Dallas, Texas.

Bulunuz, M., Jarrett, O. S., \& Bulunuz, N. (2005, April). Undergraduate and masters students' content knowledge about physical properties of air: Do demonstrations and hands-on activities bring about change? Paper presented at the annual meeting of the National Association for Research in Science Teaching, Dallas, TX.

Bulunuz, N., Jarrett, O., \& Bulunuz, M. (2004, October). What is fungus? Inquiry into different forms of fungi, Workshop presented at the annual conference of the School Science and Mathematics Association, Atlanta, GA.

Bulunuz, M., Jarrett, O. S., \& Bulunuz, N. (2004, October). The Turkish middle school students' conceptions on physical properties of air. Paper presented at the annual conference of the School Science and Mathematics Association, Atlanta.

Bulunuz, M., Jarrett, O. S., Bulunuz, N., \& Hoge, P. (2004, April). Properties of air and Bernoulli's Principle: Using discrepant events to teach inquiry-based science. Paper presented at the annual meeting of the National Science Teachers Association, Atlanta, GA.

Hoge, P., Jarrett, O. S., Bulunuz, M., Bulunuz, N., Jarrett, R., Jarrett, E., \& Adams, M. (2004, April). Science from Georgia. Workshop presented at the annual meeting of the National Science Teachers Association, Atlanta, GA.

Hoge, P., Jarrett, O. S., Bulunuz, M., \& Bulunuz, N. (2004, April). Science centers for under \$5.00. Workshop presented at the annual meeting of the National Science Teachers Association, Atlanta, GA.

Jarrett, O. S., Hoge, P., Bulunuz, M., Bulunuz, N., \& Jarrett, R. (2004, April). Playful science: Math and science investigations on the playground. Workshop presented at the annual meeting of the National Science Teachers Association, Atlanta, GA.

French-Lee, S., Jarrett, O., Bulunuz, N., \& Bulunuz, M. (2004, February). What do children do in the sand pit? A look at gender, age, and materials. Paper presented at the annual conference of The Association for the Study of Play, Atlanta, GA.

Bulunuz, N., \& Ergul, R. (2002, May). The effects of previous science experiences of preservice teachers to their self-confidence in science teaching. Paper presented at the first international education conference of Eastern Mediterranean University, Gazimagosa, North Cyprus.

Bulunuz, N., \& Ergül, R. (2001). The research for determination to self-confidence of preservice teachers in using laboratory measurement instruments and mathematic knowledge. Journal of Uludağ University Faculty of Education, 14(1), 65-71. 


\section{ABSTRACT \\ UNDERSTANDING OF EARTH AND SPACE SCIENCE CONCEPTS: STRATEGIES FOR CONCEPT BUILDING IN ELEMENTARY TEACHER PREPARATION}

by

Nermin Bulunuz

Research on conceptual change provides strong evidence that not only children but also many adults have incorrect or incomplete understanding of science concepts. This mixed methods study was concerned with preservice and inservice teachers' understanding of six earth and space science concepts commonly taught in elementary school: reasons for seasons, phases of the moon, reasons for the wind, the rock cycle, soil formation, and earthquakes. The first part of the study determined and compared the level of conceptual understanding held by both groups on topics they will need to teach in the Georgia Performance Standards [GPS]. The second part focused on whether readings or hands-on learning stations, in some cases combined with concept mapping, improves preservice teachers' understanding of these concepts. The third part described the application of conceptual change strategies of one group of preservice teachers during their field placements. The overall sample was two cohorts of preservice teachers, one cohort of preservice teachers from an alternative initial certification program, and two masters' cohorts consisting of inservice teachers. Four data sources were: a six item open-ended survey, concept maps, the field assignments, and the researcher's field notes. Rubrics were used to score answers to each survey question. Concept map scores were calculated based on the criteria developed by Novak and Gowin (1984). 
The first part of the study shows that both preservice and inservice teachers have low conceptual understanding of the earth science concepts taught in elementary school. Independent samples t-tests results indicate that both groups have similar understanding about these concepts. A two way ANOVA with repeated measures analysis demonstrated that readings and learning stations are both successful in building preservice teacher's understanding and that benefits from the hands-on learning stations approached statistical significance. A paired samples t-test shows that concept mapping added to the participants' conceptual understanding whether the participants learned the concepts through readings or stations. Finally, field assignments allowed the participants to apply knowledge that they learned in their science methods course in their classroom placements. This study has implications for teacher preparation programs, staff development, and conceptual change practices in field placements. 


\title{
UNDERSTANDING OF EARTH AND SPACE SCIENCE CONCEPTS: STRATEGIES FOR CONCEPT BUILDING IN ELEMENTARY TEACHER PREPARATION \\ by \\ Nermin Bulunuz
}

\author{
A Dissertation \\ Presented in Partial Fulfillment of Requirements for the \\ Degree of \\ Doctor of Philosophy \\ in \\ Early Childhood Education \\ in \\ the Department of Early Childhood Education \\ in \\ the College of Education \\ Georgia State University
}

Atlanta, Georgia

2006 
Copyright by

Nermin Bulunuz 2006 


\section{ACKNOWLEDGEMENTS}

The whole idea of coming to the United States and pursuing a Ph.D. started with the great support and encouragement of Dr. Olga Jarrett who became much more than a mentor or an academic advisor for me. She actually became a second "mother" for my family both emotionally and professionally. I am indebted to her for her unfailing guidance and availability for leading me to standards of excellence in research. I thank Olga and her wonderful family for welcoming us and making us a part of their family in the last three and a half years. There is also a special thank you to Olga's husband Bob for his advice and editing. He spent hours correcting my errors with great patience.

I am grateful to my committee for encouragement and guidance: Dr. Barbara Meyers, Dr. Geeta Verma, and Dr. Susan Swars, all who supported me throughout this long endeavor. Thank you all for your time reading my dissertation and giving me feedback. Dr. Barbara Meyers gave her endless expertise and care not only serving as a committee member but also being the chair of the department. I also thank Barbara because of her professional feedback for the qualitative section of the study.

I especially would like to thank the administrators of the Uludağ University in Turkey. The rector, Prof. Dr. Mustafa Yurtkuran; the dean, Prof. Dr. Mustafa Cemiloğlu; and the department chair, Prof. Dr. Muhlis Özkan supported us throughout the doctoral program.

None of this project would have been possible without my parents Nazife and Mustafa Büyücek who provided their patience, love, and support without even seeing me for years. Many thanks for their positive encouragement, belief and prayers for me throughout my doctoral program.

My thanks are also expressed to my dear son Atacan for waiting to play with me and being patient with me while I worked through my dissertation. He did not know how I felt while he was inviting me into his play in the middle of my writing.

I wish to express thanks to my husband Mizrap who had the same situation as me, as being another doctoral student in the same department. He and I shared every single requirement of the program with great patience and support.

I am thankful to my dear friend Tonia Durden who helped editing the qualitative section of the dissertation and to Dr. Brian Williams who used his creativity to make an excellent instructional model for my intervention.

This research would not have been possible without the preservice and the inservice teachers, who were the participants of the study, and every single friend, staff, and faculty member in the ECE family who provided emotional and technical support. Thank you all.

Finally, I dedicate this study to all teachers who are willing to teach science to students with a great enthusiasm. 
TABLE OF CONTENTS

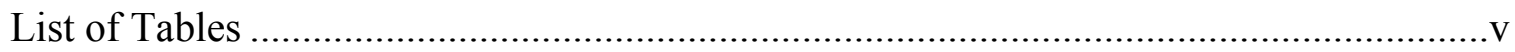

Chapter

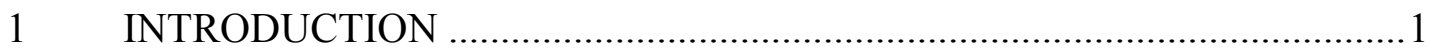

Definition of Terms ...........................................................................

Statement of the Problem .........................................................................

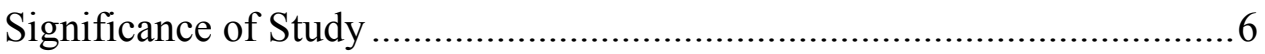

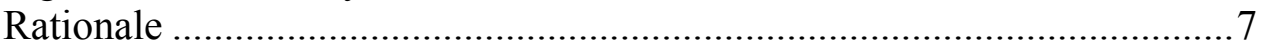

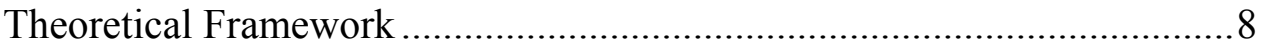

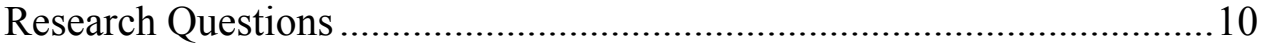

Overview of Methodology ......................................................................11

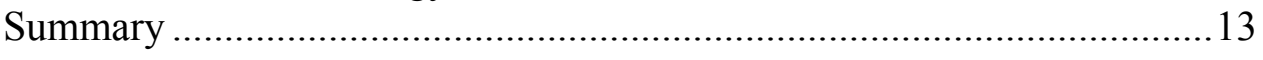

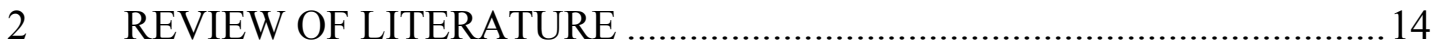

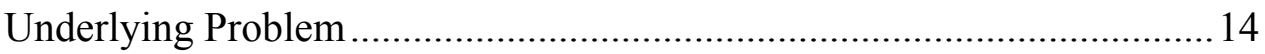

Conceptual Understanding of K-12 Students.........................................15

Conceptual Understandings of Adults ...............................................20

Developmental Theories on Concept Development ………………….......25

Piaget's Cognitive Developmental Theory ...........................................25

Vygotsky's Theory of Social Constructivism .......................................22

Theories of Conceptual Change .................................................................2.

Common Conceptual Change Strategies.....................................................36

Considerations for Teaching Preservice Teachers ......................................49

Applied Learning in Field Placements .....................................................54

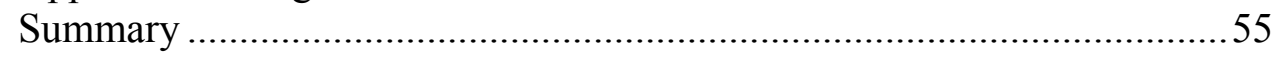

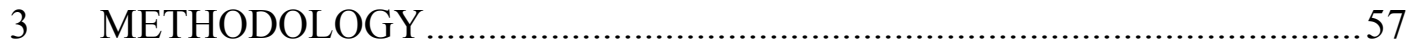

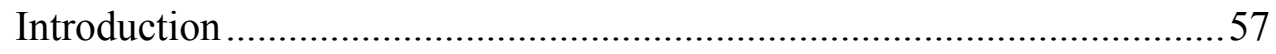

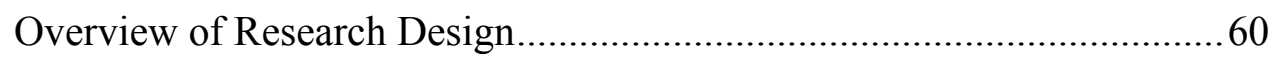

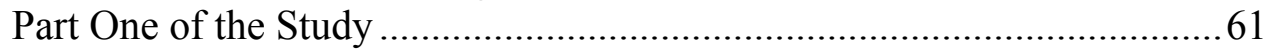

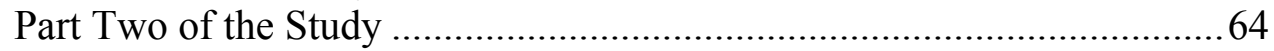

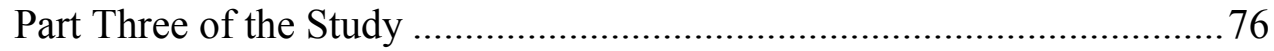

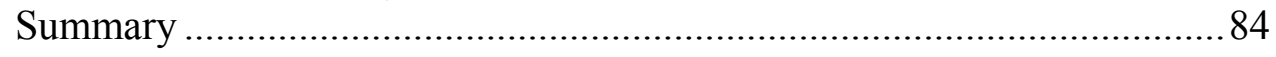




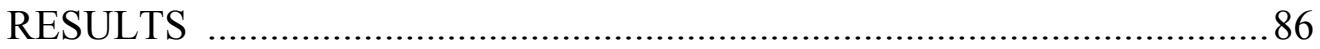

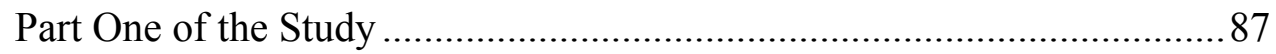

Part Two of the Study ...........................................................................94

Part Three of the Study .......................................................................110

Two Illustrative Cases..................................................................... 112

The Maple Elementary School Preservice Teachers' Guided

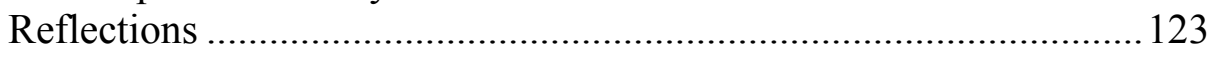

The Researcher's Field Notes ..............................................................129

Triangulation of the Field Assignments and

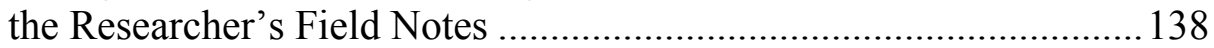

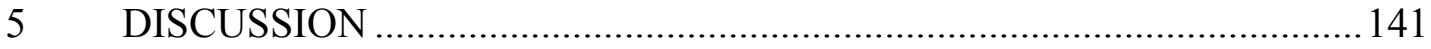

Implications for Teacher Preparation...................................................... 154

Implications for Staff Development.........................................................156

Implications of Field Assignment ............................................................ 157

Strengths and Weaknesses of the Study ..................................................159

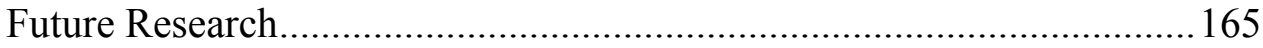

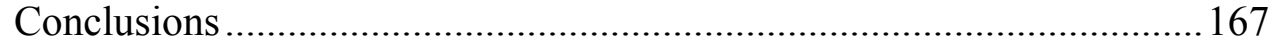

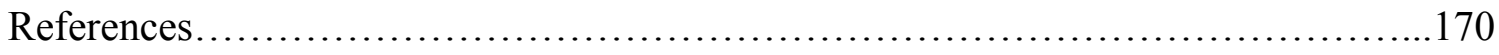

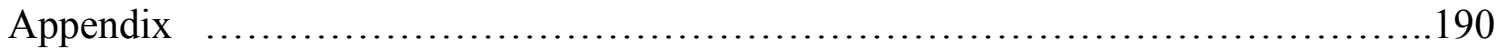




\section{LIST OF TABLES}

Table

1 Recommended grade levels for teaching six earth and space science

2 Programs and Numbers of Preservice and Inservice Teachers in Spring Semester 2006

3 Topics Learned by Two Methods:

Hands-on Activities and Textbook Reading

4 Summary of Data Collection.

5 The Means and Standard Deviations of Pretest Rubric Scores of Preservice and Inservice Teachers.

$6 \quad$ Means and Standard Deviations of Pretest Rubric Scores of Preservice Teachers, All Inservice Teachers, and Experienced Inservice Teachers

$7 \quad$ Pre and Post Means of Preservice Teachers' Rubric Scores for Concepts Learned Through Learning Stations and Through Readings

$8 \quad$ Pretest and Posttest 1 Means and Standard Deviations of The Students' Rubric Scores for Concepts Learned Through Readings and Concepts Learned Through Learning Stations.

9 Analysis of Variance for Repeated Measures Analysis of Time and Learning Method.

10 Posttest 2 Means and Standard Deviations of the Students' Rubric Scores for Concept-Mapped and Non-concept Mapped Concepts Learned through Readings and through Learning Stations

11 Analysis of Variance for Repeated Measures Analysis of Concept Mapping versus No Concept Mapping Condition and Learning Method........106

12 Most Common Answers and Descriptive Quotes of the Elementary School Group as Extracted from the Participants' Guided Reflection 
13 Examples from Preservice Teachers' Students' Initial Understanding before Station Implementation.........................................................................126

14 Examples from Preservice Teachers' Students' Final Understanding

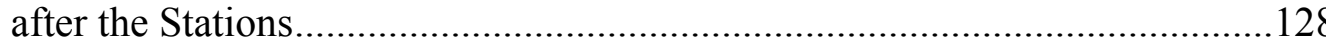




\section{CHAPTER 1}

\section{Introduction}

It is in elementary school that many of the basic concepts about earth and space science are introduced. Research shows that not only students but also preservice teachers (Trumper, 2001; Trundle, Atwood, \& Christopher, 2002) and inservice elementary school teachers (Bulunuz \& Jarrett, 2006) have many misconceptions in these areas. In the National Science Education Standards [NSES] (National Research Council, 1996), teachers' misconceptions are highlighted as a serious problem. Elementary school teachers need to have expertise to teach the entire science curriculum, including biology, chemistry, physics, and earth and space science concepts at different grade levels. If teachers are expected to teach these concepts, they must have scientific understanding of these concepts as well as knowledge of how to teach these concepts effectively to their students (Trundle, 1999). Teachers who don’t know they have misconceptions may pass their own incorrect information on to their students. Teachers who feel insecure in their knowledge of the concepts may merely assign readings from textbooks rather than teach effectively.

This dissertation research is concerned with teacher understanding of six earth and space science concepts that are often taught in elementary school: reasons for seasons, phases of the moon, reasons for wind, rock cycle, soil formation, and earthquakes. Although there is disagreement between the NSES (National Research Council, 1996) and the Benchmarks for Science Literacy (AAAS, 1993) on when these 
concepts should be taught, the recently developed Georgia Performance Standards [GPS] (Georgia Department of Education, 2006) include all six concepts in the elementary school curriculum. The following table indicates when these concepts should be taught according to the NSES, the Benchmarks, and the GPS.

Table 1

Recommended grade levels for teaching six earth and space science concepts

\begin{tabular}{lcccccc}
\hline & $\begin{array}{c}\text { Reasons } \\
\text { for } \\
\text { seasons }\end{array}$ & $\begin{array}{c}\text { Phases of } \\
\text { the moon }\end{array}$ & $\begin{array}{c}\text { Reasons } \\
\text { for } \\
\text { wind }\end{array}$ & $\begin{array}{c}\text { Rock } \\
\text { cycle }\end{array}$ & $\begin{array}{c}\text { Soil } \\
\text { formation }\end{array}$ & Earthquakes \\
\hline NSES & $5-8$ & $\mathrm{~K}-5$ & $\mathrm{~K}-4$ & $5-8$ & $\mathrm{~K}-4$ & $5-8$ \\
Benchmarks & $5-8$ & $\mathrm{~K}-5$ & $3-5$ & 9 & $6-8$ & $9-12$ \\
GPS & 4 & 4 & $4-5$ & $3-5$ & 3 & 5 \\
\hline
\end{tabular}

As can be seen in the above table, Georgia elementary school teachers must teach all six of these concepts. Therefore, teacher understanding of these concepts and research on how teachers can best learn these concepts is especially important in Georgia. Since it is generally accepted that teachers should understand more science than they are required to teach (Kikas, 2004), research on teacher understanding of these concepts also has applicability to other states, where some of these concepts may be taught at upper grade levels.

In addition to the teaching of specific concepts, this research examined the effectiveness of various conceptual change strategies that could be included in teacher preparation. Those strategies that are effective in building teacher understanding could be 
incorporated into teacher preparation classes: (a) to model effective ways for teachers to build their own conceptual understandings, as well as (b) to model ways in which teachers can develop conceptual understanding in their students.

\section{Definition of Terms}

Participants in this study were preservice and inservice teachers, the names used to differentiate the two groups. Where it is obvious that one or the other is referred to, the term participant sometimes is used for variety. The term student is reserved for elementary school children.

A concept, at the most basic level, is a mental representation that can be expressed by a single word, such as human or insect, flower or red, area or velocity (Carey, 2000; Zirbel, 2004). Two or more concepts may also be connected to build other concepts representing a complex set of ideas; for example, "cells divide" or "the earth revolves." In addition, a concept can be a product of two other concepts, like, "potential difference", "electric current", "resistance of wire", and their relationships to each other. Depending on the language we use, one can create new concepts that have special meaning. Ideas can be expressed by more complex concepts, like "Darwin's evolution theory". According to Zirbel (2004), groups of concepts can also act as building units for more complex or abstract representations, for example "the Big Bang model of the universe." The terms conceptual understanding and development of conceptual understanding are used instead of misconception when describing the proposed research. In the literature, there are many terms referring to understandings that are not consistent with accepted understanding of phenomena, including the term misconception. A misconception is defined as a concept that is not in agreement with scientific understanding of natural 
phenomena. In the science education literature, terms like "alternative conceptions" (Hewson, 1981), “children's science” (Gilbert, Osborne, \& Fensham, 1982), “children’s ideas" (Driver, Guesne, \& Tiberghien, 1985), “preconceptions” (Carlsen \& Andre, 1992), and "non-scientific preconceptions" (Guzzetti, 2000) have been used in place of misconception. All these terms imply that there is something wrong or incomplete, or do not imply a process of conceptual change. Driver, Leach, Miller, and Scott (1996) define conceptual change as a process of learning that involves making changes in students' knowledge. According to Driver et al., conceptual change goes on all the time. When the changes are not appropriate, the individual is likely to reorganize knowledge into a more appropriate one. The term "conceptual understanding" implies a process (i.e., the development of conceptual understanding) with different levels of understanding, including: lack of understanding, incomplete understanding, and accepted scientific understanding.

In this study, the term limited understanding is used to describe understanding that has fragments of scientific ideas but does not completely explain the scientific answer to a question. Also, answers without elaboration were evaluated in this category. If a person did not have any idea about a particular concept or left the answer blank, that situation was evaluated as having lack of understanding. The terms incorrect understanding and alternative conception are both used to describe understandings that contained nonscientific fragments or misconceptions. Although misconception is used here to describe what are referred to as misconceptions in the literature, incorrect understanding is used instead of misconception (or other alternative terms) when describing research methods and findings in this study. 
The term, hands-on learning stations, refers to centers set up around the room with instructions and materials for doing specific activities. At learning stations, participants did hands-on activities, discussed procedures and results of the activities with their partners, and answered questions in their journals. After a certain period of time each group rotated to another station and experienced another set of activities.

\section{Statement of the Problem}

Students come to class with ideas about the natural world. It may be difficult for people, both children and adults, to understand scientific phenomena, including earth and space science concepts, because these concepts are difficult to visualize (Callison \& Wright, 1993). Prior knowledge of individuals might be correct, partially correct, or incorrect with a misconception. Many researchers state that misconceptions play a crucial role in learning by interfering with scientific understanding (Hewson, 1992; Trundle, 1999). It is expected that individuals with misconceptions have difficulty learning new concepts because of the negative, blocking effect of their incorrect knowledge.

Middle and high school teachers generally teach specialized content. However, elementary school teachers need to have a broad range of scientific knowledge to teach their students. There is evidence that preservice (Atwood \& Atwood, 1996; Dai \& Capie, 1990; Stofflett, 1994; Trumper, 2001) and inservice teachers (Kikas, 2004; King, 2000) hold the same misconceptions as their students about earth and space science concepts. It is very likely that these teachers can easily teach their incorrect understanding to their students without even realizing it. Parker and Heywood (2000) mention teachers' weaknesses with respect to subject matter and how this can then be transferred to children. Since elementary teachers often take few science courses, especially in earth 
science, one purpose of teacher education must be concerned with helping teachers develop their conceptual understanding about scientific concepts (Parker \& Heywood, 2000).

In various studies, researchers tried to investigate the answer to this question: How can we change misconceptions? Research findings show that misconceptions are highly resistant to change by traditional interventions (Dahl, Anderson, \& Libarkin, 2005). Therefore, researchers have implemented various conceptual change strategies to change naïve ideas of preservice and inservice teachers about various science concepts. For example, researchers have used strategies such as, hands-on activities (Haury \& Rillero, 1994), concept mapping activities (Kim, Germann, \& Patton, 1998), analogies (Yerrick, Doster, Nugent, Parke, \& Crawley, 2003), and conceptual change texts (Cakir, Uzuntiryaki, \& Geban, 2002). Because it is difficult to overcome misconceptions by using just one strategy, some researchers use different strategies and compare the effects of various techniques in one study (Callison \& Wright, 1993; Tekkaya, 2003). Significance of Study

The present study is composed of three parts. The first part determined the conceptual understanding held by preservice and inservice teachers on topics they might need to teach using the Georgia Performance Standards. A finding that preservice teachers have lack of understanding or have incomplete understanding of these earth science concepts would suggest the need to include conceptual change strategies in teacher preparation programs. A finding that inservice teachers have no better understanding of these concepts than preservice teachers would suggest that teachers do 
not necessarily learn these concepts while teaching. This finding would have implications for staff development.

The second part of the study was designed to identify which conceptual change strategies would be most effective in helping to improve preservice teachers' conceptual understanding. These strategies included: assigned textbook readings, hands-on learning stations, and concept mapping. Findings that particular strategies were effective, alone or in combination, would have implications for how these concepts should be taught to teachers.

In part three, preservice teachers in the researcher's class implemented conceptual change activities in their field placements. As part of the assignment, they wrote guided reflections (i.e., reflections guided by a list of questions) and the researcher observed six preservice teachers at the same school to evaluate their teaching performance. These are the areas the researcher looked at during her observations: how they chose the concept they taught, how they constructed their own understandings as they were preparing themselves to teach the concepts, how they determined the level of student conceptual understanding, and how they implemented their conceptual change learning stations. Rationale

The earth and space concepts selected for this study are currently taught at a broad range of grade levels in the state of Georgia according to the Quality Core Curriculum [QCC's]. In the new standards (GPS), to be implemented during the 2006-2007 school year, teaching the six earth and space science concepts was to be started at third, fourth, and fifth grades based on GPS (See Table 1). However, even teachers of the primary grades need to understand the concepts covered in this research, since many topics taught 
in the primary years, such as classification of rocks and soil and observation of objects in the sky, provide grounding for concepts taught at higher grade levels.

My interest in misconceptions stems from a study I conducted in Turkey on the misconceptions of fifth graders concerning the fungus kingdom, an interest of mine as a biology major. Having detected many misconceptions among children, I became interested in whether teachers have similar misconceptions. The two geology classes that I took in the Ph.D. program affected the choice of topic for my research apprenticeship study, where I investigated the misconceptions of inservice teachers about reasons for seasons, phases of the moon, rock cycle, and earthquakes (Bulunuz \& Jarrett, 2006). Finding that many inservice teachers had incorrect understanding of these phenomena, I tried to build their understanding through hands-on learning stations. Although most of the teachers developed more accurate conceptual understandings, some incorrect understandings remained. Although that study helped me understand what inservice teachers know in this field, I began to wonder what preservice teachers know about these concepts and what other strategies might be helpful in changing their misconceptions.

\section{Theoretical Framework}

Conceptual change theories get their roots from the constructivist theory of Piaget and social constructivist theory of Vygotsky. The philosophy of these theorists gives a broad perspective on how individuals construct concepts and has influenced the design of this study.

Piaget proposed that an individual constructs his own knowledge by adapting his initial ideas and theories while engaged with the environment, either the physical environment or through social transmission (Piaget, 1970). Using the terms assimilation, 
accommodation, disequilibrium, and equilibration, Piaget explains how conceptual development requires action on the environment, bringing exposure to new experiences or ideas. For children, these actions must include concrete experiences with the physical environment. Assimilating new experiences into current thinking may cause a state of disequilibrium, if the new way of thinking does not fit current conceptual understandings. Accommodation of thinking is necessary to again reach equilibrium, a process Piaget calls equilibration. According to Piaget, assimilation and accommodation always work together in the development of conceptual understanding.

A well-established theory of conceptual change developed by Posner, Strike, Hewson, and Gertzog (1982) is derived from Piaget's theory of constructivism. Similar to the definitions of Piaget, Posner et al. (1982) defined assimilation as a process where students use existing concepts to deal with new phenomena and accommodation as a radical process in which students must replace and reorganize their prior concepts. In their conceptual change theory, Posner et al. (1982) define four conditions under which conceptual change occurs. These conditions are:

1. There must be dissatisfaction with existing conceptions.

2. A new conception must be intelligible.

3. A new conception must appear initially plausible.

4. A new concept should suggest the possibility of a fruitful research program. (p. 214).

For study participants who had weak understanding of the concepts assessed on the pretest, attempting to write explanations might have caused dissatisfaction/ disequilibrium. A goal of part two of the study was assessing whether reading about topics (social transmission) or engagement with the physical environment (hands-on learning stations) improved effectiveness in promoting accommodation and the 
development of conceptual understanding (equilibration). Post assessment rubrics attempted to determine the intelligibility and plausibility of any new conceptions developed.

In his social constructivist theory, Vygotsky presents three important ideas that are applicable to concept development (Vygotsky, 1978): zone of proximal development [ZPD], scaffolding, and social interaction. He defines ZPD as the distance between the most difficult task an individual can do by himself and the most difficult task an individual can do with other people's help. Vygotsky describes scaffolding as the assistance given to a student by a teacher or peer. In general, Vygotsky asserts that individuals' cognitive development is affected by their social interactions with their teachers and peers. According to him, people learn new concepts by asking questions or giving answers (Vygotsky, 1978). Vygotsky's theory is applied in this study in the design of group situations for learning concepts. The preservice teachers worked in groups at learning stations and during the concept mapping activity. They were encouraged to discuss the phenomena they were observing, asking each other questions, and arguing about interpretations. In addition, the researcher did scaffold the preservice teachers as she moved from station to station, clarified instructions and asked questions.

\section{Research Questions}

The following questions guided the design of this study and data analysis:

1. What initial conceptions do preservice and inservice teachers have about the following earth and space science topics: reasons for seasons, phases of the moon, reasons for wind, rock cycle, earthquakes, and soil formation? 
2. Is there a difference between preservice and inservice teachers in their understanding of these concepts?

3. Are hands-on learning stations more effective than readings in clarifying earth science concepts as measured by rubric scores and concept maps scores?

4. Does concept mapping improve rubric scores for those who experienced the learning station activities compared to those who read text explanations?

5. How do preservice teachers apply conceptual change strategies in their field assignments on conceptual change?

Overview of Methodology

This study involved a mixed-method research design with quantification of answers to open-ended survey questions using parametric descriptive and inferential statistics, and qualitative analyses of a field assignment of preservice teachers and researcher's field notes. There were three parts to this research study: (a) the first part included the first and second questions and involved three cohorts of preservice teachers (two undergraduate and one alternative certification) and two cohorts of inservice teachers; (b) the second part included the third and fourth questions and involved the two undergraduate preservice cohorts; and (c) the third part used the fifth question and involved just one of the undergraduate preservice cohorts.

In part one, the first goal was to assess preservice and inservice teacher understanding about reasons for seasons, phases of the moon, reasons for the wind, rock cycle, soil formation, and causes of earthquakes by using an open-ended survey (see Appendix A). A six-question survey was administered to three cohorts of preservice teachers and two cohorts of inservice teachers. Responses were scored as 1, 2, or 3 by 
using a rubric: A score of 1 was given for no response, incorrect answer or clearly evident lack of conceptual understanding. A score of 2 represented a partially correct answer or one that had no elaboration. A score of 3 represented an answer integrating an accepted scientific perspective and clear elaboration. The scoring rubric is found in Appendix B. Using means and frequencies, level of understanding on each question was described.

A second goal of part one was to determine whether inservice teachers have developed a better understanding of these concepts than preservice teachers. To answer question two, the overall rubric scores of the preservice and inservice teachers were compared using independent samples t-tests.

The purpose of part two of the study was to investigate which strategies were helpful in improving preservice teachers' understanding of the six concepts stated above. Three instructional interventions were implemented with two cohorts of undergraduate preservice teachers, using a convenience sample. The three interventions were: reading text, participation in hands-on learning stations, and creating concept maps. The survey questions related to the readings were re-administered after the readings and the survey questions related to the learning stations were re-administered after participation in the learning stations. For the concept mapping strategy, participants worked as teams of two or three people mapping two different concepts, one concept they read about and one that was included in the learning stations. The teams were randomly assigned the concepts they would map. The concept maps were scored by using the scoring system developed by Novak and Gowin (1984) (See Appendix C). The survey was administered a third time after the concept mapping activity. The participants' answers gave an idea about 
which strategies or combination of strategies developed better understanding of these concepts.

In part three of the study, preservice teachers in the researcher's science methods class implemented a conceptual change activity in a hands-on station in their placements. To do that, they got further instructions on conceptual change and conceptual change strategies from the researcher. The preservice teachers wrote guided reflections at the end of their field experiences and turned them in to the researcher. In their guided reflections, preservice teachers were expected to answer seven open-ended questions about the process that they went through. In addition, the researcher observed six preservice teachers at the same school to evaluate their teaching performance in their classrooms. While the researcher was observing the participants during their lessons, she took field notes and evaluated them on specific criteria. The guided reflections of preservice teachers and the researcher's field notes were analyzed qualitatively to learn about the preservice teachers' application of conceptual change strategies with their students.

\section{Summary}

A main expectation from schools is to produce scientifically literate students for the future. In order to accomplish this goal, teachers of these students need to be well educated with accurate scientific knowledge. As teacher educators, it is necessary to know what teachers already know about scientific concepts and which strategies are most effective for developing conceptual understanding. This research assesses the knowledge of preservice and inservice teachers, assesses a variety of methods for learning about earth science concepts, and analyzes what was learned and taught and by preservice teachers through a field assignment involving conceptual change. 


\section{CHAPTER 2}

\section{REVIEW OF LITERATURE}

This literature review covers: (a) research on conceptual understandings of children, older students, and preservice and inservice teachers about reasons for seasons, phases of the moon, reasons the wind blows, rock cycle, reasons for earthquakes, and soil formation; (b) developmental theories on concept development; (c) the different perspectives of conceptual change theories (i.e. conceptual change theory, revisionist theory, and other theories that discuss ontological, socio-motivational, and multidimensional perspectives of conceptual change); and (d) research on the effectiveness of common conceptual change strategies (e.g. conceptual change texts, refutational texts, concept maps, analogies, and hands-on activities). Then, this chapter presents the body of research on practices of instructors in teaching conceptual change in science methods courses. Finally, the review reports research on outcomes and the reflections of preservice teachers' field experiences based on their implementation of teaching conceptual change to students.

Underlying Problem: Incorrect Understanding of Earth and Space Science Concepts

Researchers have studied the conceptual understanding of students about earth and basic astronomy concepts at a broad range of grade levels, such as elementary school (Benacchio, 2001; Blake, 2001; Hawley, 2002; Muthukrishna, Carnine, Grossen, \& Miller, 1993; Ross \& Shuell, 1990; Ross \& Shuell, 1993; Schoon, 1992; Stahly, Krockover, \& Shepardson, 1999), middle school (Bisard, Aron, Francek, \& Neslon, 
1994; Ford, 2003; Rider, 2002), high school (Marques \& Thompson, 1997), and college (Kikas, 2003).

\section{Conceptual Understanding of K-12 Students}

\section{Reasons for Seasons}

Various studies investigated misconceptions about reasons for seasons. The most common misconception, that "seasons change because the earth's distance from the sun changes," is referred to "distance theory" (Muthukrishna et al., 1993). In his cross-age study, Schoon (1992) found that $77.6 \%$ of the students held distance theory as the primary misconception.

Phases of the moon

Research has been conducted at almost every grade level about misconceptions on the phases of the moon. The common misconceptions on this topic were the ideas that the phases of the moon are caused by "the earth's shadow on the moon," "clouds," and "the sun's shadow on the moon" (Rider, 2002, and Schoon, 1992). Benacchio (2001) listed a few of the typical misconceptions about the Moon that Italian children have, such as "Moon is emitting light, exactly as the sun does; different observers see different moon phases at the same time; and in the moon there is no gravity" (p.52). Many students do not understand that actually an "eclipse" not "the phases of the moon" occurs because of the earth's shadow on the moon. Schoon (1992) reported one of the primary misconceptions by $48.1 \%$ of the students to be that the moon's phases are caused by the shadow of the earth. Similarly, Stahly et al. (1999), in a study of four third-grade students' conceptions of the lunar phases, found that the students confused eclipses and phases of the moon. 


\section{Rock Cycle}

Children's alternative conceptions for describing and classifying rocks center on simple physical characteristics such as color or shape and reveal only very limited ideas about the origin of rocks (Blake, 2001; Happs, 1985; Hawley, 2002; Ford, 2003). Blake (2001) investigated the understandings of 7-11 years-old children in England about rocks. In his study, the children were asked to classify seven representative rock specimens, such as: sandstone, granite, slate, limestone, basalt, conglomerate, and gneiss. Also, the researcher asked the children to write down the reason why certain specimens were included. Blake found that the children classified rocks on the basis of simple physical characteristics, which included shape (30\%), color (33\%), and feel (77\%). In a case study of 14 year-old students' understanding of rocks, Happs (1985) found that students did not group rocks in terms of their origin; but rather sorted them according to everyday categories, such as "shiny rocks" or "ordinary rocks".

Children's conceptual understandings about rock formation and rock cycle were investigated by various researchers (Ault, 1984; Ford, 2003). Ault (1984) compared third and fourth graders' conceptions and understandings about rocks before and after his class. The researcher states that before the students had learned the model of horizontal, continuous strata of rocks under the ground, most of them thought that the earth was mostly dirt and full of stones. He called it "earth-is-dirt-and-stone" conception. The author reported that after the class, the students understood the idea of layered strata of bedrock. In addition, some of the examples from the students' ideas are given as: rocks travel, rocks come from under the earth, rocks come from volcanoes, and rocks fall from the moon. Ford (2003) investigated definitions and explanations of sixth graders about 
rocks and rock formation. The researcher concluded that the students were thinking the rock cycle as laundry that goes through the wash cycle like conversion of one rock type to another. In addition, the author detected an additional misconception among the students' answers that: “only igneous and sedimentary rocks can become metamorphic rocks" (p.375).

\section{Causes of Earthquakes}

Research on misconceptions about earthquakes studied students in elementary school as well as at higher grade levels. Ross and Shuell (1990) conducted research with fourth through sixth-grade students about the definition and causes of earthquakes. According to the researchers, the majority of the students correctly think that earthquakes are caused by built up pressure, tectonic plate movement, and the release of energy at zones of weakness in the Earth. However, the authors noted that some students had unclear or incorrect understandings about earthquakes. Some students thought that an earthquake is caused by the earth's core moving to the surface, the layers of the earth fighting, and atmospheric conditions.

In a subsequent study, Ross and Shuell (1993) focused on K-6 grade students' understandings on the following questions: what is an earthquake, what causes earthquakes, and what happens on the ground when there is an earthquake? They found that the question about causes of earthquakes seemed difficult for many students, and $75 \%$ of them answered that they did not know what caused an earthquake. Ross and Shuell reported that some of the students thought the causes of earthquakes were: core movement, pressure, plates, rocks moving, colliding, faults, and volcanoes. However, they did not understand how these might be related. Also, the authors state that some of 
the students were confused between earthquakes and other natural phenomena, and responded that "an earthquake and a volcano are the same thing."

\section{Reasons for the Wind}

Students' conceptions about weather have been investigated since the early 1900's. Piaget (1929) is one of the earliest researchers who focused on children's weather conceptions such as, clouds, rain, snow, ice, thunder, lightning, and wind. According to Piaget, as children develop between ages 5-11 they tend to give different answers to the same question related to the weather. For example, a six year-old child might say God caused the weather, an eight year-old might give an answer based on an analogy (e.g. clouds were made of smoke), but a ten year-old child might often give a scientific answer. Some of the conceptions of children about the wind at different ages reported by Piaget (1929) are: "the wind brings cold weather (5-1/2years-old); the wind comes from the sky and someone blows the wind from the sky (6 years-old); it is the snow which brings the cold and the wind ( 8 years-old); it is cold in winter because the wind blows (10 years-old); and there is wind only if the weather is cold (13 years-old)."

In the last three decades, understanding of the concept wind became one of the weather concepts that researchers tried to investigate with students in elementary school (Stepans \& Kuehn, 1985), middle and high school (Aron, Francek, Nelson, \& Bisard, 1994; Papadimitriou \& Londridou, 2001; Spiropoulou, Kostopoulos, \& Jacovides, 1999), and college (Nelson, Aron, \& Francek, 1992). These authors agreed that concepts associated with the wind are generally poorly understood by the students. In their crossage study (12 to18 years-old), Papadimitriou and Londridou (2001) found that in spite of the fact that all of students were aware of the movement of atmospheric gases in all 
directions, most of the them have a misconception that "gravity" is the only determining factor that affects the vertical motion of gases. In other words, students think that gases move vertically because of their gravity.

Many children think that the wind is the cause of movement of air masses (Papadimitriou \& Londridou, 2001). Children can visualize the movement of warm air and cold air in a circular motion. However, Papadimitriou and Londridou think that their answers are mechanically correct but scientifically incorrect. That is, the warm air goes up and by that it is getting colder, heavier and thus it goes downward. But, this answer does not really have full scientific understanding about why the wind blows. Children are taught in schools that air pressure and temperature are related to wind generation. However, according to the same researchers, children can sometimes either confuse air pressure with "force" or their senses can affect their way of thinking. TV weather forecasts, which affect children in constructing their own views about the generation of weather, might be the reason for this confusion (Papadimitriou \& Londridou, 2001). Some researchers reviewed common weather conceptions at various grade levels (e.g. Dove, 1998; Henriques, 2002; and Nelson, Aron, \& Francek, 1992). Dove (1998) lists various common alternative conceptions in this field. Some of the examples for Grade K-5 students are: "clouds block wind and slow it down; cold temperatures produce fast winds; wind is caused by God, man, breathing, machines, trees and movement of clouds" (p.66).

\section{Soil Formation}

Although soil is crucial for life, research on conceptual understandings about soil (or dirt) and soil formation at every grade level is limited. Researchers suggest interesting 
and effective hands-on science activities about the structure of soil and soil formation for elementary students and teachers (Furlough, Taylor, \& Watson, 1997; Eswaran, Kupelian, Levermann, \& Yost, 1990). These researchers think that although students may not understand how rocks are formed or the nature of many geological processes, most students are quite familiar with the soil in their own backyards. Therefore, they believe in educating students about elements of soil and introducing them to the techniques of the soil scientists (Eswaran et al., 1990).

According to Dove (1999), students develop alternative conceptions in physical and environmental geography for a variety of reasons. One of these reasons is that, children tend to apply broad generalizations to specific cases in geography. The researcher shows some of these reasons, together with specific examples including the ones about soil formation. Dove gives an example from the study conducted by Nelson et al. (1992). Nelson and his colleagues report that children think all shallow soil profiles are young, whereas in deserts, for example soils are thin and old because little weathering can take place.

\section{Conceptual Understandings of Adults}

The research on college students (Libarkin, Anderson, Dahl, Beilfuss, \& Boone, 2005; Trumper, 2000), preservice teachers (Abell, Martini, \& George, 2001; Atwood \& Atwood, 1996; Bereki, 2000; Callison \& Wright, 1993; Dai \& Capie, 1990; Kusnick, 2002; Rice, 2005; Stofflett, 1993; Trumper, 2001; Trundle, Atwood, \& Christopher, 2002), and inservice teachers (Bulunuz \& Jarrett, 2006; Kikas, 2004; King, 2000; and Parker \& Heywood, 1998), suggests that many people do not have enough scientific understanding about earth and space science concepts. 


\section{Reasons for Seasons}

Atwood and Atwood (1996) surveyed and interviewed preservice elementary teachers on the reasons for seasons. The researchers state that the most common misconception was the proximity of the earth from the sun (distance theory). According to them, the thinking seems to be that when part of the earth is tilted toward the sun, it is closer to the sun, and thus gets hotter; and when part of earth is tilted away from the sun, it is farther for the sun, and thus gets colder. Other examples given by the participants were indicated as "the rotation of the earth on its axis," "the way the earth positioned on its axis" and "the part facing the sun is having summer" (p.557).

On the other hand, Kikas (2004) investigated 198 inservice teachers' conceptual understanding on seasonal changes. She found that $91 \%$ of the elementary and $93 \%$ of the science teachers gave the scientifically correct answer to this question. However, the researcher thinks that they did not understand the physical reasons for seasonal changes like the basics of optics and mechanics, etc. Kikas reported some complicated explanations, such as the seasons are mainly caused due to the angle between the axis and the orbit, etc. Similarly, Parker and Heywood (1998) worked with inservice teachers to understand their explanations about reasons for seasons. In addition to distance theory, they found another main alternative conception that is called wobbly earth. They defined wobbly earth as "the oscillation of earth's axis in summer and winter" (p. 510).

\section{Phases of the Moon}

In the literature, teachers' misconceptions on the phases of the moon are very similar to the students' misconceptions. Trundle et al. (2002) focused on the conceptual understanding held by preservice teachers about moon phases. The researchers reported 
that their participants had alternative conceptions, e.g., that the moon phases are caused by the earth's shadow on the moon (eclipse) and the earth's rotation on its axis. Callison and Wright (1993) investigated preservice teachers' conceptions about earth-sun-moon relationships. They reported some of the common misconceptions held about what causes the phases of the moon: the earth's shadow, the clouds, the Earth's and the moon's tilt. Parker and Heywood (1998) investigated inservice teachers' misconceptions about the moon phases. These researchers found the majority of the teachers thought that the earth's and other planets' shadows onto the moon caused the moon phases. Rock Cycle

Kusnick (2002) conducted research with preservice teachers in her geology class to investigate their understandings about rock formation. The researcher states that most of the participants had misconceptions. Some of the participants' ideas were as follows: rounded pebbles or rocks found near the rivers must be sedimentary rocks, and rocks are formed by sediments sticking together at the bottom of rivers. In addition, Kusnick states that some of her students thought sedimentary rocks are formed through catastrophic events, such as earthquakes or explosive volcanic activity. Stofflett (1994) investigated preservice teachers' knowledge about rock cycle processes. The researcher gave three rock samples (granite, sandstone, and gneiss) to her students and asked questions about how each rock formed, how the distinguishing features formed, and which rock group each belongs to. According to the researcher, the preservice teachers understood igneous rocks more easily than sedimentary rocks.

Dove (1996) conducted a study with the first year preservice teachers and asked them to recall any rock types they knew and then to identify hand specimens. The 
researcher reports that the participants identified a piece of slate as a sedimentary rock, rather than a metamorphic one, simply because it contained layers. According to her, the preservice teachers did not think slate and coal were rocks, but rather a building material and source of energy. In addition, the author states that students called a polished specimen of granite marble because if its smooth appearance.

Rock cycle is a concept about which both preservice teachers and inservice teachers tend to hold lack of understanding, either incomplete or incorrect understanding. Bulunuz and Jarrett (2006) investigated conceptual understanding of inservice teachers about the rock cycle by using open-ended questions. The researchers reported that most of their participants left the answer blank or responded on the pretest that they did not know. Only a few of the participants mentioned three different types of rocks in their answers (igneous, sedimentary, and metamorphic) and none of them mentioned scientifically the conversion of one type of rock to another. The formation process of each rock type can also be confused by inservice teachers (Bulunuz \& Jarrett, 2006). One example from the same study is that inservice teachers think that "sediments come together to form metamorphic rocks, they break apart and form metamorphic rocks, and pieces come together to form igneous rocks" (p.9).

\section{Causes of Earthquakes}

Misconceptions about earthquakes and plate tectonics seem to be common, even amongst the college students and teachers who teach these topics (Libarkin et al., 2005; King, 2000). According to King (2000), this is not surprising because plate tectonics is taught to children at the ages of 11-14 in geography courses, but usually as a factual model. Libarkin et al. (2005) investigated the conceptual understanding of college 
students about the causes of earthquakes. According to them, gas pressure, gravity, the rotation of the earth, exploding soil, expansion of the Earth, and volcanoes were considered as the main causes of earthquakes among the participants. King (2000) investigated teachers' understandings about plate tectonics and the cross-section of the Earth. The author reported that half of the teachers did not give the correct names to the Earth's sections. For example, some of the participants did not know the outer core is liquid and the inner core is solid and about the movements of the super continent "Pangea." He believes that if the teachers have scientific understanding about the states of the Earth's sections, they would better understand the plates' movement. Reasons for the Wind

Not only elementary and middle level students but also college students and preservice teachers hold some incorrect understandings about atmospheric phenomena. Aron et al. (1994) conducted a study with a mixture of 708 high school students and preservice teachers and found lack of understanding concerning atmospheric processes and phenomena at all age levels with preservice teachers being very similar to high school students. Also, the authors conclude that the misconceptions of preservice teachers were similar to those of college students taking introductory science classes, suggesting a lack of significant improvement through the undergraduate experience.

\section{Soil Formation}

Happs (1984) clinically interviewed New Zealand students at high school, teacher training college, and university level about the structure and formation of soil. A comparison between children, adolescents, and soil scientists showed that students held many nonscientific ideas concerning the nature, origin, age, and changes of soil. Some of 
the examples to the question "What is soil?" are: "soil is a medium for plant growth and a home for small animals; soil is a food for living things; and soil is dirt" (p.177). The alternative views to the question "where does soil come from?' are: “soil has always been there; soil has formed from chiefly vegetation and volcanic source; God created soil; soil is dinosaur manure" (p. 178). According to the author, the students think that soil does not change or rock may change into soil only via surface weathering.

Preservice teachers tend to confuse the concepts underpinning "weathering" and “erosion” related to soil formation processes (Hutchinson, 2002). Dove (1999) argues that the reason for confusion is that both processes are concerned with the lowering of the land surface and operate over a long time period. Dove believes that students often believe weathering is a pre-requisite to erosion; however, they do not think these processes operate together and are dependent on each other. This makes these processes and soil formation difficult for children to understand.

Developmental Theories on Concept Development

Piaget's Cognitive Developmental Theory

Piaget (1970) proposed that an individual cannot form or build concepts by himself; instead, each individual constructs his knowledge by using current ideas and theories while interacting with the physical environment. The interaction between an individual and a material will aid learners in building and learning various concepts about natural phenomena. For example, if the teacher only lectures about the parts of a plant and its growth from textbooks, the children may memorize without developing conceptual understanding. However, if the teacher can take the students to the school backyard and let them dig the soil, plant a crop, water it, and keep track of its growth, 
then they will have an idea about a plant's structure and growth. Piaget argues that students cannot learn concepts simply by repeating prior knowledge. Rather, they need to develop knowledge by exploring and investigating.

According to Piaget (1970), every person has schemes, general ways of thinking about ideas and objects that they start using in the infant years and continue with throughout life. Our way of thinking changes very fast, depending on our biological and intellectual growth rate and ranges from simple to abstract (Berger \& Thompson, 1996).

In concept formation, Piaget explains two interrelated processes: organization, and adaptation (Piaget, 1970). People organize their ideas to make logical connections between them. Piaget defines the term adaptation by using two other terms: assimilation and accommodation (Piaget, 1970). Piaget argues that to experience "assimilation," an individual must act on the objects or materials in the environment. Because of this action, an individual incorporates the new concept into a current one. Piaget calls this situation "assimilation." If the new way of thinking does not fit his present way of thinking, the individual experiences a state of "disequilibrium.” One might experience disequilibrium when an unexpected thing occurs in life. At that point, two things can happen: another person might help us to clarify the conflict by giving more information, or we might act further on the same material to resolve the unexpected situation ourselves. Piaget calls this situation "accommodation," that is the adjustment of existing ideas to new experiences. After accommodation, an individual is expected to reach the state of “equilibrium," that is the final stage of adjustments of concepts (Piaget, 1970). 


\section{Four Developmental Factors}

Piaget argues that the process of development is based on four different factors: a) maturational (biological) factors, b) experience with physical environment, c) social transmission, and d) equilibration (Piaget, 1964). According to Piaget, equilibration is the process that unifies the other three factors. He believes that maturation is important and necessary, but it does not explain everything. Cognitive and social interaction of an individual with his environment is also required for learning. The learner must be physically active to learn new concepts and develop intellectually. Piaget also values social transmission as an important way to learn new ideas, concepts and theories from parents, peers, or teachers. Whereas, "equilibration" is the term that Piaget uses for unifying all three processes.

\section{Vygotsky's Theory of Social Constructivism}

Like Piaget, Russian psychologist Lev Vygotsky (1978) argues that children start to form concepts long before they attend school. Through play, most the children first begin to sort, classify, and count before preschool or pre-kindergarten, forming initial science and math concepts. When children start elementary school, they improve their concepts in science and arithmetic by building on their preschool concepts.

\section{Zone of Proximal Development}

One of the most important constructs in Vygotsky's theory is that of the zone of proximal development or $Z P D$. He defines this concept as the distance between the most difficult task a child can do by himself and the most difficult task a child can do with other people's help (Vygotsky, 1978). Vygotsky defines the actual development level as the level of development of a child's cognitive functions that has been formed as a result 
of already completed cognitive processes. It means, at this level, children can grasp the new concepts without any difficulty. Vygotsky argues that if one wants to teach a new concept that does not match with the actual developmental level of the child, the child will not able to learn or understand that particular concept unless he has extra assistance from adults or peers. However, he may easily grasp the same concept a year later without any help. According to Vygotsky, children learn concepts based on their actual developmental levels rather than their chronological age levels (Vygotsky, 1978).

Vygotsky uses the term "scaffolding" to describe the assistance a teacher or peer gives to a child (Vygotsky, 1978). Like a scaffold used by a housepainter working on a house, teachers or peers can help a child to learn new concepts and form his understandings by giving supporting information. But, if that assistance does not match the actual mental level of the child, learning does not occur.

Social interaction. Social interaction between the child, adults and peers accelerates or enhances the process of scaffolding. According to Vygotsky (1978), children learn new concepts by asking questions or giving answers, by imitating other people, and also by getting instruction from adults that tells children how to act. Language is the key factor that explains the impact of social interaction between a child and his environment. Although cognitive development starts long before children actually start talking, active use of language aids children in expressing themselves in a useful way for building concepts. Children learn and develop concepts from each other because of their speaking and listening abilities (Mooney, 2000).

Most current theories of conceptual change are heavily influenced by Piaget and Vygotsky's developmental theories on concept development. These theories explaining 
how people intentionally change other people's initial understandings are discussed in turn.

Theories of Conceptual Change

The Conceptual Change Theory

Influenced by Piaget (1951) in the early 1980's, a group of science education researchers and philosophers at Cornell University developed "the conceptual change theory" (Posner, Strike, Hewson, \& Gertzog, 1982). These researchers adopted the Piagetian ideas of "assimilation" and "accommodation" as well as Thomas Kuhn's (1970) description of "scientific revolution."

In his book The Structure of Scientific Revolution, Kuhn (1970) defined the concept of "paradigm shift" in the process of scientific revolutions. Kuhn argues that scientific advancement is not evolutionary or a slow process, but rather is a series of revolutions or sudden changes. According to him, first, people need to be aware of the failure of one way of thinking to provide solutions to significant problems. Kuhn called this situation "state of crisis" that is similar to Piaget's idea of "disequilibrium." Then, an alternative way of thinking that is assumed to have potential to solve the problems replaces the previous one, like the discoveries of Galileo in physics and astronomy.

Posner et al. (1982) argued that before an accommodation occurs, a person must have various “anomalies" similar to Kuhn's state of crisis. When a person realizes that his current concepts are unsatisfactory to solve problems, the person replaces the previous concept with a new one that causes a conceptual change. Thus, Posner et al. applied Kuhn's ideas about scientific revolutions to their conceptual change theory. Kuhn's ideas are similar to the Piagetian cognitive theories that explain the learning 
potential of conflict situations. A synthesis of both Piaget's and Kuhn's ideas inspired Posner and his colleagues to propose their learning theory. It then became the most widely accepted theory dominating the field of science education up to present time.

As mentioned earlier, Posner et al. widely used the terms assimilation and accommodation adapted from Piaget's cognitive developmental theory. They defined assimilation as a process where students use existing concepts to deal with new phenomena. Moreover, they defined accommodation as a radical process in which students must replace and reorganize their prior concepts. In this theory of accommodation, these theorists basically tried to define two different areas. These are the conditions for accommodation and the concept of conceptual ecology.

\section{Conditions for Accommodation}

Posner et al. hypothesized four conditions that must be fulfilled before accommodation can occur. The first condition is dissatisfaction in which learners first realize that their conceptual understanding does not solve their problem. The second condition is intelligibility in which learners are able to repeat the main points of the concept to others. The third condition is plausibility in which the new concept needs to make "more" sense than the old one. The new concept needs to have the capacity to solve the problem better. The last condition is fruitfulness in which the new concept not only should do more than solve the problem, but it also open up new areas of inquiry. In order to call a concept plausible, that concept must first be intelligible and students must believe that this is how the world actually is. For a concept to be fruitful, it must first be intelligible and plausible and should be seen as something useful to solve the problem. 


\section{Conceptual ecology}

Conceptual ecology implies all the current knowledge and beliefs that a person might have. Conceptual ecology includes anomalies, analogies, metaphors, scientific beliefs, concepts of science, and competing concepts. Among all these features, Posner et al. (1982) report that anomalies and basic scientific assumptions guide the change process from one conception to another. That is, if the students think about anomalies seriously, they can create some sort of cognitive conflict for themselves. The cognitive conflict helps the cognitive ecology to be ready for an accommodation. In addition, they assert that conceptual ecology influences the conceptual change process to explain how current conceptions influence the way that an individual views new information.

Hewson (1981), one of the authors of the conceptual change theory, elaborated on the theory and also emphasized that it might be always possible to add new conceptions into the conceptual ecology through experience, personal development, and communicating with others. According to him, all the concepts in a conceptual ecology interact with each other and that determines their "conceptual status." Hewson clarifies what he means by conceptual status by explaining the various possibilities when a person is faced with a new conception.

The new conception might immediately be rejected or three other possible results might occur. First, the new concept can simply be memorized, where no learning and accommodation take place. Second, a person can make sense of a new concept and see it in the context of his current knowledge. Hewson calls this situation "conceptual capture" or weak conceptual change. Third, a person might completely replace his current concept with the new one; that is what Hewson calls "conceptual exchange" or strong conceptual 
change. He notes that after the same instruction, one student might simply reject the new concept, another might memorize it, or another might go through conceptual exchange or accommodation. The result is not only based on the types of instruction or a teacher's strategy, but also on the student and the new concept to be replaced.

\section{Revisionist Theory of Conceptual Change}

Many studies have used Posner et al.'s conceptual change theory, which has received considerable attention in science education research. However, there has been some criticism of this theory from different points of view. Most theoretical frameworks on conceptual change were based only on cognitive factors. However, researchers recognized that not only cognitive factors, but also additional factors such as motivation, goals, and interests influence conceptual change.

There were two important criticisms of the original conceptual change theory. The most important one is that conceptual change theory is only based on logical and rational thinking; i.e., it only focuses on the learner from a cognitive point of view, rather than as a whole, complex person (Pintrich, Marx, and Boyle, 1993). It means this theory ignores other socio/affective factors such as motivation, values, goals, beliefs, and interests. The second criticism is that this theory does not consider other elements of the learning process such as the teacher and other students.

Based on these criticisms, Strike and Posner (1992), two of the authors of conceptual change theory, revised their original ideas and proposed that a wider range of social and motivational factors should also be considered in understanding conceptual change. They emphasize that concepts based on a person's social interactions, motivations, and personal goals need to be included in conceptual ecology. According to 
them, all of these factors should be included in teaching and learning environments for conceptual change. They expanded the general characteristics of conceptual ecology and reported that conceptual ecology should also include scientific and alternative conceptions.

Theory of Conceptual Change from the Perspective of Ontological Categories

Websters’ New Collegiate Dictionary (1977) defines the term ontology as “a particular theory about the nature of being or existence" (p.802). Chi, Slotta, and Leeuw, (1994) define ontology as "the fundamental essence" of the nature of concepts. Their main notion of conceptual change is to re-assign a concept from its initial category to another one. For example, if one needs to change his initial concept of whale from "fish" to "mammal," a change of ontological category is required.

Chi et al. (1994) investigated why some science concepts are difficult to learn and others are not. They tried to clarify why people's initial concepts are very resistant to change. Many reasons have been proposed for this condition of resistance in the literature on conceptual change: Concepts are abstract and very technical; therefore, they do not overlap with everyday life. Chi et al. conducted various experiments on physics concepts about light, heat, and electrical current to understand the reason why some of the concepts are resistant to change. Their findings showed that this difficulty originates from unsuitable matching or "incompatibility" between the category of students' initial concepts and that of scientific concepts.

According to Chi et al., all the things in the world belong to one of the primary ontological categories, which are matter, process, and mental states. They referred to them as "trees." Concepts in the matter tree are more concrete than the abstract and 
descriptive concepts in the process or mental states trees. If a concept belongs to a matter category, it can be classified as living, nonliving or artifacts. If a concept belongs to the process category, it can be a procedure, event or constraint-based instruction. However, if a concept belongs to the mental states category, it can either be an emotional or intentional concept. All of these are "subcategories" of the primary categories in this theory.

Chi et al. report that misconceptions arise because students initially place concepts in a category where they do not belong. For example, when young children are asked about how animals grow, one of their explanations is that "the animals want to." Here, they interpret basic biological phenomena in terms of the desires and wants of the animals rather than their natural physiological needs. In other words, they place their initial concept into the category of mental states instead of the category of processes.

Chi et al. state that if the misconceptions and the scientific concepts are compatible (from the same tree), then students can correct their misconceptions easily even at a very early age. However, if these two are not from the same tree, it will be very difficult to grasp the scientific concepts even after college-level instruction. For example, 10 year-old children expressed the misconception that bread mold (a kind of fungus), is non-living. After intervention, they readily understood that it is actually living, because both fungus and bread mold are part of the matter tree (Bulunuz, Jarrett, \& Bulunuz, 2005). On the other hand, many college students, preservice teachers, and teachers still hold misconceptions about "phases of the moon" and "reasons for seasons" even after instruction, because of the mismatch between the matter tree and the process tree (Kikas, 2004). 


\section{Conceptual Change Model Based on Student Motivation, Interest, and Values}

The previous theories of conceptual change generally involved only cognitive roles of an individual. Therefore, Pintrich, Marx, and Boyle (1993) called these theories “cold conceptual change." The researchers highlighted the role of students' motivational beliefs, interests, and values in influencing both the students' cognitive engagement and the process of conceptual change in an academic task. They also asserted that academic learning should not be isolated from peer and teacher interactions. In other words, not only individual beliefs, but also the interactions between students and teachers influence the conceptual change process. Since these factors had not previously been considered by Posner et al., the conceptual change model of Pintrich et al. opened a new perspective by discussing students' goals, values, self-efficacy, and classroom interactions.

\section{Multidimensional Perspectives}

Until the late 1990's, many researchers focused only on one theoretical perspective of conceptual change in their studies. Later, Tyson, Venville, and Harrison (1997) defined a new type of perspective in the field that is called "a multidimensional framework" on conceptual change. Tyson et al. combined the three basic ideas on conceptual change to create what they call a "holistic" picture of conceptual change. These three ideas are: conceptual status (Posner et al., 1982), the ontological categories (Chi et al., 1994), and socio/affective factors (Pintrich et al., 1993). Tyson et al. suggest that a multidimensional framework should be used to understand whether or not these three aspects are beneficial to each other in different learning environments.

It is clear from all the theories, frameworks, and models discussed above that changing current ideas and adopting new ways of thinking does not happen easily. 
Transmitting a new concept or telling learners that their initial ideas are not correct will not necessarily facilitate conceptual change. Therefore, teachers, educators, and researchers may need to implement a variety of different conceptual change strategies and encourage learners to take an active role in organizing their ideas and knowledge. Some of the common conceptual change strategies are discussed in the following section.

\section{Common Conceptual Change Strategies}

Since the mid-1980's, a number of researchers have focused on determining methods for changing students' alternative conceptions in science. Some of these researchers reviewed a number of studies in this field (Guzzetti, Snyder, Glass, \& Gamas, 1993; Wandersee, Mintzes, \& Novak, 1994; Duit \& Treagust, 2003) and published a meta-analysis (Guzzetti et al., 1993) that has documented effectiveness of various conceptual change strategies at all grade levels. The strategies mentioned in this metaanalysis are: conceptual change texts, refutation texts, concept maps, bridging analogies, computer simulations, demonstrations, computer-aided instruction, field trips, and learning cycles. These strategies were used to elicit students' alternative conceptions, as well as to address incorrect ideas through instruction.

Scott, Asoko, and Driver (1991) identified two main groups of strategies aimed at promoting conceptual change. The first group is based on cognitive conflict and resolution of conflicting perspectives, such as refutational texts, discrepant events, and dialogue-based strategy. The second group builds on learners' existing ideas and extends them through metaphor or analogy (Duit, 1994). Based on these categories, the following section will discuss conceptual change texts, refutational changes texts, concept maps, analogies, and hands-on activities, plus their effectiveness for various age groups. 


\section{Conceptual Change Texts}

One of the common conceptual change strategies in this field is the use of conceptual change texts (Wang \& Andre, 1991; Chambers \& Andre, 1997; MikkilaErdmann, 2001; Sungur, Tekkaya, \& Geban, 2001; Cakir, Uzuntiryaki, \& Geban, 2002; and Tekkaya, 2003). Tekkaya (2003) mentions ways for identifying alternative conceptions and forcing students to confront their prior conceptions by conceptual change text design. According to the researcher, students' alternative conceptions are first obtained, and then students are informed of correct scientific explanations supported by examples to create dissatisfaction.

Chambers and Andre (1997) listed steps for application of conceptual change texts in classrooms. They are: a) the instructional designer or teacher first identifies common alternative conceptions, b) students are asked to predict what would happen in a situation before they present the inconsistency between common nonscientific and the scientific conceptions, c) common alternative conceptions are introduced with evidence that they are wrong, and d) instruction presents the correct scientific explanation.

Conceptual change text design has been used frequently in various science topics. In physics, Chambers and Andre (1997) investigated college students' understanding of direct current in electricity by using conceptual change texts. They stated that the texts that were used had two parts; one was for activating the students' prior conceptions and the other was for challenging their misconceptions. Each part had diagrams about electric circuits for visualizing the situation. The researchers found that conceptual change text led to better conceptual understanding of electricity concepts for college students. They also suggested that text-based conceptual change strategies are useful in large classroom 
environments.

Regarding biological concepts, Sungur et al. (2001), Tekkaya (2003), and Mikkila-Erdmann (2001) demonstrated the effectiveness of conceptual change text instruction on $9^{\text {th }}$ and $10^{\text {th }}$ grade high school students' understanding of the human circulatory system, diffusion/osmosis, and photosynthesis. In chemistry, Cakir et al. (2002) reported the effectiveness of conceptual change texts in creating conceptual change and promoting meaningful learning in $10^{\text {th }}$ grade high school students regarding acids and bases.

It is clear from these studies that researchers tend to conduct research to identify the effectiveness of conceptual change texts mostly for older students such as, high school $\left(9^{\text {th }}, 10^{\text {th }}\right.$, and $11^{\text {th }}$ graders $)$ or college students. Guzzetti et al. (1993) reported that older students seem to profit from conceptual change texts compared to young learners. According to them, a text might cause a kind of discomfort for young learners. In addition, just explaining the correct way to understand a scientific phenomenon is not sufficient for young children. Instead, children need to act on materials in a hands-on way.

\section{Refutational Texts}

The refutational text approach was developed by Hynd and Alvermann (1986) based on the conceptual change model of Posner et al. (1982). According to the researchers, refutational texts are materials written to challenge and change students' common nonscientific conceptions. In this design, common alternative conceptions are contrasted with scientific conceptions. However, students are not asked to predict a common situation before refutation is given. In other words, the major difference 
between refutational text and conceptual change text is whether students are asked to predict a situation (Hynd, 2001).

A number of studies using refutational texts have provided considerable evidence that this technique can help students at different grade levels (Hynd \& Alvermann, 1986; Guzzetti et al., 1993; Guzzetti, 2000; Hynd, 2001; Palmer, 2003; and Diakidoy, Kendeau, \& Ioannides, 2003). In most of these studies, the researchers wanted the students to read either a refutational text that refuted a nonscientific conception, or a non-refutational text (also called control text) that consisted of a scientific explanation of a given concept.

Guzzetti et al., (1993) reported that refutational texts were more effective than nonrefutational texts.

Diakidoy et al. (2003) conducted research to see effects of text structure on the acquisition of energy concepts in physics with sixth-graders. In this research, the participants read either a simple expository text presenting factual information or a refutational text that addressed common preconceptions and proceeded to refute them. They found out that students who read the refutation text were more successful than the ones who read simple expository texts.

Palmer (2003) investigated the effectiveness of refutational texts to improve $9^{\text {th }}$ graders' comprehension of ecological roles in biology. The researcher gave a list of living organisms (trees, kangaroos, fleas, starfish, bacteria (germs), and butterflies) and asked the students about the role of these organisms in nature. On the first interviews, half of the participants believed that some living things do not have a role in nature. The post interviews indicated that participants learned better from the refutational texts than from a control text. 
Hynd and Alvermann (1986) conducted research with college students on alternative conceptions about motion. The researchers gave two types of texts concerning the same principle of motion theory: refutational and non-refutational texts. The refutation text presented information on certain principles of motion but discussed those ideas in contrast with students' intuitive ideas. The non-refutational version of the physics text described Newtonian mechanics; but did not discuss any of the ideas as opposite to common misconceptions. Hynd and Alvermann indicated that the refutational text was by far more effective at getting students to change their prior alternative conceptions than non-refutational text.

Hynd, Alvermann, and Qian (1997) investigated changes in preservice teachers' conceptions about projectile motion by a combination of demonstration and refutational texts that they called demo-text condition. The preservice teachers either participated in a demonstration before reading or only read a text. The demonstration-text condition was created to bring about dissatisfaction with one's current conception. In order to create dissatisfaction, one asks participants to predict the outcome of a demonstration, then to view it, explain it, and read about it. The researchers found that text-only condition produced long-term conceptual change; however, a combined demo-text condition was more effective on immediate posttest.

Hynd (2001) summarizes the results of research on high school physics students. In this study, the researcher had students read excerpts about projectile motion from different texts, including several textbooks, narratives, non-refutational texts, and refutational texts. Students were asked to tell what they liked and disliked about them. The findings showed that students preferred refutational texts to other kinds. Specifically, 
the researcher reported that high school students found these texts understandable, useful, and related.

Criticisms of refutational texts have come from Vosniadau (1994) and Wichman, Gottdenker, Jonassen, and Milrad (2003). Vosniadau (1994) believes that some conceptual change strategies (like refutational texts) can cause cognitive conflict. According her, these strategies do not cause strong or radical conceptual change, because the students usually learn the concepts in a superficial way. Wichman et al. (2003) state that learners need to generate hypotheses, design experiments, analyze data, and predict results to construct knowledge collaboratively.

\section{Concept Mapping}

The concept mapping technique was developed by Joseph D. Novak at Cornell University in the 1960's. Novak's and his colleague Gowin's early work on the nature of knowledge and learning explored factors that influence students' understanding of concept meanings (Novak, 1998; Novak \& Gowin, 1984). The idea behind concept maps was derived from Ausubel's (1962) theory of "meaningful" versus "rote" learning. According to this theory, when humans build meaning, they establish a relationship between new information and existing knowledge. Rote learning occurs because a student simply memorizes information with no motivation to relate that information to prior knowledge. Novak (1998) believes that Ausubel's meaningful learning theory is a powerful model of learning to guide education.

A concept map visually represents knowledge as a hierarchical framework of concepts and concept relationships (Iuli, 2004). Novak and Gowin (1984) define a conceptual map as a "schematic device for representing a set of concept meanings 
embedded in a framework of propositions" (p.15). Increasingly, concept maps are used in a number of settings from elementary school to adult education. Research has been done with elementary school students (Fellows, 1993), high school students (Cakir et al., 2002; Tekkaya, 2003), college students (Gonzalez, 1997; Van Zele, Lenaertz, \& Wierne, 2004), preservice (Kim, Germann, \& Patton, 1998), and inservice teachers (Cakir \& Crawford, 2001).

In a study about 6 th grader students' understanding about matter and molecules, Fellows (1993) compared concept maps over time and reported changes in the conceptual understandings of the students. Fellows reports that the students had added new concepts to their vocabulary and their maps became more organized with more hierarchical levels after instruction.

Concept mapping is an effective technique for teaching earth science concepts according to Ault (1985), Gonzalez (1997), and McConnell, Steer, and Owens (2003). Ault (1985) explains concept map preparation steps on earth science concepts and gives examples of concept maps about igneous rocks, fossils, and precipitation drawn by students in introductory geology and earth science courses.

Investigating Spanish university students' conceptual understanding of a geology topic (silicates) in a two-year longitudinal study, Gonzalez (1997) trained students in concept mapping techniques. By analyzing the students' pre and post concept maps, Gonzalez found that the mapping technique proved an efficient tool in understanding the cognitive structure of college students and in showing the evolution of their knowledge.

Concept mapping has been used in combination with other strategies. Sungur et al. (2001), Cakir et al. (2002), and Tekkaya (2003) investigated the effectiveness of both 
concept maps and conceptual change texts on Turkish high school students' biological concepts and reported positive effects of concept maps in changing alternative conceptions on biological concepts. In her general review of effective strategies in science, Gabel (2003) argues that concept mapping, though sometimes a boring exercise for children, can be effective when used with other teaching techniques.

\section{Analogies}

Analogies have been seen as both a means of natural learning and an important teaching method. In science education, analogies are comparisons between something familiar to students and an unfamiliar area in science that teachers want students to understand (Else, Ramirez, \& Clement, 2002).

Many educators including Scott et al. (1991), Thiele and Treagust (1991), Clement and Steinberg (2002), Guzzetti et al. (1993), and Gabel (2003) have advocated use of analogy to promote students' conceptual change. Studies have investigated the use of analogies in conceptual change of elementary school students (Gallas, 1992; Newton \& Newton, 1995; Yanowitz, 2001), middle school students (Else et al., 2002), high school students (Tsai, 1999; Venville, \& Treagust, 1996), and preservice teachers (Taylor \& Coll, 1997; Yerrick et al., 2003).

Glynn (1991) proposes the Teaching-with-Analogies (TWA) Model of instruction. It prescribes the following procedures for using an analogy to aid comprehension of a target concept: 1) introduce the target concept, 2) bring up students' knowledge of the analog (item or thought with which the analogy is made), 3) identify relevant features of both, 4) map their similarities, 5) draw conclusions about the target concept, and 6) indicate where the analogy breaks down. Analog and target tend to share 
attributes in a relationship, which helps students can gain a better understanding by comparing the unfamiliar scientific principle with one that is familiar (Thiele \& Treagust, 1991; Gabel, 2003).

Analogies have been used as an instructional tool for primary and secondary school students. Newton and Newton (1995) conducted research on 6-7 year-old students' understanding of electrical current with and without an analogy. The researchers presented a demonstration of a water circuit and one electricity activity by using battery, bulb, and wires for the experimental group. On the other hand, they let the control group experience only the electrical activity. Some of the answers were:

"electricity is like the water through the pipe," "it is like the tube, it will go down the wire to light the bulb," and "the electricity will crash together like the water," etc. The authors found the answers of the experimental group more descriptive than the control group answers. Yanowitz (2001) conducted research with fourth and sixth graders about infections, enzymes, ants, aphids, and mitochondria. The researcher wrote short paragraphs in analogical and non-analogical formats that had about the same length and assigned the students randomly to either analogical or control conditions. The results showed that elementary school students benefited from the analogies.

Analogies are used as a conceptual change strategy for earth science concepts (Blake, 2001; and Blake, 2004). Blake (2001) conducted a study with English 7-11 yearsold children in which aluminum can recycling was used as an analogy for the rock cycle to assist children in developing a more scientific understanding of the origin of rocks. The researcher assigned the students randomly to a control group (without analogy) and an experimental group that was exposed to analogical teaching with comparisons of 
aluminum can and rock recycling stories. Blake found that the post-intervention scores were significantly higher for the analogy group. However, the author highlights that analogy is only effective when the concept is difficult to grasp. According to him, the aluminum can recycling analogy was helpful enough to scaffold the students' understanding of the rock cycle.

In research with preservice teachers, Taylor and Coll (1997) investigated the power of analogies in clarifying preservice teachers' conceptions about solubility. In an experimental study, they found that use of analogy was effective in remediation of alternative conceptions based on the posttest interviews. They concluded that one of the major advantages of using analogies is that this approach is potentially less detrimental to learners' confidence than a conflict approach. However, analogies might have certain constraints. For example, they noted that useful analogies may not always be available for specific concepts. Or, their use may not necessarily produce desired results. They reported that an uncritical use of analogies might generate alternative conceptions in students who are unfamiliar with the analogy. In other words, the use of this teaching tool can cause incorrect learning about the analog-target relationship. Nevertheless, appropriate analogies can play an effective role in instruction for conceptual change.

\section{Hands-on Science Activities}

In many studies it was reported that students' alternative conceptions couldn't be eliminated by traditional methods involving primarily lecture (Marinopoulos \& Stavridou, 2002; Weaver, 1998). In contast, hands-on activities make students more active learners in science classrooms (Cetin, 2003). Students should be able to apply what they learn in school to their daily life situations. Research has shown that students find 
science topics more interesting when they are relevant to daily life or experience (Weaver, 1998).

Popular terms in the world of practicing teachers, including 'doing science', 'hands-on science', and 'real-world science' are frequent descriptors of inquiry-based learning approaches (Crawford, 2000). Crawford states that these types of projects with hands-on science instruction enhance opportunities for construction of knowledge. Costa (2003) reported that based on the study of "hands-on science network," hands-on activities were indicated as the most effective way of acquiring scientific knowledge for most of the children and adolescents. The researcher noted that the pedagogical usefulness and effectiveness of hands-on experimental activities were clearly seen in different grade levels and disciplines in Europe.

Using hands-on activities for conceptual change in science has become very popular in the last four decades. To overcome students' alternative conceptions, a number of researchers have explored the effects of hands-on activities and science experiments for different age groups. These researchers focused on elementary school students (Dalton \& Morocco, 1997; Weaver, 1998; Pyle \& Akins-Moffatt, 1999; Marinopoulos \& Stavridou, 2002), middle school students (Ertepinar \& Geban, 1996; Alexopoulou \& Driver, 1996), high school students (Wood-Robinson, Lewis, \& Leach, 2000; Hofstein, Navon, Kipnis, \& Mamlok-Naaman, 2005), college students (Colburn \& Henriques, 2000; Niaz, 2002), preservice teachers (Kelly, 2000; Gibson, Bernhard, Kropf, Ramirez, \& Van Strat, 2001; Plourde \& Klemm, 2004), and inservice teachers (Bulunuz \& Jarrett, 2006; Parker \& Heywood, 2000). The research done with elementary school students, preservice teachers and inservice teachers will be the focus here. 


\section{Research with Elementary Students}

Dalton and Morocco (1997) conducted research about electricity with fourth graders, including students with learning disabilities. These researchers compared the effects of hands-on science-supported inquiry science (SIS) and activity-based-science (ABS) approaches in urban and suburban classrooms. Both curricula engage students in extensive manipulation of batteries, wires, and bulbs for a certain period of time.

Although the SIS curriculum was designed to focus on students' misconceptions, the ABS curriculum paid little attention to the role of misconceptions. During the conductivity experiment, students tried to find out what happened to the circuit when an insulator was inserted. They used different insulators for different materials and shared their ideas with each other. The researchers reported greater concept learning in the SIS classrooms than in the ABS classrooms.

In her cross-age study, Weaver (1998) investigated the successes of hands-on activities and experiments with fourth, eighth grade, and tenth grade students. Weaver reports that the students found hands-on activities very valuable and suggested that hands-on science activities and experiments can promote conceptual change, when combined with discussion and reflection.

Hands-on science activities are also used as an effective strategy to change incorrect conceptual understanding in earth and space science (Ebert \& Elliot, 2002; Gutierrez, Coulter, \& Goodwin, 2002; McConnell, Steer, \& Owens, 2003; and Stepans \& Kuehn, 1985). Stepans and Kuehn (1985) compared the responses of second and fifth grade students about wind when taught by reading from the textbook versus through hands-on activities. The researchers found that the students at both grade levels gave 
more scientific responses to open-ended interview questions, if they were taught the concepts by a hands-on approach compared to a textbooks approach. Research with Preservice and Inservice Teachers

Gibson et al. (2001) conducted their study with preservice teachers enrolled in an introductory physical science course taught using hands-on activities, cooperative group work, manipulatives, and real life applications. Researchers analyzed the participants' weekly reflective journals at the end of the course and found that an introductory science course taught using constructivist methods had a positive impact on preservice teachers' scientific understandings.

Parker and Heywood (2000) conducted research on in-service teachers' concepts about floating and sinking by implementing hands-on activities, such as: pushing an inflated balloon into a tank of water; exploration of a range of everyday objects with respect to floating and sinking; observation of large, heavy floaters and small, light sinkers; and floating a screw cap jar in a tank of water. The researchers found that through hands-on science activities, teachers engaged successfully with difficult and abstract scientific ideas. They also observed that, if teachers were learning by doing, they could identify the characteristics of the learning process itself within specific subject domains.

McConnell et al. (2003) compared the conceptual understanding of college students in traditional versus inquiry-based earth science classes where students were active and collaborative, while engaged in hands-on activities. Their interviews of the students show that most of the participants enjoyed the inquiry-based class, preferred the hands-on activities to a traditional lecture class, and would recommend this course to 
their peers. Gutierrez et al. (2002) offered a summer workshop to elementary school teachers focusing on earthquakes, volcanoes, floods, hurricanes, and tornadoes. The researchers reported that the teachers improved their understanding $31 \%$ after the workshop. In addition, Ebert and Elliot (2002) conducted a study with preservice teachers in a laboratory techniques course about rock and mineral identification and obtained significantly positive results. The researchers reported that the activities provided the students with an excellent review of minerals and rocks.

Considerations for Teaching Preservice Teachers

\section{Modeling Appropriate Practices}

In his social learning theory, Bandura (1974) explains how most human behavior is learned observationally through modeling. In other words, people observe the behaviors of others and profit from results of these actions in addition to their direct experiences. According to Bandura, people form an idea of how new behaviors are performed, then this coded information serves as a guide for their actions. Preservice teachers are likely to model the strategies they experienced during their school years, unless other strategies are modeled in science methods courses.

Some researchers and teacher educators are engaged in helping preservice teachers develop a different style of teaching than they experienced in their undergraduate and graduate courses (Palmer, 2001; Watanabe, McGinnis, \& McDuffie, 1997). Watanabe, McGinnis, and McDuffie (1997) interviewed preservice teachers who took Maryland Collaborative for Teacher Preparation mathematics and science courses that tried to model good instruction. The students rated their courses as high in quality and asserted that the teaching strategies that were modeled in these courses could be 
practiced in classrooms.

Palmer (2001) investigated the effect of modeling hands-on methods on the attitudes of preservice teachers. Interviews with four preservice teachers after they completed a hands-on methods course found that they enjoyed the class, found it practical, and planned to apply in their own classrooms the classroom practices and hands-on teaching strategies that were modeled in the course.

\section{Teaching For Conceptual Change in Science Methods Courses}

In the literature, it is argued that preservice teachers need to experience conceptual change pedagogy first as learners in the methods course and then to apply this experience in classrooms (Marion, Hewson, Tabachnick, \& Blomker, 1999; Stofflett \& Stoddart, 1994). Therefore, these researchers developed elementary science methods courses, specifically called elementary science conceptual change methods courses, in which conceptual change theories, strategies and methodologies were taught. In these courses, the instructors modeled good practices as complete conceptual change science lessons so that preservice teachers learned science in a very different way from their previous experiences (Marion et al., 1999). The researchers investigated the applicability of the conditions of accommodation in the conceptual change science methods courses (Stofflett, 1994; Stofflett \& Stefanon, 1996).

Stofflett (1994) reported that the instructors could easily implement conditions of accommodation in the methods courses with preservice teachers. They were not able to determine if preservice teachers had become dissatisfied with their existing conceptions or not. In the study of Stofflett and Stefanon (1996), although the course was completely designed for teaching conceptual change, only $25 \%$ of the teacher candidates thought 
they were able to change their students' misconceptions, and only 3 out of 76 reported that these (IPDF) conditions had been effectively met in their field placements.

Unfortunately, most preservice teachers have never personally experienced learning science content through conceptual change methods (Stofflett \& Stoddart, 1994; Tabachnick \& Zeichner, 1999; Thorley \& Stofflett, 1996). According to Stofflett and Stoddart (1994), because many teacher candidates came from traditional didactic instruction and previously completed limited science related courses, their science content knowledge could not be expected to be strong enough for them to teach science. The same researchers compared preservice teachers' science content knowledge and ability to apply this knowledge in two science methods courses that received content instruction through either traditional or conceptual change methods. They found that the conceptual change group planned to use conceptual change strategies and performed discovery activities with children by translating this conceptual change pedagogy into practice. However, the traditional group did not plan to use the conceptual change pedagogy in their teaching.

Many preservice teachers have difficulty in using their new conceptual change experiences in creating new conceptual change lessons for their students (Meyer, Tabachnick, Hewson, Lemberger, \& Park, 1999; Stofflett \& Stefanon, 1996; Tabachnick \& Zeichner, 1999). Tabachnick and Zeichner (1999) analyzed the action research that was conducted by teacher candidates in their field experiences after they completed the conceptual change methods course. The researchers found that most of the preservice teachers began to think about their students' prior knowledge and what the students learned at the end. However, it was reported that the preservice teachers' prior 
knowledge, conditions of school placements, and cooperating teachers' resistance also affects the outcome of conceptual change pedagogy and its success in the classroom (Stofflett, 1994; and Tabachnick \& Zeichner, 1999). According to the same authors, preservice teachers' nonconstructivist views of science teaching, the lack of modeling conceptual change teaching in school placements, preservice teachers' lack of deep science content knowledge, and the lack of conceptual change teaching in preservice teachers' own education might be the reasons why the preservice teachers could not effectively implement conceptual change strategies in their classrooms.

\section{Organizing Hands-on Activities through Learning Stations}

One way to structure hands-on activities is through centers or learning stations. Although the terms learning centers, interest centers (Jones, 1999), science centers (Irwin, Nucci, \& Beckett, 2003), and science discovery centers (Radeloff, 2001) are used interchangeably in the literature, the term hands-on learning station (Bulunuz \& Jarrett, 2006) is used throughout this study. In this approach, the idea of students working together as active learners is consistent with the National Science Education Standards (National Research Council, 1996). Research with Preservice Teachers

Plourde and Klemm, (2004) investigated effects of learning stations on preservice elementary teachers' concepts about sound through five learning stations, including one in which students used a slinky, a rope, cardboard, paper, and construction paper to demonstrate sound. The findings were that the preservice teachers were engaged in the learning experiences associated with the specific hands-on inquiry activities and also developed their conceptual understandings about sound. Research by Bulunuz, Jarrett, 
and Bulunuz (2005) on air pressure and by Bulunuz and Jarrett (2006) on earth and space science concepts showed that learning stations could be used to clarify student concepts. As discussed earlier, the modeling literature recommends that teachers be taught in ways they can implement in the classroom. The following research discusses the applicability of learning stations with children.

\section{Research with Children}

Learning stations are frequently used at the elementary level because they help children develop their content knowledge, while giving children an opportunity to explore materials and objects and to conduct open-ended science activities (Irwin et al., 2003; Jones, 1999; and Radeloff, 2001). This approach can be an excellent tool for teachers to encourage positive interaction among students of different backgrounds and ability levels (Irwin et al., 2003).

Jones (1999, p. 27) defines "the workshop approach" as a model for organizing and using learning stations to provide students with a number of experiences centered on concepts in science. The researcher states that in this approach, children are given opportunity to work within a variety of social configurations: alone, with one or two other children, in small groups, and in larger groups. While students rotate through stations, the teacher circulates among the stations asking thoughtful, open-ended questions, observing, and assessing student and group progress in the classroom.

The advantages of implementing learning stations in the school settings were reviewed by Irwin et al. (2003) based on their work with elementary school children. The researchers listed some of the positive characteristics of this approach: (a) learning stations celebrate students' differences, (b) working together help students to learn more, 
(c) stations are accessible and beneficial for all, (d) diverse materials encourage students' learning, and (e) simple directions help them understand the activities better.

Applied Learning in Field Placements

According to Moore (2003), field experiences have great importance for providing preservice teachers the opportunity to make connections between learning theory and practice. Hanuscin (2003) notes that although preservice teachers learn many strategies and methods for teaching, applying these strategies in the classroom is not easy. Researchers have examined the effects of field experience during elementary science methods courses in terms of the following: changes in preservice teachers' behavior (Sunal, 1980), concern and attitudes toward science and science teaching (Strawitz \& Malone, 1986), conceptions of teaching and learning science (Mellado, 1998), knowledge and performance in inquiry skills (Sunal, 1976), and personal science teaching self-efficacy belief (Wilson, 1996). The findings of these studies confirm that field experiences are positive experiences in general education classes, methods courses, and science methods courses.

\section{Hands-on Learning Stations as a Field Assignment}

Some teacher education programs require implementation of learning stations during field experiences (Hanuscin, 2003 and Radeloff, 2001). Radeloff (2001) described the experiences of preservice teachers in a methods class as they created science learning stations for preschool children. They found that preservice teachers had a great experience doing these stations, and the children were eager to participate. Her student teachers realized that when children were experimenting with materials, they communicated with their peers, as if they were teaching each other. Similarly, Hanuscin 
(2003) assigned her preservice teachers to implement learning stations in their field placements. Hanuscin found that the preservice teachers reported noticeable differences in students' understandings and their confidence after several rotations. According to her, the preservice teachers were able to relate students' cognitive functioning to course topics on misconceptions and conceptual change.

Watters and Ginns (2000) investigated the effect of collaborative learning workshops and hands-on practices on understanding of a range of concepts (e.g., energy, matter, earth, weather, life science, and space) in a science methods course. As part of the course assignment, preservice teachers were observed in the classrooms to ensure they could apply hands-on approaches with children. According to Watters and Ginns, this methods course helped the participants understand some of the concepts they had not understood in their own high school science, and direct experience with teaching children science in field experience sessions enhanced preservice teachers' outcome expectancy for the teaching of science.

\section{Summary}

This chapter reviews the evidence that not only children but also preservice and inservice teachers hold a variety of alternative conceptions about earth and space science concepts. The findings of the literature on student teachers highlight an important issue: that future teachers do not know enough subject matter in earth and space science to enable them to teach it to students. Research points out the importance of changing preservice teachers' incorrect understandings in order for them to not pass them to their future students. 
Piaget's and Vygotsky's developmental theories and conceptual change theories argue that it is very hard to change tenacious misconceptions to scientific ones at almost every age level. A variety of conceptual change strategies are reviewed, some of which (e.g. refutational texts) are more appropriate for adults than for children. The research suggests the advantages of practicing student-centered, hands-on conceptual change strategies that create cognitive conflict and let a learner be active with different materials. Modeling theory implies that teachers should be taught using methods they can apply in the classroom, which further suggests that conceptual change strategies appropriate for children be included in teacher preparation. Research on field assignments indicates that practice of strategies learned in class helps preservice teachers connect theory and practice. 


\section{CHAPTER 3}

\section{METHODOLOGY}

Introduction

The purpose of first part one was to determine what understandings preservice and inservice teachers had about basic earth and space science concepts taught in elementary and middle school. The purpose of part two was to evaluate the effectiveness of various learning methods for clarifying these concepts in a preservice science methods class. The purpose of part three was to describe how preservice teachers implemented a conceptual change activity station in their field placements.

The following questions guided this research:

Part one of the study:

1. What understanding do preservice and inservice teachers have on the following earth and space science concepts: reasons for seasons, phases of the moon, reasons for wind, rock cycle, earthquakes, and soil formation?

2. Is there a difference between preservice and inservice teachers in their understanding of these concepts?

Part two of the study:

3. Are hands-on learning stations more effective than readings in clarifying earth science concepts as measured by rubric scores and concept map scores?

4. Does concept mapping improve rubric scores for those who experienced the learning station activities compared to those who read text explanations? 
Part three of the study:

5. How do the preservice teachers apply conceptual change strategies in their field assignment on conceptual change?

\section{Participants and Context}

Members of five cohorts in early childhood education programs at a large southeastern urban university were the subjects for this research. All were registered for classes Spring Semester 2006. These cohorts represented three different programs within the Department of Early Childhood Education: the undergraduate Bachelors of Science in Education program, the Urban Alternative Preparation Program (alternative certification masters program, with a preservice cohort in its certification year and an inservice cohort in its masters year), and the Collaborative Masters Program (for experienced teachers). The following table gives the number of preservice and inservice teachers registered for classes Spring Semester 2006 in the three programs:

Table 2

Programs and Numbers of Preservice and Inservice Teachers in Spring Semester 2006

\begin{tabular}{lcccc}
\hline & $\begin{array}{l}\text { Undergraduate } \\
\text { Program }\end{array}$ & $\begin{array}{c}\text { Urban Program } \\
\text { (GTAPP) }\end{array}$ & $\begin{array}{c}\text { Collaborative } \\
\text { Master Program }\end{array}$ & Total \\
\hline Preservice & Cohort 1 (25) & 19 & - & 72 \\
& Cohort 2(28) & & 20 & 36 \\
Inservice & - & 16 & 20 & 108 \\
Total & 53 & 34 & & \\
\hline
\end{tabular}




\section{Undergraduate Program}

Undergraduates wanting a degree in early childhood education go through an application process and are admitted into cohorts at the beginning of their junior year. The primary difference between cohorts is that they generally have field placements in different school systems. The program is heavily field-based with school placements each semester in schools having various levels of partnership with the university. Following a developmental sequence, cohort members are first placed in pre-K and kindergarten classrooms and eventually are placed in grades four or five classrooms. The undergraduate cohorts included in this study were second semester juniors and were placed in first grade classrooms the first half of the semester and second or third grade classrooms the second half of the semester. They were in schools two days a week, placed with an experienced cooperating teacher and observed at regular intervals by a university supervisor. Cohort members took classes on campus two days a week. One of their courses was a three-credit science methods course, Science and Inquiry in Early Childhood Education in which the instructional intervention research was implemented. During Spring Semester 2006, one cohort with 25 members (Cohort 1) was taught by another doctoral student, and the second cohort with 28 members (Cohort 2) was taught by the researcher.

\section{Urban Program}

Two additional cohorts of participants were students in an urban alternative certification masters program; a cohort of 19 preservice teachers in their first year of the program (certification year) and a cohort of 16 inservice teachers in their second year of the program (masters year). The purpose of the urban program is to prepare excellent 
teachers for urban high poverty schools with marginalized populations. The preservice teachers are placed with experienced teachers in urban schools four days a week and also attend classes at the university one day and two evenings a week. The inservice teachers have a range of experience teaching in urban schools. Of the 16 members of this cohort, 11 were first year teachers and the other five had up to four years of teaching experience. Each preservice and inservice teacher has a university coach who visits him/her regularly. Each of these cohorts was taught a course by the same professor, who agreed to allow the participants in her class to be surveyed.

\section{Collaborative Masters Program}

The last group of participants is a cohort of 20 inservice teachers in the Collaborative Master Program in the same department. This is a constructivist-based program for experienced teachers. The teachers in this cohort had a range of 3-23 years of classroom teaching experience. Cohort members are involved in decision making to determine what and how they will learn in this program. The program lasts two academic semesters plus two summer semesters. During Spring Semester 2006, the participants were over half way through the program. The program coordinators agreed to allow class members to be surveyed during one of their class sessions.

\section{Overview of Research Design}

This study involved: quantification of answers to open-ended survey questions, parametric descriptive and inferential statistics, qualitative analyses of two preservice teachers' field assignments that received the highest and the lowest scores in the class, and summaries of the qualitative analyses of six preservice teachers' reflections and of the researcher's field notes. 
Part one is descriptive in nature. To answer question one, teacher understanding of six concepts (measured with an open-ended survey and scored on a rubric), results are described using means and frequencies. Question two involves a comparison between preservice and inservice teachers on their answers using independent samples t-tests.

Part two is experimental in nature. Answering questions three and four involves a quasi-experimental design in which two cohorts were taught through various conceptual change strategies. Inferential statistics were employed to determine which strategy or combination of strategies best improved preservice teachers' understanding of the six concepts.

Part three is exploratory. Answering question five involves the qualitative analysis of two preservice teachers' field assignments, the summary of six preservice teachers' reflections on conceptual change station, and the researcher's field notes that gave an in-depth perspective about how one group of preservice teachers applied what they learned about teaching with conceptual change approaches.

Part One of the Study: Description of Conceptual Understanding

\section{Participants}

Although 108 participants were registered for early childhood education classes of the three preservice and two inservice cohorts during Spring Semester 2006, only 99 participants were included in this part of the study. One preservice teacher did not give informed consent. Eight people were absent for the pretest (two undergraduates, one preservice and four inservice teachers in the urban masters program, and one inservice teacher in the Collaborative Masters Program). 


\section{Data Sources}

Open-ended Survey Administration

A six-item survey headed, "How well do you understand these science concepts?" followed by six earth science concepts was administered in each class either by the researcher or the course instructor. The questions were adapted from a survey used by the dissertation chair as a teaching tool in her classes. The students were able to fill out the survey in 10-15 minutes. The open-ended survey can be found in Appendix A. The preservice and inservice teachers' answers to the six open-ended questions were scored according to level of understanding for each phenomenon. The researcher used rubrics to classify the participants' responses about these concepts.

\section{Rubric Scoring}

Pilot study scoring. The scoring rubrics for four of the questions were created by the researcher for a previous study (Bulunuz \& Jarrett, 2006). Those questions concerned the reasons for seasons, phases of the moon, rock cycle, and earthquakes. In that study, an answer was coded as: (1) if there was no response, incorrect answer or clearly evident misconception; (2) if the answer was partially correct or had no elaboration; and (3) if the answer was integrated with a clear scientific perspective and elaboration. In order to prepare the grading rubrics for that study, the researcher reviewed answers from past surveys, extracted examples of answers that would have been scored as 1,2, or 3, and created a grading manual with examples in each coding category. The authors separately scored the survey answers, and the researcher calculated the inter-rater reliability coefficient for each question. The coefficients were calculated as: (a) reasons for seasons, 0.86; (b) phases of the moon, 0.61; (c) rock cycle, 0.89; and (d) earthquakes, 0.72. 
Additional rubric scoring. Because the reliability coefficient of phases of the moon was low, the researcher created a new rubric for this concept. Also rubrics were created for the two concepts that had not been studied in the previous research, reasons for wind and soil formation. The rubrics for all six concepts can be found in Appendix B. Using pilot data collected in a science methods class during a previous semester, new inter-rater reliability coefficients for the above three concepts were calculated according to the new scoring rubrics. The researcher and the instructor of another undergraduate preservice cohort separately scored the survey answers, and the researcher calculated the inter-rater reliability coefficient for each question. The new inter-rater reliability coefficients were calculated as: (a) phases of the moon, 0.85 ; (c) reasons for wind, 0.88 ; and (d) soil formation, 0.95 .

\section{Data Analysis}

To answer question one, concerning understandings of preservice and inservice teachers on the six concepts (reasons for seasons, phases of the moon, reasons for wind, rock cycle, soil formation, and causes of earthquakes), means and standard deviations of the rubric scores for each question were calculated.

To answer question two, on whether inservice teachers have greater understanding of these concepts than preservice teachers, independent samples t-tests were calculated comparing the survey scores of the two groups. It was expected that preservice and inservice teachers would be similar in their understanding of these concepts. Therefore, the researcher predicted that the following null hypothesis would not be rejected: 
$\mathrm{H}_{\mathrm{o}}=$ Preservice and inservice teachers have similar understanding of the six earth science concepts.

Part Two of the Study: Experimentation with Conceptual Change Strategies

\section{Participants}

Preservice teachers in the two undergraduate cohorts were the subjects for this part of the study. Cohort one had 25 members and Cohort two had 28 members.

\section{Data Sources}

The open-ended survey used in part one was the pre data for this section of the study. In addition, this survey was administered two more times as two post-tests $\left(2^{\text {nd }}\right.$ and $3^{\text {rd }}$ administration). The same scoring rubrics were used (See Appendix B for examples).

Concept maps were another data source to determine participant understanding of the six concepts. Concept maps were drawn by teams of two or three participants and were scored using the scoring criteria for concept maps developed by Novak and Gowin (1984). See Appendix C for the scoring criteria and Appendix H for the calculation of the scores for the master concept maps.

\section{Overview of Research Design for Instructional Interventions}

In this study, three instructional methods were implemented with the preservice teachers. They were: 1) textbook reading assignments, 2) hands-on learning stations, and 3) concept mapping. The researcher determined the effects of these interventions on the participants' scores derived from the survey answers and group concept map scores. Before implementing the interventions with the two undergraduate cohorts, the readings, learning stations, and concept mapping were piloted with the preservice teachers in the urban program. Field notes, participant journals, and suggestions from participants were 
helpful in making needed adjustments before implementing these interventions with the study cohorts.

The two types of learning methods (textbook reading versus learning stations) were purposely distributed between the two undergraduate cohorts. To insure that the concepts for the reading assignments and learning stations were of equal difficulty, an analysis was conducted of the answers on the same survey questions, previously completed by a class of undergraduates during Fall Semester 2005. The participants' answers were scored as either "correct" or "incorrect." During the scoring process, an answer was coded as " 1 ", if the answer was partially correct without elaboration or if the answer was completely correct with scientific perspective. It was coded " 0 ", if there was no response, a completely incorrect answer or a clearly evident misconception. The researcher calculated the percentage of correct and incorrect answers for each concept. Then, she assigned three concepts for reading assignments and three concepts for handson learning stations, so that in each undergraduate cohort the concepts to be learned through reading and through hands-on activities were of equal difficulty. Approximately $67 \%$ on the concepts to be taught by readings and $67 \%$ on the concepts to be taught by learning stations were at least partially correct in the 2005 pilot. Table three shows which concepts were taught by the two methods to undergraduate Cohorts 1 and 2 . 
Table 3

Topics Learned by Two Methods: Hands-on Activities and Textbook Reading

\begin{tabular}{lll}
\hline & \multicolumn{2}{c}{ Undergraduate program } \\
\cline { 2 - 3 } & Cohort $1(\mathrm{n}=24)$ & Cohort $2(\mathrm{n}=28)$ \\
\cline { 2 - 3 } Hands-on learning stations & 1. Rock Cycle & 1. Phases of the moon \\
on the three topics: & 2. Reasons for wind & 2. Reasons for Seasons \\
Activities/small group discussion & 3. Earthquakes & 3. Soil formation \\
Reading assignment: & 4. Phases of the moon & 4. Rock Cycle \\
Learning through reading & 5. Reasons for Seasons & 5. Reasons for wind \\
from a textbook & 6. Soil formation & 6. Earthquakes \\
\hline
\end{tabular}

\section{Description of Interventions}

Textbook reading assignments. The researcher selected reading assignments from the textbook, Science K-8: An integrated approach by Victor \& Kellough (2004). The assigned readings are: reasons for seasons (pp.194-196), phases of the moon (pp. 199200), reasons for wind (pp. 267-270), rock cycle (pp. 217-219), causes of earthquakes (pp. 228-230), and soil formation (pp. 237-238). These readings were selected because they all come from a science methods book specifically written to clarify concepts for teachers. They represent the type of reading a teacher might do when preparing to teach these concepts. For each undergraduate cohort, the researcher gave reading assignments for the three concepts they were to learn through textbook reading. 
The researcher made copies of the reading assignments and gave them to the undergraduate preservice teachers after the first administration of the survey to the two undergraduate cohorts. Participants read the assigned articles as homework and came to the next class meeting prepared to list in their dialogue journals the "big ideas" related to the articles. In class, the researcher asked participants to write about one specific concept. This assignment was a random check on whether the students had done the assigned readings. Then, the researcher re-administered the three questions from the open-ended survey concerning the concepts covered in the reading assignments.

Hands-on learning stations. In both undergraduate cohorts, the researcher set up six stations with one or two activities each at table around the classroom. The activities at these stations focused on the three concepts that were taught in that cohort through handson activities. Approximately four or five students were assigned to each station. The participants in Cohort 1 rotated through stations on the rock cycle, reasons for wind, and causes of earthquakes. The participants in Cohort 2 rotated through stations on phases of the moon, reasons for seasons, and soil formation. The stations' activities were adapted from various science activity books and geology lab courses. Before participants rotated through the stations, the researcher presented general instructions for working in the stations. In addition, there were written instructions for each activity to clarify the procedures for participants. For the activity instructions see Appendix D.

Each group of participants rotated through the stations. They read the instructions on the sheets at the tables and completed the hands-on earth and space science activities. While they were implementing the activities at each station, they also helped each other use the materials. Participants had enough time to discuss the activities with their group 
partners. At each station, participants answered questions and listed the "big ideas" in their journals. The researcher observed them, answered questions, and helped them use the materials appropriately. Short descriptions of the stations assigned to each cohort appear below. The stations about the concept of reasons for wind and reasons for seasons included more than one activity. An attempt was made to structure the stations so the activities in each station took approximately the same length to complete:

\section{The Stations for Cohort 1}

Rock cycle. There were two stations about this concept. They were: 1) crayon rock cycle and 2) rock classification. In the first station, participants simulated rock formation; however, in the second station they observed and classified real rock samples. The purpose of the first station was to simulate the conversion of one type of rock (sedimentary rock) to other types of rocks (metamorphic and igneous) by using colored crayons, aluminum foil, and a hot plate. Participants applied pressure and heat to shaved crayon pieces to see the differences. The researcher specifically informed participants that this was the station where adult supervision was needed with students. The purpose of the second station was to see and classify different types of sedimentary, metamorphic, and igneous rocks.

Reasons for wind. There were two stations on this concept. Each station had two activities. The following are names of the first and the second stations' activities: "movement of air in the balloon," "inflated bags," "sinking of icy-water," and "prevailing winds." The purpose of the first station was to simulate the model of how air under high-pressure travels to areas where it has low pressure by letting air out of a balloon and by pressing on a bag of air connected to an empty bag with a plastic tube. 
The purpose of the second station was to provide a model of "why the local and global wind blows." In order for participants to learn about local winds, blue ice water and uncolored warm water were used to represent the movement of warm and cold air currents. Participants saw how fluids of different temperatures interact. For the prevailing wind activity, snow globes that contained blue pearlized rheoscopic fluid and a homemade lazy Susan with an aluminum plate and some marbles were used. Snow globes represented earth, the blue pearlized fluid in the globes represented the atmosphere around earth, and the lazy Susan facilitated globes' rotation on their axis. When participants rotated the snow globes counter-clockwise on the lazy Susan, the blue fluid rotated in the globes from the equator through the poles. This way, the preservice teachers could understand the reasons for the global winds.

Causes of earthquakes. There were two stations on this concept. These stations were: (1) earthquake model and (2) Plate movements with graham crackers. The purpose of the first station was to help participants understand how the increased pressure between the plates of the earth (here two bricks) causes sudden and huge energy releases that we call "earthquakes." Participants used a ratchet, cord, sander paper, and spring scale to count and predicted how many clicks of the ratchet it would take to move the bricks. Then, they measured how many pounds of tension there were on the scale when the "earthquake" occurred and measured how far the bricks moved. The purpose of the second station was to simulate different plate movements (sliding plates, divergent plates, convergent plates, and subduction) by moving graham crackers. 


\section{The Stations for Cohort 2}

Phases of the moon. For this station, the dissertation chair and another science faculty member designed two new models for participants to visualize the relationships of the moon, the earth, and the sun at the same time. The first model was a black box that had a lamp to represent the sun, a Styrofoam ball with a flag marking the U.S. to represent the earth, and a smaller ball representing the moon. One participant held the moon by a skewer stuck through it and kept the face of the moon toward the earth, when revolving the moon around the earth in a counter-clockwise direction. Participants noticed how the lighted part of the moon, as seen from the perspective of a person on earth, seemed to change shape from a thin line, or crescent, to a full moon and turn back to a new moon. They also rotated the earth counter-clockwise on its axis to see day and night.

The second model was a big empty rectangular box with the lid representing space. A ping pong ball representing the moon was hung from the middle of the lid with a string. There were little square windows all around the box for viewing. A UV light source taped at a hole in one of end of the box represented the sun. Participants looked in each window at the lit up "moon" to see the different phases. When participants visited this station, they had a chance to engage with both models to understand the reasons for phases of the moon.

Reasons for seasons. There were three activities for this station. They were: (1) modeling reasons for seasons by using a Styrofoam ball and flash light, (2) using people as models of the sun and earth, and (3) how warm is slanted vs. direct sunlight In the first activity, participants used a Styrofoam ball (leaning to the north) with a pencil through it 
as the axis and a mark around the center as the equator. By rotating the ball around the flashlight, they tried to see which part of the earth gets direct and tilted sunlight. Also, participants drew the areas $\mathrm{A}_{1}$ and $\mathrm{A}_{2}$ seen on paper by direct and slanted light. In the second activity, group members were the models for the sun and the earth. The earth people revolved counter-clockwise around the person who represented the sun by always leaning to the same direction (north). In the last activity, they used two thermometers to measure temperature, when one thermometer got direct light but another got slanted light from the same distance.

Soil formation. This station had two activities. At one, participants looked at two different types of soil (dirt) (one from near a creek, one from a garden) by using magnifying glasses and a microscope to look for components of soil. The other activity involved making sand by shaking small rocks and a little water together in a can and examining the resulting broken particles. This activity modeled erosion, one way in which small inorganic particles become parts of soil.

\section{Concept Maps}

The week after participating in the station activities, the researcher instructed both undergraduate cohorts about concept mapping by using the concept water with which they were familiar. The researcher talked about what a concept map is, why concept maps are effective tools in science education, how to draw concept maps, and how to score concept maps for use as an assessment tool in class. After the groups finished their concept maps about water, they scored their concept maps by using the scoring criteria of Novak and Gowin (1984) and discussed different ways of drawing concept maps with classmates. 
According to Novak and Gowin's scoring system, relationships, hierarchy, cross links, and examples are the four criteria to be scored. Points are given on these criteria, if they are valid and meaningful. To calculate the total points of a concept map score, one needs to multiply the number of relationships by one, the number of hierarchical levels by five, the number of cross links by ten, and the number of examples by one. Then the scores are added. If a concept map had a misconception, invalid expressions, or meaningless links, they were not considered as points (see Appendix C for the details).

Following instruction, the researcher assigned participants to nine teams with two-three participants in each. Each team was randomly assigned to draw a concept map of one concept they learned about through stations and one concept they read about in their textbook reading assignments. There were nine teams in each cohort, representing all the possible combinations of a concept they learned from readings and a concept they learned from the station activities. Appendix E shows the concepts that were mapped by each team in the two cohorts.

During the concept mapping activity, participants received manila file folders for drawing their concept maps. Post-it notes were helpful for them to try different configurations of their concept maps on the folders. After the groups finalized their concept maps with post-it notes, they drew their maps on the folders and submitted them to the instructor before the class ended.

\section{Data Sources}

Two sources of data were used in this part of the study. They were:

1. The open-ended survey "How well do you understand science concepts?" scored with the rubrics discussed in part one. 
2) Concept maps, scored according to instructions given in Appendix C.

\section{Administration of Survey}

The survey given in part one formed the pretest for part two of the study. This survey was given twice as posttests. The first posttest [Posttest 1] was the day the assigned readings were due, and the preservice teachers participated in the learning stations. They answered the three questions on the concepts they read about after writing in their dialogue journals and the questions on the other three concepts after participating in the learning stations. The survey was administered again [Posttest 2] after the concept mapping activity.

\section{Data Analysis}

Question three concerned whether participation in earth science hands-on learning stations was more effective in clarifying concepts than reading about these topics in textbooks. Answering this question involved two analyses. In the first analysis, a twoway ANOVA with repeated measures was computed, using pre and post survey scores to determine whether the concepts were taught more effectively through reading or learning stations. The repeated measures were time (pre-post) and instructional intervention (having learned the concept by reading versus learning stations). The dependent variable was the mean of the rubric scores on the concepts taught under the two conditions. There were both possible main effects and interactions. The researcher predicted that participants would be higher in understanding on the second administration of the survey and that there would be an interaction effect with participants learning more through the learning stations than through reading. 
$\mathrm{H}_{\mathrm{o}}=$ Participants have similar understanding of the concepts before and after instructional interventions

$\mathrm{H}_{\mathrm{a}}=$ Participants show increased understanding of the concepts after instructional interventions.

$\mathrm{H}_{\mathrm{o}}=$ Participants have similar understanding when taught by the two methods. $\mathrm{H}_{\mathrm{a}}=$ Participants have greater understanding when learning through hands-on learning stations than from readings.

A second analysis was designed to provide another outcome measure, concept mapping score, to determine the effect of learning method. In this analysis, the score on the group concept map was the dependent variable. Each case was a team of two or three students. The students were randomly grouped and the concepts were randomly assigned for these groups.

Master concept maps of six earth science concepts were created by the researcher (see Appendix G) and their scores (see Appendix H) were calculated by using Novak and Gowin (1984)'s scoring rubric (see Appendix C). The researcher calculated each group's concept map raw scores by using the same scoring rubric (see Appendix I for the example group concept maps). Based on the master map scores, the groups' concept map raw scores were converted to the percentage scores. Since eight concept maps were more complex than necessary, these concepts maps got the higher scores than the scores of the related master maps. Therefore, the paired samples t-test was computed two times. First, the percentage scores of eight groups that had higher scores than master maps' scores were considered as $100 \%$. Then the actual percentages were recomputed, e.g., a score of 75 when the master map score was 60 would receive a percentage score of $125 \%$. 
Because the research literature does not explain how to analyze maps scored higher than the master maps, separate analyses were computed using the two types of percentage scores.

The researcher predicted that participants' concept maps would be more complete for the concepts they learned through hands-on learning stations.

$\mathrm{H}_{\mathrm{o}}=$ Participants have similar concept map scores for concepts they learned about through readings and through learning stations.

$\mathrm{H}_{\mathrm{a}}=$ Participants have higher concept map scores for concepts they learned about through learning stations than through readings.

To answer question four, whether or not the concept mapping activity as an intervention helped the students to better understand the concepts, answers on the third administration of the survey (second posttest) were analyzed using a repeated measures ANOVA. The subjects were all participants in part two of the research. The two repeated measures were: (a) concept map/no concept map and (b) learning method; i.e., stations versus reading. The dependent variable was the score on the third administration of the survey calculated as follows:

1. Score on concept learned through learning station and concept mapping,

2. Score on concept learned through reading and concept mapping,

3. Average of the scores for the two concepts learned through learning stations with no concept mapping, and

4. Average of the scores of the two concepts learned through reading and no concept mapping. 
In testing whether concept mapping aided in clarifying concepts, an interaction was predicted; i.e. that concept mapping would be more useful combined with learning stations than with readings.

$\mathrm{H}_{\mathrm{o}}=$ Concept mapping makes no difference in learning the six earth science concepts

$\mathrm{H}_{\mathrm{a}}=$ Concept mapping has a positive effect on learning the six earth science concepts

$\mathrm{H}_{\mathrm{a}}=$ Concept mapping is more effective in clarifying concepts when combined with hands-on activities than when combined with readings.

Part Three of the Study: Application of Conceptual Change Strategies during Field Experience

The last part of the study explored how the preservice teachers in the researcher's class applied conceptual change strategies in their second or third grade field placements.

\section{Field Assignments}

The preservice teachers in the researcher's class designed and implemented learning stations in their school placements. In this assignment they developed at least four hands-on learning stations that gave children experience with one or more topics and created connections with other subjects. Participants developed a management plan for moving the children among stations. See Appendix F for the assignment. In at least one of the stations, they were expected to apply conceptual change strategies that they were taught in class. Participants looked through the Quality Core Curriculum [QCC's] to determine which science concepts are to be taught at their grade level. The QCC's form the current science curriculum, since the Georgia Performance Standards [GPS] will be 
implemented in most grade levels, starting in Fall 2006. The preservice teachers talked with their cooperating teachers about which concepts have already been taught and how. They found out what the children know about the concept. Overall, all participants used a KWL (Know, Wonder, and Learn) chart. On this chart, the preservice teachers noted what their students said they know about the topic, the areas that their students wonder about, and after the learning stations, what their students learned based on the strategies that they applied. The preservice teachers implemented their stations in the last month of their second placements.

During the first week of the study, the researcher made a short introduction to the field assignment and gave general instructions. During the third and fourth weeks of the study, the researcher focused on details of the assignment and answered questions in class, if needed. She gave instructions about the terms "concepts," "conceptual understanding," "conceptual change as a process," and "common conceptual change strategies in science."

In this assignment all the preservice teachers were required to develop hands-on learning stations in their field placements. Conceptual change texts, concept mapping activity, and analogies were also discussed as other conceptual change strategies in one class period. A conceptual change text on "food chain," described in a research article (Palmer, 2003) was shared with the class and the details were discussed. The effects of using analogies in changing students' incorrect understandings in science were discussed by giving examples from life science (blood cells) and physical science (electricity). Participants had experienced concept mapping activity on earth science concepts during a whole class period as part of this research. 
The researcher reminded the class that after their students rotated through the hands-on learning stations, they could also process their students' final understandings by using additional strategies. For example, the preservice teachers could: a) give different examples from analogies; b) let the students make comparisons between what they already knew and what they learned about the concept; or c) ask additional questions to highlight the scientific explanation of that concept.

\section{Data Sources}

In this qualitative part of the research, three data sources were used, the first two including the participants' guided reflections of their field assignments: (a) two preservice teachers' field assignments, (b) six preservice teachers' reflections on conceptual change stations, and (c) the researcher's field notes about six preservice teachers' teaching performance in their placements.

\section{Guided Reflections}

In reflecting on their conceptual change stations, the preservice teachers answered a series of questions. Participants submitted their guided reflections to the researcher by the last class meeting. The questions were as follows:

1. What science concept did you choose and why?

2. How did you determine your students' initial understandings of that concept?

3. How did you make sure you completely understood the concept yourself, and what did you do to develop your own understanding?

4. What conceptual change strategies did you use in your center(s)?

5. What influenced you in your choice of strategies? 
6. Do you think you were successful in building your students' conceptual understandings?

7. How do you know whether you were successful?

Two preservice teachers' field assignments. Two of the preservice teachers in the researcher's class, Amy who received the highest score and turned in elaborate and wellwritten field assignment and George, who received the lowest score, were selected as illustrative cases. Their field assignments were used as the data sources in the first section of the qualitative analysis. Both Amy and George are pseudonyms.

Six preservice teachers' reflections. Six preservice teachers (Hanna, Kayla, Candice, David, Suzanne, and Sandy, all pseudonyms) in the researcher's class were placed at the same elementary school (Maple Elementary School). There were 1,137 students at Maple Elementary School most of whom had low socio economic status and most of the population was Hispanic (54\%) and African American (29\%) (Georgia and U.S. Departments of Education, 2004). The percentage of students who have English as a second language is $37 \%$. The average teaching experience of teachers is 10 years and the number of students per teacher is 12 . Their guided reflections about the conceptual change station they implemented in their classrooms were the second qualitative data source in this study.

\section{The Researcher's Field Notes}

To provide a second, perhaps more objective, measure of how the conceptual change stations were planned and implemented, the researcher observed the above six preservice teachers at the same elementary school while they were implementing their 
learning stations. She took field notes about each participant's teaching performance and evaluated the station assignment in general.

\section{Data Analysis}

\section{Trustworthiness of the Research Design}

Several steps were considered to ensure the trustworthiness of the data (Lincoln $\&$ Guba, 1985). Multiple data sources were used to triangulate across data sources such as Amy and George's personal reflections in their field assignments, six preservice teachers' personal reflections in their field assignments, and the researcher's field notes about six preservice teachers' performance concerning their conceptual change stations. Because the researcher was also the participants' science method courses instructor, this role gave her access to observe the preservice teachers' classroom application in their school placements.

The researcher used a constant comparison method (Lincoln \& Guba, 1985; Strauss \& Corbin, 1990) to analyze the data in the third part of the study. As reported earlier, the preservice teachers were required to turn in science learning station field assignment with the following five sections: lesson plan, management plan, a photo of each station, observers' feedback, and guided reflection. To analyze Amy's and George's field assignments qualitatively, the researcher first read all six sections of their field assignments as a whole and made sure whether or not all the assigned sections were complete. Neither of them reported their personal reflections according to the seven guided reflection questions that were assigned in the syllabus. However, Amy's personal reflection was more elaborative and informative than George's reflection so that the researcher could pull out the related answers of the guided reflection questions from 
Amy's answers. Because the researcher did not observe Amy and George in their classroom placements, George's short reflection did not give her enough information about each guided reflection question.

After a general reading of both assignments, the researcher highlighted the sentences in Amy and George's personal reflections that had the related answers to each guided reflection question in their field assignments. Then, she classified their related answers, copied these answers into another word document, and organized them according to each guided reflection question. By doing this, the researcher determined the illustrative quotes under each question in both of their field assignments. For some of the questions, there was more than one quote that might be appropriate to be included for the dissertation. If so, the researcher read these quotes many times and chose the clearest quotes as the illustrative examples from their assignments. Each participant's field assignments were read many times until no more additional information emerged from their responses. The researcher specifically focused on the sections where Amy's assignment was common or different than George's assignment. In addition, strengths and weaknesses of Amy and George's field assignments were reported.

To analyze the six preservice teachers' reflections on their conceptual change stations, the researcher first read all six sections of these participants' field assignments to get a general idea about how they handled their stations' implementation with students. Because the researcher observed them during their lessons in their classrooms, she had a better idea about how everything went in their placements than she had with Amy and George. 
The researcher also checked whether all the required sections of the preservice teachers' field assignments were complete. The researcher realized that like Amy and George, some of the six preservice teachers did not organize their personal reflections according to the seven guided reflection questions. After a general reading, the researcher had to reread their reflections again and highlighted the related statements according to each question. Then, the researcher typed each participant's answer under each guided reflection question in a separate word document and organized these answers. All the answers for each question were read again from the new document. It was easier to organize the participants' answers, determine the similarities and differences, and find the common themes in the new document than their original field assignments where the answers were mixed.

Because six preservice teachers were placed in either second or third grade classrooms at the same school, their teaching environments were similar. Therefore, instead of reporting each of these six preservice teachers' reflections separately, the researcher focused on the most common answers in their field assignments. Among their answers that were grouped and organized according to each guided reflection question, the researcher tried to find the common themes and also pulled out the illustrative examples from their reflections. The summary of their reflections, common themes, and illustrative examples were evaluated according to the seven guided reflection questions.

To analyze the researcher's field notes about the six preservice teachers' teaching performance, the researcher read the first draft of her field notes in detail and deleted the sections that either did not make sense or would not have added much to the current study. Then, the researcher typed all her field notes into a new word document and read 
them many times to compare and refine the emerging themes. She highlighted the common statements about six participants' performance until no more themes were revealed and then organized them. Seven themes were identified and were illustrated by giving examples from the researcher's field notes. In addition, weaknesses and strengths of the field assignments were reported on the overall summary of the preservice teachers' field assignments.

In the final section of the qualitative analysis, the researcher's field notes and the six preservice teachers' personal reflections in their field assignments were compared in terms of their performance of implementing learning stations. Because the researcher observed these preservice teachers at Maple Elementary School in their classrooms, consistencies and inconsistencies between the two sets of data were reported. The researcher read both her field notes and the participants' answers to the guided reflection questions several times and compared what they said in their reflections versus what she actually saw in their classrooms.

All participants signed informed consent letters allowing their data to be used in this research. See Appendix J for the informed consent letters. The following timeline of the preservice teachers in the undergraduate program provided an overview of interventions and the data collection during class.

Week 1 (February 28 and March 1):

Cohort 1: First administration of the survey, reading assignments.

Cohort 2: First administration of the survey, reading assignments, introduction to the field assignment. 
Week 2 (March 14 and 15):

Cohort 1 \& Cohort 2: Listing the "big ideas" covered in the assignments in their dialogue journals, answering three open-ended questions about the reading assignments, rotating through hands-on learning stations, and answering three other open-ended questions about the stations.

Week 3 (March 21 and 22):

Cohort $1 \&$ Cohort 2: Learning how to draw concept maps. Drawing two concept maps as a group. Third administration of the survey $\left(2^{\text {nd }}\right.$ posttest $)$.

Cohort 2: Preparation for conceptual change learning station assignments Week 4 (March 28 and 29):

Cohort 2: Questions and answers about conceptual change learning station assignments Week 5 (April 17-18 or April 24-25):

Cohort 2: Implementation of the hands-on learning stations in the placements Week 6 (April 26):

Cohort 2: Field assignment presentation in the class Week 7 (May 3):

Cohort 2: Field assignment presentation in the class

Summary

This dissertation study had a mixed-methods research design and was composed of three parts. In the first part, the initial conceptual understandings of preservice and inservice teachers were investigated and compared by using an open-ended survey on six earth and space science concepts. In the second part, the effects of the following learning methods on preservice teachers' conceptual understandings were examined: (a) reading 
text versus hands-on learning stations and (b) concept mapping versus no concept mapping. In the third part, guided reflections of the preservice teachers in one cohort and the researcher's field notes were analyzed for how the preservice teachers employed conceptual change strategies in field assignments. Table 4 summarizes the data collected by cohort.

Table 4

Summary of Data Collection

\begin{tabular}{ll}
\hline Types of data collection & Participants \\
\hline Pre-test $\left(1^{\text {st }}\right.$ admin.) & All students: 5 cohorts \\
Post-tests ( $2^{\text {nd }}$ admin.) & Cohort 1 and 2 of undergraduate program \\
Concept maps & Cohort 1 and 2 of undergraduate program \\
Post-post tests ( $3^{\text {rd }}$ admin.) & Cohort 1 and 2 of undergraduate program \\
Field assignment (guided reflections, & Cohort 2 \\
cooperative teacher's feedback) & \\
\hline
\end{tabular}




\section{CHAPTER 4}

\section{RESULTS}

The findings of this chapter are presented in three parts. In the first part, the initial understandings that preservice and inservice teachers had about six earth and space science concepts (reasons for seasons, phases of the moon, rock cycle, reasons for the wind, soil formation, and causes of earthquakes) are reported. The purpose of the second part is to report the effectiveness of various instructional methods (hands-on learning stations versus readings from the textbook and concept mapping) in clarifying these concepts in science methods classes for preservice teachers. The last part of the chapter presents how preservice teachers implemented a conceptual change activity station in their field placements.

In this mixed methods study, quantitative analysis was used in the first and the second part and qualitative analysis was used in the third part of the study to answer the following research questions:

Part one of the study:

1. What understanding do preservice and inservice teachers have on the following earth and space science concepts: reasons for seasons, phases of the moon, reasons for the wind, rock cycle, earthquakes, and soil formation?

2. Is there a difference between preservice and inservice teachers in their understanding of these concepts? 
Part two of the study:

3. Are hands-on learning stations more effective than readings in clarifying earth science concepts as measured by rubric scores and concept map scores?

4. Does concept mapping improve rubric scores for those who experienced the learning station activities compared to those who read text explanations?

Part three of the study:

5. How do preservice teachers apply conceptual change strategies in their field assignment on conceptual change?

Part One of the Study

What Understanding Do Preservice and Inservice Teachers Have on Six Earth and Space Science Concepts?

Participants and Implementation of the Survey

For the first part of the study, the plan was to administer the open-ended survey to the 108 participants who were the members of three preservice cohorts and two inservice cohorts in early childhood education classes during Spring Semester 2006. However, one preservice teacher did not give informed consent. In addition, eight people were absent for the pretest (two undergraduates, one preservice and four inservice teachers in the urban masters program, and one inservice teacher in the Collaborative Masters Program). Therefore, 99 subjects participated in part one of the study.

The researcher administered the surveys in all cohorts except for the Collaborative Masters Program, which met off campus. In this program the coordinators offered to administer the survey. It took 10-15 minutes for the participants to fill out the six open-ended questions about earth and space science concepts. The inservice teachers 
were asked to report their number of years of teaching on the survey. However, three inservice teachers in the Collaborative Master Program did not give that information. Therefore, the data of these teachers could not be used in the comparison between preservice teachers and experienced teachers.

Statistical Analysis

The researcher used the 3 point grading rubrics described in Appendix B to score the preservice and inservice teachers' answers to the six open-ended questions. An answer was coded as (1) if there was no response, an incorrect answer or a clearly evident misconception. (2) if the answer was partially correct or it had no elaboration, and (3) if the answer had scientific explanation and the answer was clear with elaboration.

To answer question one, concerning initial understandings of preservice and inservice teachers on the six concepts, means and standard deviations using the rubric scores for each question were calculated. See Table 5 for the means and standard deviations of each concept. The means showed that both the preservice and the inservice teachers had very low initial understanding on these six earth science concepts. For both groups the lowest score was on the reasons for the wind and the highest score was on the causes of earthquakes. 
Table 5

The Means and Standard Deviations of Pretest Rubric Scores of Preservice and Inservice Teachers $(N=99)$

\begin{tabular}{lcccccc}
\hline \multicolumn{1}{c}{ Concepts } & \multicolumn{3}{c}{ Preservice Teachers } & \multicolumn{3}{c}{ Inservice Teachers } \\
\hline & $\mathrm{N}$ & Mean & $\mathrm{SD}$ & $\mathrm{N}$ & Mean & $\mathrm{SD}$ \\
\hline Reasons for seasons & 68 & 1.50 & .66 & 31 & 1.87 & .56 \\
Phases of the moon & 68 & 1.25 & .47 & 31 & 1.58 & .72 \\
Rock cycle & 68 & 1.20 & .41 & 31 & 1.29 & .53 \\
Soil formation & 68 & 1.72 & .75 & 31 & 1.90 & .79 \\
Reasons for the wind & 68 & 1.17 & .38 & 31 & 1.16 & .37 \\
Causes of earthquakes & 68 & 1.91 & .57 & 31 & 2.06 & .57 \\
\end{tabular}

Examples of Preservice and Inservice Teachers' Initial Understandings

Following are common examples that were extracted from the participants' survey answers about six earth science concepts in five cohorts:

Reason for seasons. "Distance theory" was the most common incorrect understanding of the preservice and inservice teachers. Following are the two answers by a preservice teacher and an inservice teacher with the same misconception: "As the earth turns and becomes closer and further from the sun, it causes changes in temperature to rise and fall" and "The earth rotates on its axis and we move closer and farther away from the sun." Most of the participants correctly reported that the earth revolves around the sun. Some of the participants incorrectly used the word "rotate" instead of the word "revolve" to explain the movement of the earth around the sun. However, the answers with the word "rotate" were not counted off on the rubric scoring (see Appendix B). 
The following are other examples of their incorrect understanding: "The sun goes around the earth, there will be changes," "when it is winter, the sun is on the other side of the earth," and "the sun rotates." In addition, one preservice teacher wrote the advantages of having seasons on the earth: "So, the earth can cycle, the leaves fall and provide nutrients to the soil. Winter comes and kills the germs."

Phases of the moon. The most common incorrect understanding among the answers of preservice and inservice teachers to this question was "the earth blocks the sunlight on the moon (the earth's shadow)." Although most participants knew that the earth revolves around the sun, they did not report that the moon revolves around the earth. Another incorrect understanding about this concept is that the moon is orbiting the sun. Some apparently could not visualize the moon's revolution around the earth and the earth's revolution around the sun at the same time. Following are the other nonscientific answers: "Other planets and weather," "there are planets moving in front of the moon that change phases," "the way the planets align," "the earth rotates around the moon," and "the tilt of the sun."

Rock cycle. The rock cycle is the concept on which most of the preservice and inservice teachers left the answer blank or responded that they did not know. For example, two participants reported that: "I did not even know rocks had cycles" and "I have never heard about rock cycle." The rest of them had incomplete understanding. In other words, they mentioned either one or two rock types instead of three, listing sedimentary and metamorphic rocks but not igneous rocks. One preservice teacher's answer was: "rock cycle is a result of erosion of sediment that becomes hard." Erosion and the compaction of sediments are the most common statements in their answers about 
formation of sedimentary rocks. Some participants' answers showed that they had heard about three different types of rocks; however, they did not seem to understand the correct relationship among them.

Soil formation. The answers generally reported either organic (decomposition of dead plants, animals, earthworms, bacteria, and bugs) or inorganic components (weathering of rock, minerals, and sediments) of the soil, but not both. Following are the several answers as an example of their incomplete understanding: "decomposition of dead plants and animal leftovers," "thousands of years of decay of animals and plant life," "soil is formed when rocks break down into smaller pieces," and "soil is formed by the erosion of mountains." Although the participants used the words erosion, decomposition, break down of materials, they did not seem to understand the crucial role of living organisms (e.g. worms, bacteria, and bugs) in the process of soil formation. The only uncommon answer of an inservice teacher was that: "Soil is formed from the Earth's ashes."

Reasons for the wind. This is the concept on which the participants had the lowest initial understanding $\left(\mathrm{M}_{\text {Preservice }}=1.17\right.$ and $\left.\mathrm{M}_{\text {Inservice }}=1.16\right)$. Most of the participants either left the answer blank or they had incorrect understanding. The examples from their initial understanding are: the wind blows because of "storms," "tides," "ocean currents," "clouds," "the sun," "motion of machines and artificial sources like large fans," and "currents from bodies of water." Also, four participants misinterpreted the question and answered about the advantages of the wind for living organisms: "Plants need the wind blow for reproduction and carrying spores. So, wind helps life cycles" and "to spread pollen and eggs for plants and reproduce." 
Causes of earthquakes. The preservice and inservice teachers had the highest rubric scores about the concept of causes of earthquakes $\left(\mathrm{M}_{\text {Preservice }}=1.91\right.$ and $\mathrm{M}_{\text {Inservice }}=$ 2.06). Most of the preservice teachers reported one of the following statements in their answers: movement of plates (e.g. rubbing or pulling each other), movement of earth's crust, plate tectonics, shifting of plates, and pressure release. Several examples from their answers are: "the plates on the earth shift," "earthquakes are caused by the activity of the earth's crust," "hot magma in the center of the earth," and "pressure builds up and two surfaces collide."

Is There a Difference Between Preservice and Inservice Teachers in Their Understanding of These Concepts?

\section{Statistical Analyses}

To test whether preservice and inservice teachers have similar understanding on the six earth and space science concepts, the pretest scores of the preservice teachers were compared with the inservice teachers' scores by using independent samples t-tests. The results indicated that the mean for the inservice group on the concept reasons for seasons $(\mathrm{M}=1.87)$ was higher than the preservice group $(\mathrm{M}=1.50), t(97)=2.88, p<.05$. Similarly, the mean for the inservice group on the concept phases of the moon $(\mathrm{M}=1.58)$ was higher than the preservice group $(\mathrm{M}=1.25), t(97)=2.34, p<.05$. However, the assumption of equal variances (Levene's Test) was tested for the concepts of reasons for seasons and phases of the moon and found to be violated $(\mathrm{F}<.05)$. The assumption of equal variances was found to be homogeneous for the other concepts $(F>.05)$. There were no differences on those concepts. 
To determine whether experienced teachers understood the concepts better than the preservice teachers, the 21 experienced teachers were compared to the preservice teachers. The rest of the inservice teachers (7) were in their first year of teaching and 3 inservice teachers did not specify number of years of teaching. The 21 experienced teachers were at least in their third year of teaching. The following table presents the means and standard deviations of the preservice teachers (as was shown in Table 1) with the means and the standard deviations of the experienced teachers. The means of all inservice teachers are also included in the table for comparison.

Table 6

Means and Standard Deviations of Pretest Rubric Scores of Preservice Teachers, All Inservice Teachers, and Experienced Inservice Teachers

\begin{tabular}{|c|c|c|c|c|c|c|c|c|c|}
\hline \multirow{2}{*}{ Concepts } & \multicolumn{3}{|c|}{ Preservice Teachers } & \multicolumn{3}{|c|}{$\begin{array}{l}\text { All Inservice } \\
\text { Teachers }\end{array}$} & \multicolumn{3}{|c|}{$\begin{array}{c}\text { Experienced } \\
\text { Inservice } \\
\text { Teachers } \\
\end{array}$} \\
\hline & $\mathrm{N}$ & Mean & SD & $\mathrm{N}$ & Mean & $\mathrm{SD}$ & $\mathrm{N}$ & Mean & $\mathrm{SD}$ \\
\hline Reasons for seasons & 68 & 1.50 & .66 & 31 & 1.87 & .56 & 21 & 1.90 & .62 \\
\hline Phases of the moon & 68 & 1.25 & .47 & 31 & 1.58 & .72 & 21 & 1.61 & .74 \\
\hline Rock cycle & 68 & 1.20 & .40 & 31 & 1.29 & .53 & 21 & 1.28 & .56 \\
\hline Soil formation & 68 & 1.72 & .75 & 31 & 1.90 & .79 & 21 & 2.04 & .74 \\
\hline Reasons for the wind & 68 & 1.17 & .38 & 31 & 1.16 & .37 & 21 & 1.19 & .40 \\
\hline Causes of earthquakes & 68 & 1.91 & .57 & 31 & .57 & .57 & 21 & 2.14 & .57 \\
\hline
\end{tabular}


A comparison between preservice and experienced inservice teachers found differences on the same two concepts only, reasons for seasons, $t(87)=2.49, p<.05$ and phases of the moon, $t(87)=2.15, p<.05$. There are no significant differences on the other concepts.

Part Two of the Study

Are hands-on learning stations more effective than readings in clarifying earth science concepts as measured by rubric scores and concept map scores?

Participants and Implementation of the Surveys: Posttest 1

Participants in this part of the study were the members of the two undergraduate cohorts. After answering the questions on the pretest, they were assigned readings on three concepts. Each cohort received three different concepts. At the beginning of their next class, they answered the three survey questions that related to those readings. Then, the preservice teachers rotated through hands-on science learning stations about the other three earth science concepts. At the end of the class, the participants answered the questions that related to the concepts covered in the learning stations.

In Cohort 1, one student was absent and another participant did not answer the questions about readings. A third participant did not answer the questions related to three concepts learned through learning stations although she had participated the stations. Two participants in Cohort 2 talked with the researcher and mentioned that they did not read their reading assignments at home. Because these two participants did not answer the questions, they were considered as missing data. 


\section{Statistical Analyses}

Two outcome variables were used to determine whether participation in earth science hands-on learning stations was more effective in clarifying concepts than reading about these topics in textbooks. The two dependent variables were rubric scores and concept map scores.

First analysis (Mean of the rubric scores as dependent variable). Based on a pilot study, the researcher decided to group the concepts to be taught by readings and those taught by learning stations and to distribute the concepts between the two undergraduate cohorts. In a pilot study, conducted during Fall Semester 2005, the answers of preservice teachers who were in a previous cohort were scored as either "correct" or "incorrect." Then, the percentages of correct and incorrect answers for each concept were calculated. The researcher assigned three concepts for the reading assignment and three concepts for the hands-on learning stations so that in each undergraduate cohort, the concepts to be learned through reading and through hands-on activities were of equal difficulty.

The following table shows which concepts were learned by readings and by hands-on learning stations by each cohort and the means of their pretest and posttest 1 scores on those concepts: 
Table 7

Pre and Post Means of Preservice Teachers' Rubric Scores for Concepts Learned Through Learning Stations and Through Readings

\begin{tabular}{|c|c|c|c|c|c|c|}
\hline & \multicolumn{3}{|c|}{ Cohort $1(\mathrm{~N}=22)$} & \multicolumn{3}{|c|}{ Cohort $2(\mathrm{~N}=28)$} \\
\hline & Concepts & Pretest & Posttest 1 & Concepts & Pretest & Posttest 1 \\
\hline \multirow{3}{*}{$\begin{array}{l}\text { Hands-on } \\
\text { stations }\end{array}$} & \multirow{3}{*}{$\begin{array}{l}\text { Reasons for the } \\
\text { wind } \\
\text { Earthquakes }\end{array}$} & $\begin{array}{l}1.25 \\
1.16\end{array}$ & $\begin{array}{l}2.27 \\
2.59\end{array}$ & \multirow{3}{*}{$\begin{array}{l}\text { Reasons for } \\
\text { seasons } \\
\text { Phases of the } \\
\text { moon } \\
\text { Soil formation }\end{array}$} & 1.69 & 2.57 \\
\hline & & \multirow[b]{2}{*}{2.08} & \multirow[b]{2}{*}{2.54} & & 1.15 & 1.85 \\
\hline & & & & & & \\
\hline \multirow{4}{*}{$\begin{array}{l}\text { Textbook } \\
\text { reading }\end{array}$} & \multirow{4}{*}{$\begin{array}{l}\text { Reasons for seasons } \\
\text { Phases of the moon } \\
\text { Soil formation }\end{array}$} & \multirow{4}{*}{$\begin{array}{l}1.37 \\
1.33 \\
1.91\end{array}$} & \multirow{4}{*}{$\begin{array}{l}2.18 \\
1.95 \\
2.36\end{array}$} & \multirow{4}{*}{$\begin{array}{l}\text { Rock cycle } \\
\text { Reasons for the } \\
\text { wind } \\
\text { Earthquakes }\end{array}$} & \multirow{3}{*}{$\begin{array}{l}1.07 \\
1.26\end{array}$} & \multirow{3}{*}{$\begin{array}{l}2.30 \\
1.87\end{array}$} \\
\hline & & & & & & \\
\hline & & & & & & \\
\hline & & & & & 1.80 & 2.38 \\
\hline
\end{tabular}

To determine the effectiveness of readings versus hands-on learning stations the rubric scores of the three concepts learned through readings and three concepts learned through stations were averaged. In this analysis, a two way ANOVA with repeated measures was computed, using averaged survey scores (pretest and posttest 1) to determine whether the concepts were learned more effectively through learning stations or through reading. The repeated measures were time (pre-post) and instructional intervention (having learned the concept by learning stations versus reading). The dependent variable was the mean of the rubric scores on the concepts taught under the two conditions. The following table shows the means and the standard deviations of 
pretest and posttest 1 rubric scores for concepts learned through readings and concepts learned through learning stations.

Table 8

Pretest and Posttest 1 Means and Standard Deviations of The Students' Rubric Scores for Concepts Learned Through Readings and Concepts Learned Through Learning Stations.

\begin{tabular}{lcccccc}
\hline & \multicolumn{3}{c}{ Pretest } & & \multicolumn{3}{c}{ Posttest 1 } \\
\cline { 2 - 7 } Learning Method & $\mathrm{N}$ & Mean & SD & $\mathrm{N}$ & Mean & SD \\
& & & & & & \\
\hline Learning Stations & 47 & 1.55 & .38 & 47 & 2.39 & .34 \\
Readings & 47 & 1.48 & .33 & 47 & 2.18 & .31 \\
\hline
\end{tabular}

Differences were found on time, $F(1,46)=214, p<.001$ and learning method, $F$ $(1,46)=8.74, p<.005$. Interactions approached significance, $\mathrm{p}=.085$. Following is the ANOVA table for this analysis.

Table 9

Analysis of Variance for Repeated Measures Analysis of Time and Learning Method

\begin{tabular}{lccc}
\hline Source & Df & $F$ & $P$ \\
\hline & & Within subjects \\
Time (pre/post) & 1 & 214 & .000 \\
Learning Method & 1 & 8.74 & .005 \\
Time x Learning Method & 1 & 3.102 & .085 \\
Time x Learning Method within group error & 46 & $(.110)^{*}$ &
\end{tabular}

* Value enclosed in parenthesis represents mean square error. 
The first research hypothesis to be tested in this analysis was the null hypothesis that: Participants have similar understanding of the concepts before and after instructional interventions. This null hypothesis was rejected. Understanding of the concepts increased from the pretest to the posttest. The second research hypothesis to be tested in this analysis was the null hypothesis that: Participants have similar understanding when taught by the two methods. This effect was tested by the interaction between time and learning method. The interaction effect approached significance, $\mathrm{p}=.085$ suggesting a slight trend toward more improvement in understanding through the hands-on activities (an increase of .84 points) rather than through readings (an increase of .70 points).

However, the null hypothesis was not rejected.

\section{Examples of Preservice Teachers' Answers on Posttest 1}

The following examples illustrate growth in understanding between the pretest and posttest 1 .

Reasons for seasons. It was already presented that distance theory was the most common nonscientific understanding among pretest answers. The following pretest answer had both correct statements and an incorrect statement: "Seasons occur because of the earth's tilt and spin on its axis. We have summer when the earth is close to the sun and we have winter when it is farther away" (cohort 2, code \# 32). However, after this person studied this concept via learning stations and she did not report any misconception in her second answer: 
We have seasons because the earth revolves around the sun doing a complete cycle in 365 days. Depending on the tilt of the earth, we have summer or winter. For instance, if northern hemisphere is tilted towards the sun then they will have summer.

Similarly, another participant also changed her same misconception after she studied this concept via textbook readings and reported scientific statements in her second answer: "The earth orbits the sun with certain tilted axis. When the northern hemisphere points directly towards the sun, the northern hemisphere has summer while the southern hemisphere has winter" (Cohort 1, code \# 5).

Phases of the moon. A preservice teacher (Cohort 1, code \# 12) had an incorrect understanding on the pretest and answered that question as follows: "Depending upon the position of the earth spinning we see phases on a cycle." The same participant studied this concept through readings from the textbook. She changed her initial understanding with a scientific understanding on the first posttest: "The moon travels around the earth and the sun reflects its light on it causing us to see it as a lighted source. Depending on its position in relation to the sun and the earth, we see phases of the moon."

Another preservice teacher had lack of understanding in her pretest and studied this concept through learning stations. Her posttest 1 answer included several scientific statements: "I think we see different phases of the moon because of rotation [sic] of the moon around the earth. When the moon rotates, the sunlight shines on it at/from different angles allowing only certain parts of the moon to be visible at certain times" (Cohort 2, code \# 26). 
Rock cycle. As reported earlier, most of the participants had a lack of understanding about the rock cycle on the pretest. One preservice teacher's (Cohort 1, code \# 4, pretest) answer to that question was: "I can not recall the rock cycle at this moment." The same participant learned about this concept via learning station and reported the following answer:

There are three types of rocks: sedimentary, metamorphic, and igneous. Sedimentary rock form when sediments are compacted together, then when heat and pressure is placed upon sedimentary rocks, they turn into metamorphic rocks. Once magma cools down and crystallizes, igneous rocks are formed. All three types of rocks can be turn back into sediments due to weathering and erosion (Cohort 1, code \# 4, posttest 1).

Another participant left a blank for this question on her pretest. Then, this person studied the concept through readings and gave a very elaborative answer in the posttest 1: Igneous rocks: "formed from fire" comes from the molten lava. Some rock cools below and some rock cools above the earth's surface. Sedimentary rock: Formed through erosion. Minerals deposits [sic] in water and settle to the bottom of water. Metamophic rocks: Forms below the earth's surface under extreme pressure (Cohort 2, code \# 27, posttest 1).

Reasons for the wind. The following posttest 1 answer was given by a preservice teacher, who said on the pretest that the wind was caused by "tides," learned about this concept via learning station, (Cohort 1, code \# 5):

Air pressure moves from high to low. The earth rotates and the wind blows from west to east that is called global wind. Local wind is caused by changes in the air 
temperature. Cool air because of its high pressure moves toward warm air which has lower pressure (Posttest 1).

Another preservice teacher in the second undergraduate cohort had lack of understanding about this concept on the pretest and studied this concept through readings. Her second answer indicated that she understood the reasons for "local winds." In spite of the fact that she also knows about the "global winds," her answer did not have much elaboration: "The cool air denser than hot air. The difference in temperature causes wind to form. Also, the earth rotates in a specific orbit" (Cohort 2, code \# 29).

Soil formation. Following pretest answer indicated an incomplete understanding, mentioning only organic components of soil: "Soil is formed when plants, animals, and certain decayable materials make soil" (Cohort 2, code \# 30, Pretest). However, the second answer of this person who studied this concept through learning stations included both organic and inorganic components of soil on posttest 1: "Soil is formed when rocks, decaying material, plants, animals, and other particles through the help of rain, the sun, and wind break down and to become a usable material that win help to grow lots of vegetation."

Another participant had lack of understanding about this concept on the pretest and learned this concept through readings. Her second answer included both organic and inorganic components of soil: (Cohort 1, code \# 4, Posttest 1): "Soil is formed from weathering with pieces of rocks and minerals. Soil becomes fertilize [sic] when humus is mixed it. Humus is the remains of dead organisms."

Causes of earthquakes. A preservice teacher had a limited understanding about earthquakes before the interventions: "Earthquakes occur when the plates of the earth 
surface shift" (cohort 2, code \# 40, Pretest). This participant learned the concept via readings from the textbook and reported more elaborative answer on the posttest: "There are tectonic plates underneath the earth's surface. When these plates shift, they cause friction and movement of the earth's surface called an "earthquake" (Posttest 1).

Another participant had lack of understanding on the pretest and learned the concept via learning stations. His second answer is as follows: "The movement of plates causes earthquakes. When one plate slides under another plate and when the plates release tension earthquakes occur" (Cohort 1, code \# 4, Posttest 1).

Second Analysis (Group Percentage Concept Map Score as Dependent Variable)

Participants and implementation. The researcher implemented the concept mapping activity in a regular class period. The instructor of the other cohort helped the researcher both during the concept mapping instruction and while groups were drawing their concept maps on two earth science concepts. Being from the same cohort, all the members of concept mapping group had initially learned about the concepts they mapped in the same way (one concept through readings and the other concept through learning stations).

To determine the effect of whether or not the preservice teachers learned the concepts through readings or stations on the complexity of the concept maps, a paired samples t-test was computed to compare the concept map scores for each team of students' concept taught by learning stations or reading. The dependent variable was the percentage score on the group concept map. Because the students worked together in groups on their concept maps, they received group scores rather than individual scores. 
Therefore, the unit of analysis was the group; and since there were 18 groups within the two cohorts, the $\mathrm{N}$ was 18 .

To compute the percentage score, first, master concept maps of six earth science concepts were created by the researcher and their scores were calculated by using Novak and Gowin (1984)'s scoring rubric (see Appendix C for the details of the scoring rubric and Appendix G for the master concept maps). The master map scores of the concepts were calculated as follows: (a) reasons for seasons: 64, (b) phases of the moon: 60, (c) rock cycle: 123, (d) reasons of the wind blow: 75, (e) soil formation: 79, and (f) causes of earthquakes: 96 (See Appendix H for the scoring rubric calculations). Secondly, each group's concept map raw scores were calculated by using Novak and Gowin's (1984) scoring rubric (See Appendix I for the group concept maps about phases of the moon, the rock cycle, and causes of earthquakes). Then, based on the master map scores, the groups' concept map raw scores were converted to the percentage scores. The groups' raw scores showed that eight concepts maps (1: phases of the moon; 3: reasons for seasons; 2: reasons for the wind; and 2: soil formation) got higher scores than the scores of the related master maps because their concept maps were more complex than necessary.

The paired sample t-test was computed two times. First, the percentage scores of the groups that had higher scores than master maps' scores were considered as $100 \%$. Findings showed that there is no significant difference between mean percentage scores of the concept maps of the concepts learned through stations $($ Mean $=69.72, \mathrm{SD}=28.25)$ and readings $(\mathrm{Mean}=67.58, \mathrm{SD}=26.32), t(17)=.274, p>.05$. 
Because the above analysis did not give extra credit to the eight groups whose actual percentages scores were over 100, the scores were recomputed for a second time. For this analysis, actual percentages were calculated, e.g. a group with a master map score of 60 and a raw score of 76 had a percentage score of 127 . Based on the new calculations, the actual percentage score for readings was $(\mathrm{Mean}=74.19 ; \mathrm{SD}=37.16)$ and the actual percentage score for stations was (Mean $=78.70, \mathrm{SD}=42.22$.) Again, there were no significant difference; $t(17)=.445, p>.05$.

Because there was no significant difference between the percentage scores of the concept maps according to learning method, the researcher did not reject the null hypothesis that participants have similar concept map scores for concepts they learned about through readings and stations. In both analyses the means of the concepts learned by stations were only slightly higher than that those learned through readings.

Does concept mapping improve rubric scores for those who experienced the learning station activities compared to those who read text explanations?

\section{Participants of Posttest 2}

The second posttest was administered at the end of the class period after the groups turned in their concept maps about two earth science concepts. In Cohort 1, all the students attended the class. On the other hand, one student was absent in Cohort 2. Statistical Analysis (Independent variable: concept mapping vs. no concept mapping)

To answer question four, whether or not the concept mapping activity as an intervention helped the students to better understand the concepts, answers on the third administration of the survey (second posttest) were analyzed using a repeated measures ANOVA. The two repeated measures were: (a) concept map/no concept map and (b) 
learning method, i.e., stations versus reading. The dependent variable was the score on the third administration of the survey calculated as follows:

5. Score on concept learned through learning station and concept mapping,

6. Score on concept learned through reading and concept mapping,

7. Average of the scores for the two concepts learned through learning stations with no concept mapping, and

8. Average of the scores of the two concepts learned through reading and no concept mapping.

In this analysis, the posttest 1 and posttest 2 scores of the participants were not compared. Posttest 2 scores were analyzed to see whether participants had greater understanding of the concepts they had mapped compared to the concepts they had not mapped.

Table 10 shows the means and standard deviations according to condition, and Table 11 is the Analysis of Variance table. 
Table 10

Posttest 2 Means and Standard Deviations of the Students' Rubric Scores for ConceptMapped and Non-concept Mapped Concepts Learned through Readings and through Learning Stations.

\section{Posttest 2}

\begin{tabular}{|c|c|c|c|c|c|c|c|}
\hline \multirow{2}{*}{ Condition } & & & & & \\
\hline & $\mathrm{N}$ & Means & $\mathrm{SD}$ & Condition & $\mathrm{N}$ & Means & SD \\
\hline Concept & & & & No concept & & & \\
\hline maps/readings & 51 & 2.37 & .56 & maps/readings & 51 & 2.10 & .39 \\
\hline Concept & & & & No concept & & & \\
\hline maps/stations & 51 & 2.45 & .61 & maps/stations & 51 & 2.13 & .48 \\
\hline
\end{tabular}

\section{Table 11}

Analysis of Variance for Repeated Measures Analysis of Concept Mapping versus No Concept Mapping Condition and Learning Method

\begin{tabular}{llll}
\hline Source & $D f$ & $F$ & $P$
\end{tabular}

Within subjects

Concept mapping condition

1

17.7

.000

(Con. map. vs. No con. map.)

Learning method

1

.616

.436

Concept mapping condition $\mathrm{x}$ Learning method

1

.105

.748

Concept mapping condition $\mathrm{x}$ Learning method

50

$(.293)^{*}$

within group error

* Value enclosed in parenthesis represents mean square error. 
Drawing the concept maps had an additive effect in building student understanding no matter how the concepts were learned. The students scored higher on the concepts for which they drew concept maps, $F(1,50)=17.71, \mathrm{p}<.001$ but there were no differences according to whether they had originally learned about the concept by reading or by learning stations. There were no interactions.

Because there was a significant difference between the students' scores of the concept for which they drew concept map and the average scores of the two concepts for which they did not draw concept map, the researcher rejects the null hypothesis that concept mapping makes no difference in learning the six earth science concepts. On the other hand, because there was no interaction effect, the second alternative hypothesis was rejected that concept mapping is more effective in clarifying concepts when combined with hands-on activities then when combined with readings.

\section{Examples of Preservice Teachers' Final Understanding on Posttest 2}

Following section presents illustrative answers of preservice teachers who increased their rubric score from a one or two on posttest 1 to a three on posttest 2.

Reasons for seasons. A preservice teacher originally learned the concept of reasons for seasons through readings. On posttest 1 she mentioned the revolution of the earth around the sun but did not mention tilted axis of the earth: "We have seasons because the earth revolves around the sun and that causes a year of seasons (Cohort 1, code \# 17)." However, the same participant drew the concept map of this concept with her group and her final answer on posttest 2 indicated that she understood the tilted axis of the earth around the sun: "We have seasons based on the earth's tilt. When the earth 
spins on its axis, it is 23.5 degrees. If the Northern hemisphere towards the sun, we have summer, when it is away from the sun, we have winter."

Another participant originally learned this concept through learning stations. In her second answer she mentioned the tilted axis of the earth but did not mention the angle of sunlight. However, this person drew the concept map of this concept and gave a more elaborative answer in her third answer:

Because of the tilt of the earth's axis and the angle of sunlight that hits the earth. The more direct sunlight the warmer temperature causing summer in one hemisphere and slanted sunlight causing cooler temperature and winter in the other hemisphere (Cohort 2, code \# 48).

Phases of the moon. In her answer on posttest 1, after reading about phases of the moon one of the preservice teachers only reported the time of the moon's cycle: "We see phases of the moon because the moon cycles the earth in 29.5 days (Cohort 1, code \# 11)." After drawing the concept map, her answer on posttest 2 included two scientific statements: "Because the moon revolves around the earth. It waxes (grows) and wanes. The sunlight is reflected on the moon to provide the earth with light. The moon repeats its cycle after 29.5 days."

Another participant still had a misconception (shadow of the earth on the moon) on the posttest 1 after learning about this concept through learning stations. The same preservice teacher drew the concept map of this concept and her last answer to this question did not have the same misconception and included several scientific statements: "The earth revolves around the sun on its orbit. The moon also revolves around the earth. It takes 28 days for the moon to go around the earth" (Cohort 2, code \# 29). 
Rock Cycle. One of the preservice teachers who learned about this concept through learning stations (Cohort 1, code \#18) had an incomplete understanding about this concept on posttest 1: "Rocks are made from the cooling of magma heat or pressure. Then igneous rocks formed depending on the state of heat/pressure." After drawing the concept map, she improved her conceptual understanding: "Sedimentary rocks are caused by weathering and erosion. Metamorphic rocks are formed by heat and pressure and igneous rocks develop from cooled magma or lava."

Another participant in the other cohort originally learned about this concept through textbook readings and had incomplete understanding in her second answer (Cohort 2, code \# 30). Then, the same person drew the concept map of the concept of rock cycle and gave a more elaborated response in her last answer to the same question:

There are 3 types of rocks: metamorphic, igneous, and sedimentary. Sedimentary rocks are formed in water bodies. Igneous rocks are formed either intrusively or extrusively. Metamorphic rocks come from particles of igneous and sedimentary rocks fused together through high pressure

Soil formation. One preservice teacher, who learned about this concept through learning stations, only mentioned the inorganic component of soil in her answer on posttest 1: "Soil is formed by the decomposition of rocks. As rocks hit together, they begin to break apart" (Cohort 2, code \# 45). After drawing the concept map, her final answer to the same question on posttest 2 included both inorganic and organic components of soil: "Soil is formed due to erosion and decomposition. Organic and inorganic materials decompose and turn in to soil. Things such as leaves, animals, and minerals, this process [soil formation] take a long period of time." 
Among the participants who originally learned this concept through readings, none of them improved their understandings after they drew the concept map of this concept.

Reasons for the wind. None of the participants increased their scores in the posttest 2 after concept mapping. For example, a preservice teacher learned about this concept through readings and her second response on the posttest 1 was incomplete. After she drew the concept map of this concept, she still did not mention the reasons for both local and global winds in her third answer: "The wind blows because of the unequal heating of the earth by the sun. Since cold air is denser than worm air, warm air rises which create wind" (Cohort 2, code \# 43).

Causes of earthquakes. One participant, who learned about earthquakes through learning stations, gave the following incomplete answer on posttest 1: "Shifting of the earth's mantle causes earthquakes" (Cohort 1, code \# 12). After the concept mapping, this person improved her understanding on posttest 2: "Shifting of plates on the earth. There are different types that slip and cause friction and jolting. They cause earthquakes."

Another preservice teacher originally learned about this concept through readings and had mentioned only the "movement of plates" in her second answer. The same participant drew the concept map of this concept and mentioned pressure release of the Earth's plates on posttest 2: "Pressure and gas were built under huge Earth's plates. When enough pressure was built, the plates shift causing movement of the land on the earth's surface" (Cohort 2, code \# 27). 


\section{Part Three of the Study}

\section{Field Assignment}

The students in this study were placed in first grade classrooms the first half of the semester and second or third grade classrooms the second half of the semester. The third part of the study focused on how preservice teachers in the researcher's class applied conceptual change strategies in their second or third grade field placements. They were in their field placements two days a week, placed with an experienced cooperating teacher, and observed at regular intervals by a university supervisor.

The preservice teachers designed and implemented learning stations in their placements as part of the researcher's science methods class requirement that was assigned in the course syllabus (see Appendix F). They developed at least four hands-on learning stations on science topics identified in the Quality Core Curriculum [QCC's]. At least one of these learning stations was required to be designed as a "conceptual change station" where the preservice teachers were assigned to implement conceptual change strategies. The purpose of this learning station was for preservice teachers to attempt to change their students' initial understanding about a particular science concept. After the implementation of their learning stations, the preservice teachers turned in a "guided reflection" to the researcher at the end of the semester.

\section{Participants}

The researcher had 28 students in the class; however, eight of these students were selected as the subjects of this section. The guided reflections of Amy, who received the highest score and turned in an outstanding field assignment for the class requirement, and George, who received the lowest score for the assignment, were analyzed as two mini 
case studies in this study. In addition, six preservice teachers, Hanna, Kayla, Candice, David, Suzanne, and Sandy, all placed in the Maple Elementary School during the semester were observed by the researcher as they were implementing the learning stations. Data include (a) the researcher's field notes taken by the researcher during the observations, and (b) the preservice teachers' reflections on the seven open-ended questions (see Chapter 3). Pseudonyms have been assigned to the preservice teachers and to the elementary school.

\section{Qualitative Analysis of the Field Assignments and the Researcher's Field Notes}

The qualitative analysis of the fifth research question was organized into five sections. First two cases are presented to provide a detailed portrait of how two very different preservice teachers approached the conceptual change field assignment. The cases are followed by a comparison of the field assignment reflections of six additional preservice teachers all placed at Maple Elementary School. This comparison identified common themes regarding the conceptual change station and example of their students' initial and final understandings. The researcher's field notes are discussed based on the seven themes that were extracted and finally, a general summary of the eight preservice teachers' performance for the assignment is presented. Finally, six preservice teachers' field assignment reflections and the researcher's field notes about these six preservice teachers' implementation of the conceptual change station are compared and general consistencies and inconsistencies are discussed.

\section{Two Illustrative Cases}

In this section, Amy, who turned in an elaborate and well-written field assignment which received one of the highest scores in the class (30 out of 30), will be presented 
first, and then George, who received the lowest score (20 out of 30) from the assignment, will be reported.

Amy (Highest Score)

Context. Amy is a female Hispanic preservice teacher who had 20 third grade students in her second placement when she implemented her field assignment. According to the records of Georgia and U.S. Departments of Education (2004), her school had over 1,046 students with a predominantly Hispanic (36\%) and African American student (26\%) population. About $13 \%$ of the students attending this school are enrolled in the "English to Speakers of Other Languages" program.

In her personal reflection on the way science was taught at the school, Amy reported that the way science taught at her school was mostly by direct instruction. According to her, the students learn most of their science knowledge from the textbook and the teacher's lectures. Because the students are tested on theoretical knowledge, there was little opportunity for teaching science with a hands-on approach. Therefore, the hands-on science learning stations that she implemented with students were new to them and addressed many incorrect science concepts.

Amy had an advantage of having extra time to implement her learning stations in the classroom. She reported in the field assignment that her cooperating teacher allowed her the whole afternoon plus additional time before and after to teach the children. It was assumed that this additional time was helpful for her to implement five stations successfully in her classroom.

Amy's learning stations. Amy conducted six hands-on learning stations in her classroom. She identified two stations as the conceptual change stations for this 
assignment. Amy chose the concept "floating and sinking" for the conceptual change stations. From the students' answers, Amy discovered that the students held what she called "an incomplete misconception" that was: heavy objects sink while light ones float. She reflected that: "They were not taking into consideration the surface area of an object or its density." Therefore, Amy decided to focus on surface area and density to change her students' initial ideas (she was correct in her use of the term density, but she should have referred to volume instead of surface area).

At the first conceptual change station, Amy provided a plastic bucket for water, a variety of items (e.g. wood stick, peeled and unpeeled orange, potato, apple, marble, coins, floating rock, and $\mathrm{CD}$ ), aluminum foil precut in equal squares, pennies, and a floater or sinker prediction chart. Amy wanted the students to make a prediction from a variety of objects. Amy's students tried to figure out why a pumice rock could float while the other rocks sank. She let the students create different size boats, make predictions on the amount of pennies their boats will hold, and explain their results.

At the second conceptual change station, Amy included a plastic bucket for water, raisins, Alka-Seltzer, and the directions chart. The main question was: how can we make a sinker float? By using Alka-Seltzer, the students observed the floating objects that were sinking before. Amy wanted them to observe the dancing raisins, discuss why they were dancing, and draw a picture of what her students did to make the sinker float. Then, Amy asked open-ended questions while the children were exploring the materials and collected their drawings.

Amy's reflection. Amy's answers to the seven open-ended questions of guided reflection are as follows: 
1. What science concept did you choose and why?

Amy chose the concept why do some objects float and others sink? for the conceptual change stations. She gave three reasons for picking this concept. One reason is because she believed that the concept of floating and sinking was not an easy concept for her students. Secondly, her students were not familiar with the scientific process. Amy thought they could practice a variety of scientific approaches at the stations. She notes; "I also noticed that they [her students] did not have a lot of experience collecting and analyzing data and I thought this activity would offer them exposure to the scientific process."

The third reason for Amy's selection was because she felt that some of her students had incomplete understandings about the concept. Amy stated that she became aware of these misconceptions from the open-ended questions that she asked them during their explorations and predictions on the Scientist Log Sheets.

2. How did you determine your students' initial understandings of that concept?

In order to determine her students' initial understandings, Amy talked to her students about what they knew about sinking and floating. She stated that learning about the students' initial understandings was not difficult and she really enjoyed the process: Surveying [trying to know their conceptual understanding] children is really not that hard. They love to talk and they will answer any questions and give you quick insight into what they know and how they perceive the world around them.

3. How did you make sure you completely understood the concept yourself, and what did you do to develop your own understanding? 
Amy reflected that some of the concepts she chose were challenging and therefore she wanted to learn more about them: "It [her assignment] gave me the opportunity to learn new concepts through lots of research. I did a lot of research [from books and internet] and learned concept well-enough to address any misconceptions that the children might have had."

4. What conceptual change strategies did you use in your station (s)?

Amy chose hands-on activities as the conceptual change strategy for this assignment. She supplied various kinds of materials for every station so the students could have enough opportunity to experience with manipulatives: "My main goal was to give them enough hands-on opportunity so they could come up with questions that challenge their misconceptions..."

5. What influenced you in your choice of strategies?

It was understood from Amy's explanations that the difficulty level of the concept and the students' low background knowledge about scientific process influenced Amy in selecting hands-on activities as the conceptual change strategy: "Although I realized that the concept of floating and sinking was not an easy one, I wanted to provide the students with a hands-on experience that sparked a lot of questions."

In addition, the activities that she chose for the conceptual change stations are the ones that she experienced in the science class throughout the semester. Although she did not specifically say that she learned the ideas from her science class, the researcher realized that from her further explanations that Amy's previous experiences influenced her implementing the same ideas in her classroom. 
6. Do you think you were successful in building your students' conceptual understandings?

Amy reported the results of the stations objectively. She thought that she was successful in building her students' conceptual understanding, and that her students learned a lot from the stations. However, Amy did not think that all of her students gained complete scientific understanding: "They still do not have a full understanding about sinking and floating but, they know that there is more to it then just weight." 7. How do you know whether you were successful?

Amy mentioned that she held a final meeting with students where she addressed students' questions. After the stations she analyzed the students' answers to the question "what makes an object sink and another one float?" She reported the percentages of the students who changed their initial understandings as follows: "At least $85 \%$ of the kids accepted that there is more to sinking and floating than just weight. At least $40 \%$ grasp the concept of surface area [volume] and only $20 \%$ were able to explain the concept of density."

Because Amy was very successful with the stations, her classroom teacher suggested that she re-implement the same stations in another teacher's classroom. Following is her reflection about her teacher's recommendation: "My cooperating teacher asked me to re-do the stations with another teacher because, they thought it was great for the children to be part of it. It was accepted gladly and I will be repeating these stations with another $3^{\text {rd }}$ grade class."

Summary of Amy's field assignment. Overall, Amy's field assignment was very well-organized according to the criteria that were assigned in the syllabus (See Appendix 
F) Generally, Amy grasped the purpose of the assignment correctly, understood the importance of knowing students' conceptual understanding as a teacher, learned her students' initial understanding before implementing the stations, implemented the stations in her classroom successfully, and tested her students' final understandings. In addition, the content of the field assignment that she turned in was more reflectively-written than her classmates' field assignments.

The researcher detected a series of strengths in Amy's assignment. First, Amy developed five well-designed learning stations that were managed with a variety of materials for this assignment. She put great effort into developing these stations, finding the appropriate materials, and implementing them.

Another strength is that Amy is the only preservice teacher who specifically presented the scientific explanation of the misconception with what she called "truth" in her reflection: "Weight is only part of it. The amount of space an object occupies, relative to its weight is also important. Different objects have different densities, and depending on their relative densities to solutions, they will either sink or float." Third, although most of the preservice teachers caught students' misconceptions and specifically mentioned them, they did not give the correct or scientific explanation for these misconceptions. Therefore, it was hard for the researcher to determine whether the preservice teachers correctly understood the content knowledge about the concept.

\section{George (Lowest score)}

Context. George is a white American male preservice teacher who had 24 students in his third grade classroom when he implemented the field assignment. His school was one of the most highly populated schools $(1,143$ in 2004) (Georgia and U.S. Departments 
of Education) within its district and had predominantly Hispanic (46\%) and African American student population (21\%). In this school, the number of students per teacher is 12 and the average teacher experience is 13 years. About $37 \%$ of the students attending this school are enrolled in the "English to Speakers of Other Languages" program.

George pointed out that science was generally taught theoretically in his classroom. He reported that the students did not get many opportunities to learn science through hands-on activities; especially about the concept "fossil formation" which he later selected as his conceptual change station. Therefore, he reported that implementing this conceptual change station was a great opportunity for his students to learn from the activities instead of just enjoying them as fun, time filling activities.

George's learning stations. George conducted two hands-on learning stations in his classroom. One station was about designing paper airplanes. He aimed to teach the effect of different materials (e.g. colored papers and decorative materials) on the planes that the students would create by themselves and to introduce the idea of variables in an experiment. The students would attempt to design a paper plane that will stay in flight for the longest period of time by using a "plane guide." The second learning station was the one that George presented as the conceptual change station. George let the students create their own molds out of Crayola clay and plastic bug creatures. The purpose of this station was to teach students what fossils are, how they form, and the difference between paleontologists and archeologists.

George's reflection. George's answers to the seven open-ended questions of guided reflection are as follow:

1. What science concept did you choose and why? 
George chose the concept of how fossils are formed? for the conceptual change station. However, he did not mention if he used QCC's to determine what science concepts are taught at his grade level. It is understood from his assignment that he decided the science concept by himself and did not talk with his cooperating teacher about which concept he would choose. George described his topic fossils and explained the reason why he chose this concept as the conceptual change station:

To prepare myself for the conceptual change station, I tried to think of a topic that could be modeled as well as learned within the stations. The station I chose because it gave the students an opportunity to see first hand how a certain type of fossil would first begin its formation millions of years ago.

It was understood from George's observer's feedback that this concept was not taught to the students before: "..... but I understood this was an introductory activity." 2. How did you determine your students' initial understandings of that concept?

Although George gave some examples from his students' initial understanding, he did not give any information about how he assessed his students' knowledge about the concept. It is unclear whether he asked students open-ended questions, had them write their initial ideas in their science journals, or let students fill out a KWL chart. In terms of the students' initial knowledge about the fossils, George reflected the following: "The students either had no clue what they [fossils] were or simply thought they [fossils] were the bones of dinosaurs."

Additionally, George highlighted that his students did not know what fossils actually are and the difference between paleontologists and archeologists: 
The children at first just thought that dinosaurs died, they left their bones behind, and archeologists dug them up later. They had no idea that it was actually paleontologists who excavate pre-historic creatures and that fossils are not actually bone at all but the remnants of bones from millions of years ago.

3. How did you make sure you completely understood the concept yourself, and what did you do to develop your own understanding?

It is difficult to understand whether George completely understood the concept himself. He did not give any information about the way that he learned this concept so that he could teach it to the students. George's science content knowledge about fossils and fossil formation needs more elaboration so that he could present the scientific explanation to his students. The observer appeared to agree with the researcher by writing: "I would like to have seen more in-depth coverage of the content" 4. What conceptual change strategies did you use in your station (s)?

George used hands-on activities as the conceptual change strategy in the learning stations: "The learning stations I chose to use in my classroom placement were both chosen on the basis of creating an activity in which students could connect to a new idea through hands-on experience."

However, George thought that implementing only hands-on activities were not enough to change students' initial understandings. So, he wished to use other conceptual strategies in addition to the hands-on activities: "I would allow the students to do some more research with texts, the internet, and so forth on the development of fossils after we completed the initial activity." 
5. What influenced you in your choice of strategies?

It was understood from George's reflection that his students did not have much experience in terms of doing hands-on activities in their classroom. Following is his reflection on that: "The students do not get many opportunities to do a lot of hands-on activities, especially ones in which they get to use clay and fly paper airplanes." He reported that using hands-on activities for the stations was very helpful for his students since they were not familiar with this approach in science.

However, the science support specialist of the school where George was placed reported that: "There is an emphasis on student understanding based on their interests using scientific knowledge and the inquiry process. Students learn best when they construct their learning through discovery. To this end we are heavily hands-on." 6. Do you think you were successful in building your students' conceptual understandings?

George did not record information about how many of his students changed their initial understanding after they visited the conceptual change station. He did not give examples from the students' post understanding. However, George stated that: "In general, the stations were a great success in my classroom. The students really seemed to be genuinely interested in the topics and ideas discussed."

7. How do you know whether you were successful?

Although George wrote that he would let the students answer open-ended questions in their science journals which will give information on what they did, he did not really thoroughly state whether or not the students answered the questions or whether he read their journals. It is hard to understand how successful he was in terms of 
changing the lack of understandings and incomplete or incorrect understandings of his students.

Summary of George's field assignment. George wrote a descriptive management plan for both learning stations in his field assignment. From beginning of the class to the end, he explained each step in terms of the students and the teacher's activities. Based on his further explanations and the observer's feedback, George did not seem to have a management problem during his class period.

It is the researcher's general impression from reading George's field assignment that he did not prepare himself thoroughly. The researcher detected a series of weaknesses:

George developed only two hands-on learning stations instead of four that were assigned in the syllabus. He chose one of these two stations as the conceptual change station for this assignment.

George's field assignment was not complete in terms of the number of sections assigned in the syllabus. The field assignment required five sections including lesson plans, management plan, guided reflection with seven open-ended questions, observer's reflection about the preservice teachers' performance, and the photos of each station. Because George did not take pictures of the stations, the instructor did not have any visual documentation about how he set up the materials in the classroom. In addition, George's did not clarify on whether the observer was a student or a cooperating teacher.

The Maple Elementary School Preservice Teachers' Guided Reflections

The Maple Elementary School was selected by the researcher to observe six preservice teachers (Kayla, Candice, David, Suzanne, Sandy, Hanna) in their field 
placements during the implementation of the hands-on stations. There were two reasons for choosing this school. First, the researcher had six students at the same school that was very convenient for her to observe them in their classrooms and second, Maple Elementary School is a professional development school for the large southeastern urban university where the study was conducted. In this partnership, student interns learn about teaching as they develop into future educators.

When asked to describe the philosophy of teaching science, the preservice teachers observed both "hands-on" and "textbook-based" approach. For example, Suzanne (one of the six preservise teachers observed at the Maple Elementary School) reported that her cooperating teacher really enjoyed teaching science and did not use a textbook very often. Suzanne defined her cooperating teacher as: "the most hands-on in science in all of her experiences interning." Suzanne also highlighted that the station assignment was not a new idea in her class because the teacher often use stations with other subjects. Suzanne's observation was confirmed by the Professional Development Schools University liaison, who is also a science methods professor. The university liaison reported that during her weekly visits to Maple Elementary, students visit the science laboratory once a week to engage in various hands-on science activities.

Whereas Hanna remarked: "I saw very little science being taught and when [it was] through reading in free time or from textbook. Before I implemented the stations, there were no hands-on activities I observed."

The Summary of the Maple Elementary Preservice Teachers' Reflections

The six preservice teachers were observed at Maple Elementary School by the researcher. Four were placed in second grades (Hanna, Kayla, Candice, and David) and 
two were placed in third grades (Suzanne and Sandy). The researcher analyzed their personal reflections in their field assignments and found the most common answers which are summarized in Table 12. Illustrative examples based on guided reflection questions are also provided for each. 
Table 12

Most Common Answers and Descriptive Quotes of the Elementary School Group as Extracted

from the Participants' Guided Reflection

\begin{tabular}{|c|c|}
\hline \multicolumn{2}{|c|}{ Q1. What science concept did you choose? Why? } \\
\hline The most common answer & Descriptive Quote \\
\hline States of matter (physical science) & $\begin{array}{l}\text { I chose states of matter because; this is what was in } \\
\text { agreement with the Maple Elementary curriculum }\end{array}$ \\
\hline Because, it is in the curriculum. & (David, grade 2). \\
\hline $\begin{array}{l}\text { Because, students had } \\
\text { misconceptions. }\end{array}$ & $\begin{array}{l}\text { I found that students had a misconception about air and that } \\
\text { it did not move or did not take up space (Kayla, grade } 2 \text { ). }\end{array}$ \\
\hline \multicolumn{2}{|c|}{ Q2. How did you determine your students' initial understandings of that concept? } \\
\hline KWL organizer & $\begin{array}{l}\text { By doing the KWL chart, I found that the students knew that } \\
\text { sugar was in soda [coke], diet coke has less sugar than } \\
\text { regular coke, and it is bubbly (Candice, grade } 2 \text { ). }\end{array}$ \\
\hline Open-ended question & $\begin{array}{l}\text { I first needed to find out what knowledge my } \\
\text { students had about a food chain. I asked them to tell } \\
\text { me what they knew about the term food chain } \\
\text { (Suzanne, grade } 3 \text { ). }\end{array}$ \\
\hline
\end{tabular}

Q3. How did you make sure you completely understood the concept yourself and what did you do to develop your own understanding?

By searching from the internet When I was planning my stations, I thought of questions that the students may ask and if I did not know them, I looked them up on the internet and wrote them down as reference (Kayla, grade 2).

Q4. What conceptual change strategies did you use in your station (s)?

Hands-on activities It [conceptual change station] provided a hands-on approach and allowed the students to investigate and enquire [sic] new knowledge (Suzanne, grade 3).

Q5. What influenced you in your choice of strategies?

The teacher's science book The teachers' science book also influenced this choice because it displayed the experiment (Kayla, grade 2).

Their own science class

After working with the toad in my own science class, I really wanted my students to experience the fun activity (Sandy, grade 3).

Q6. Do you think you were successful in building your students' conceptual understanding? Yes, they think they were I feel that this station went very well. I think I changed their successful. lack of understanding by using this activity at my station (Hanna, grade 2).

Q7. How do you know whether you were successful?

Science journals, the KWL charts, When I asked the students why they believe this happened, open-ended questions they were able to tell me the correct response. (David, grade 2). 
1. What science concept did you choose and why?

The preservice teachers chose the following concepts: Kayla and Hanna (states of matter), Suzanne and Sandy (food chain), David (does air have mass?), and Candice (how coke is made?). When preservice teachers were asked to give a rationale for their conceptual change station's concept, the typical reasons were reported: the particular concept was required by the state curriculum and pupils had developed misconceptions as determined by the open-ended questions or the KWL strategy.

2. How did you determine your students' initial understandings of that concept?

The preservice teachers predominantly used the KWL organizer (chart) or openended questions to understand what their students already knew about the particular concept. Most of them used these strategies at the beginning of the class before stations started. Please see Table 13 for illustrative examples from the students' initial understanding.

Table 13

Examples from Preservice Teachers' Students' Initial Understanding before Station Implementation

\begin{tabular}{ll}
\hline Preservice teacher's name / Concept & Student comments \\
\hline Kayla (States of matter) & "Air does not move" \\
& "Only solids and liquids take up space." \\
Sandy (Food chain) & "It [food chain] is a type of restaurant." \\
& "It [food chain] is what happened to grapes when \\
& they turn into raisins." \\
& "Toads eat bugs and plants because they are \\
& green." \\
& "Toads are baby frogs." \\
& "Frogs and toads are the same." \\
& "Coke is only made up of sugar." \\
\hline
\end{tabular}


3. How did you make sure you completely understood the concept yourself, and what did you do to develop your own understanding?

The most common preservice teacher response about how they developed their own understanding was internet search. To refresh their memories, they looked up information on the internet and read books like, teacher's science textbooks. They also used the internet to research the lesson plans, find recipes for play dough, and interactive computer games on food chain.

4. What conceptual change strategies did you use in your station (s)?

All the preservice teachers used only hands-on activities as the conceptual change strategy for their particular station.

5. What influenced you in your choice of strategies?

The two most common influences to preservice teachers' choice of strategy were their science methods class and the teacher's manual. Suzanne and Sandy reported that they decided to use the food chain after experiencing a toad activity in their science methods class since the toad activity was something that they really enjoyed. Kayla and David reported that they got the idea from their teacher's science textbook to choose their activity.

6. Do you think you were successful in building your students' conceptual understandings?

All preservice teachers reported that they were successful in implementing the assignment. Generally, they thought they changed their students' incorrect ideas, and replaced them with an accurate scientific understanding. Hanna was an exception because she pointed out that she would implement the KWL chart much earlier than the day of the 
stations, and that she would consult with the classroom teacher to determine the students' initial understanding. Similarly, David reported that he would use another scale and spend at least a week introducing the subject of matter.

7. How do you know whether you were successful?

The preservice teachers included the students' science journals, the KWL charts, and the students' final answers to the open-ended questions as evidence of their success on this assignment. See Table 14 for illustrative examples from their students' final understanding.

Table 14

Examples from Preservice Teachers' Students' Final Understanding after the Stations

\begin{tabular}{|c|c|}
\hline $\begin{array}{l}\text { Preservice teacher's name } \\
\text { Concept }\end{array}$ & Student comments \\
\hline Kayla / States of matter & $\begin{array}{l}\text { "Air can take up space." } \\
\text { "Air is matter to even though you can't see it." } \\
\text { "Only solids and liquids take up space." }\end{array}$ \\
\hline Sandy / Food chain & $\begin{array}{l}\text { "It [food chain] is when animals eat other animals or } \\
\text { plants to survive." } \\
\text { "In the food chain animals depend on one another for } \\
\text { energy." }\end{array}$ \\
\hline $\begin{array}{l}\text { Candice / How soda (coke) is } \\
\text { made? }\end{array}$ & $\begin{array}{l}\text { "Diet soda/coke has less sugar than regular soda." } \\
\text { "Soda/coke has seltzer water." } \\
\text { "Soda can be in different colors [food coloring]." }\end{array}$ \\
\hline David / Does air has mass? & $\begin{array}{l}\text { "The balloon with air was heavier because air has mass. } \\
\text { It has weight." }\end{array}$ \\
\hline $\begin{array}{l}\text { Hanna / States of matter } \\
\text { (making play dough) }\end{array}$ & $\begin{array}{l}\text { "I learned that flour and salt is solid, oil is liquid." } \\
\text { "Solid and liquid makes a solid experiment [play } \\
\text { dough]." }\end{array}$ \\
\hline
\end{tabular}




\section{The Researcher's Field Notes}

The researcher observed each preservice teacher implement his or her science learning station in their classroom and took field notes. While the researcher was observing the participants, she used a blank note pad to write her free observation notes about the participants' general performance on implementation of the stations. She particularly focused on whether or not the participants were well-prepared for the stations, how they handled the students while they were rotating through the stations, how they managed the stations, what they specifically did at the conceptual change station, and whether or not the stations appeared to enhance the students' understandings. The researcher also reported some of the preservice teachers' questions and the students' responses to these questions as additional information.

From the analyses of the researcher's field notes, seven themes emerged: (a) preparation, (b) the ways of determining students' initial understanding, (c) the conceptual change strategy and the effectiveness of its implementation, (d) preservice teacher's management, (e) students' motivation, (f) role of cooperating teacher, and (g) preservice teacher's overall performance.

\section{Preparation}

The researcher observed that all six preservice teachers were well-prepared for this assignment. The preservice teachers provided sufficient materials for the activities and these materials were well-organized on the tables. The instructions for the stations were placed either on the tables or on the walls. All but Hanna had prepared science journals for each student to write their initial and final understanding. The science journals had the KWL charts, several open-ended questions to assess the students' 
conceptual understanding or both. Kayla's learning stations and science journals were even color coded so that her students could rotate through the stations easily without further instructions. In addition, David and Kayla put content related books on the tables as additional resources so that students could read and learn more about the concepts. The researcher noted that all the preservice teachers in the school thoroughly planned their assignments.

\section{The Ways of Determining Students' Initial Understanding}

All the preservice teachers used either a KWL chart or open-ended questions to assess their students' initial knowledge. Although the researcher expected that the preservice teachers would assess students' knowledge prior to the stations' implementation, this was not the case for five of the six preservice teachers. It was hoped that preservice teachers would be aware ahead of time of what kind of incorrect understanding they needed to change via the learning stations. Instead, for example, Suzanne and Sandy asked open-ended questions about the food chain just before the students started to rotate through their stations. Similarly, David drew a KWL chart on to the board and filled it with the students' comments on the same day. Therefore, they did not really have a chance to read and analyze the students' answers or reflections from the KWL charts so that they could particularly focus on what the students already knew and what they would like to know. Only Candice mentioned that she was already aware of her students' incorrect understanding based on a previous conversation between herself and a student. 


\section{The Conceptual Change Strategy and Its Implementation}

The researcher required for the preservice teachers to use hands-on activities at the stations that were assigned in the syllabus (see Appendix F). In addition, she gave examples from other conceptual change strategies (conceptual change text, analogies, and concept mapping) in the class and suggested that her students implement these strategies after their students finished rotating through the stations (for the details of the instruction see Appendix D). However, none of the participants implemented these processing strategies either because they ran out of time after the stations or because these additional strategies were not required in the syllabus. Instead, they basically implemented hands-on activities at the stations.

All preservice teachers implemented the hands-on activities effectively at the learning stations. The researcher felt that the whole group was aware that students should be engaged by using manipulatives in the development of their conceptual understanding. The preservice teachers generally let their students freely act on the materials at the stations to develop their understanding of scientific concepts. However, Hanna made uncooked play dough with oil, flour, cornstarch, food coloring, water, and salt to teach the concept of states of matter. It is understandable that because Hanna did not want her students making a mess on the carpet, she was actually in charge of mixing the ingredients in a big bowl. Although she let all the students add some materials and mix the play dough, the researcher wished that Hanna had let her students to have a first-hand experience making their own play dough. Also, the play dough activity was not best example for her students to understand to concept of states of matter. Hanna could have selected an activity to present different states of matter more clearly by using a hot plate 
under her supervision (e.g. ice, water (liquid), water vapor or solid naphthalene versus evaporation of naphthalene without actually seeing liquid naphthalene).

Preservice Teacher's Management

Generally, the preservice teachers did not have management problems and the students easily followed instructions. The preservice teachers all highlighted the general rules and instructions for the students at the beginning of each class. As noted earlier, instructions were typed with large fonts either on a sheet of paper at the table or as a chart placed on the walls. Kayla asked a student to repeat the instructions to her classmates before the stations.

Unlike Kayla's well though out management plan, Candice had difficulty managing her learning stations. Since in one instance Candice had put a lot of information and questions on the instruction sheets as well as the science journals, the students were sometimes confused. Also, Candice provided too many materials for her students to make their own soda (coke) and therefore became overwhelmed in assisting students with measuring the ingredients. This situation made the management of the conceptual change station difficult for Candice.

Time restriction was another issue for the participants. For example, David ran out of time to implement each group at each station; therefore, he gave quick instructions to his students to rotate through the stations, not giving them enough time to engage in the activities and understand the content that was presented.

\section{Students' Motivation}

The students were highly motivated during the implementation of the stations. Since, they generally do not have stations in their science class, they were all excited 
about rotating through the stations and engaging with the materials. Hands-on approaches for learning science were new for most of the students. In Suzanne and Sandy's classrooms, the students really appreciated the toads and enjoyed working with them. The students were cheering, sometimes screaming, and competing with each other to touch the toads. The researcher reported that the students were able to work with live animals and learn new concepts through something that they might not see on a daily basis.

Candice had provided different sizes of measuring cups which helped students improve their measuring skills while making their own soda (coke). Her students were not familiar with measuring cups. At the end, she encouraged her students to taste the soda. Some of them tasted and really liked it, but some of them did not. Tasting their own drink (even if it did not taste good) was a great experience for the students. In other words, the students got to experience how much fun science can be, and the station allowed the students to explore and engage in an active approach to learning science concepts.

\section{Role of Cooperating Teacher}

Because of the fact that most of the preservice teachers tended to stay at the conceptual change station throughout the class period rather than visiting other stations, the classroom teachers sometimes helped the preservice teachers manage the students at the other stations to make sure they were following directions. For example, Sandy's cooperating teacher first observed the event of feeding the toad with meal worms. Another group of students were at the computer station and they were learning about the food chain through a web-based interactive game. Then, Sandy's cooperating teacher started to ask additional questions (e.g. producers, consumers, or decomposers) to the 
students to help them to make connections between the conceptual understanding that they learned at conceptual change station and at other stations. Although her class was not chaotic, Sandy did not seem to monitor all stations at the same time.

On the other hand, Kayla monitored all the stations at the same time by herself. Her teacher was supportive in terms of giving ideas and sharing experiences with her; however, she did not directly interact with the students as they rotated among the stations. David's teacher played a "people manager" role during the stations. Since David had a time limit, his teacher helped the students rotate from one station to another.

Preservice Teacher's Overall Performance

The preservice teachers were very enthusiastic about teaching new science concepts to the students. They used correct vocabulary during the implementation: such as initial understanding (Hanna), conceptual understanding (Candice), lack of understanding (Suzanne), misconception (Candice and Suzanne), and sound understanding (David). Moreover, some of the students used an alternative term instead of the ones that were listed above. Hanna used the term current level understanding instead of initial understanding and David used the term concrete knowledge instead of scientific understanding. Their new terms were understandable and made sense to the researcher.

Suzanne and Sandy, who are twin sisters, both used the toads, crickets, and worms for their conceptual change stations. Although their original concept was food chain, they asked some open-ended questions that carried the initial discussion into different topics. Instead of talking about the terms producers, consumers, or decomposers and their relationships in nature, they asked some questions about toads'favorite food. In 
other words, some of their questions were not directly related to the concept that they had planned to focus on. Also, these questions don't include the vocabulary being taught.

Three preservice teachers did not really compare the students' initial and final understanding in depth. The researcher believes that this happened because: (1) they had time restrictions, they did not have a chance to let the students write their final understanding in the KWL charts or ask open-ended questions to summarize what they did and what they learned, or (2) they did not really figure out how to analyze the students' pre and post-intervention answers in the KWL charts and science journals.

However, Hanna, Kayla, and Suzanne had a chance to let their students fill out the $L$ part of the KWL charts at the end of the class. They also asked open-ended questions to make sure their students learned something new from the stations and changed their incorrect understanding. After the students were done with the stations, Kayla sat them on the carpet and after getting their full attention asked additional open-ended questions like: "Was the paper towel wet or dry?" or "What prevented paper towel so that towel was still dry in the cup?" A female student answered these questions as "an air prevented it to be wet." Kayla made a general review of the content and got their reflections. Then, she gave students time to complete their KWL charts. The researcher noted that the wrapup part of this class was very helpful to the students. On the other hand, since David, Sandy, and Candice ran out of time to identify their students' final ideas, they had to continue the activity during the next lesson or on the following day.

In general, the preservice teachers seemed to be comfortable with the fact that the researcher (as their science methods instructor) was in the classroom to observe their performance. However, David and Candice seemed to rush at the end of the class period 
because of time restrictions and having variety of materials at the conceptual change station. Finally, the researcher had an impression that all preservice teachers had professional coordination with their classroom teachers who helped and supported them at every step for the implementation of the learning stations.

\section{Summary of Field Assignments}

The weaknesses and the strengths of all six preservice teachers' field assignments will be presented below.

\section{Weaknesses}

General performance of the preservice teachers might have been affected by several factors. First, the instruction the researcher gave to the preservice teachers on conceptual change and conceptual change strategies could be more elaborative and research-based. A detailed discussion could have been encouraged by giving more examples of conceptual change strategies and their implications. The researcher could have given several articles as additional resources for the preservice teachers to read on implementation of different conceptual change strategies before they implemented their stations. These articles could have given them specific idea about choosing the concept of the conceptual change station, implementing different conceptual change strategies, learning about students' initial understanding, presenting the scientific explanation of incorrect understanding to the audience, and comparing student's initial and final understanding.

Secondly, some of the preservice teachers had a limited understanding about how to manage students while they were rotating through learning stations in the classroom. They generally tended to stay at the conceptual change station instead of becoming a 
guide for all the stations. Thus, more detailed information could have been given to the preservice teachers in terms of flow of traffic between the stations.

Another weakness is that more collaboration between the preservice teachers and their classroom teachers was needed so that the teachers could give them a better idea about what students already knew about the concept they chose based on the curriculum. Although collaboration with classroom teacher was highly recommended in the syllabus (see Appendix F), the importance of being in contact with the cooperating teacher could have been specifically pointed out in the class.

In addition, as mentioned earlier, the preservice teachers did not tend to use KWL charts for planning of their learning stations. They let their students fill out the KWL charts either before their students started to rotate through the stations or before they gave the instructions for the learning stations on the board. Therefore, the researcher believes that not all of the preservice teachers had a concrete idea about their students' initial understanding about the science concept that they chose.

Finally, most of the preservice teachers did not really compare and give examples of their students' initial understanding with their final understanding. Although they collected the student's work (e.g. KWL charts and science journals) and attached them into their field assignments, they did not keep track of students' first and final responses in the KWL charts and journals by reporting the specific examples.

\section{Strengths}

Overall, the preservice teachers successfully implemented the science learning stations in their placements. They realized that students either had lack of understanding or a variety of incorrect understanding about the selected science concepts. The 
participants understood that it is important to know students' incorrect ideas as a teacher to teach science in an effective way. Some of the preservice teachers could not detect any incorrect understanding from their students' initial responses.

The participants stated how difficult it was to change students' incorrect ideas even after well-prepared interventions. They were objective in terms of reporting whether or not they really developed their students' understanding. However, all of the preservice teachers pointed out that they saw an improvement at the students' answers after the learning stations. In general, the researcher's field notes and the preservice teachers' personal reflections indicated that they were successful in terms of building the students' conceptual understanding.

\section{Triangulation of the Field Assignments and the Researcher's Field Notes}

Because the researcher did not observe Amy and George in their field placements, their responses were analyzed based only on their personal reflections in field assignments. However, the field assignments of the other six preservice teachers were confirmed by observation and the field notes of the researcher. The researcher could compare what they wrote in their reflections versus what she actually saw in their classrooms during the implementation of the stations. This gave her a chance to triangulate the data reported in their field assignments with the researcher's personal observations and the notes that she took in the classrooms.

Generally, the researcher did not detect serious inconsistencies between the two sets of data. However, following are several examples that were not quite the same in the reflections and the researcher's field notes: 
From observing in the classroom, it appears that some participants made overgeneralizations about changing their students' incorrect or lack of understandings in their reflections. Some either did not learn about students' initial understanding prior to implementation or they did not analyze their students' initial and final answers from the KWL charts or the science logs. For example, in her personal reflection Hanna reported that "I feel that this station went very well. I think I changed their lack of understanding by using this activity at my station." However, the researcher observed that Hanna learned about her students' initial understanding right at the beginning of the class and there was not much time for her students' to write their final understanding after the stations. There were not actually much data for her to draw upon to conclude that her students' understandings improved. On the other hand, David reported that it was hard for him to change students' initial understandings completely. In his reflection he wrote that "I still did not feel good about adding to their sound understanding of the subject."

As mentioned earlier, the concepts that Hanna (ready, set, let's dough!) and Candice (how soda/coke is made?) choose were not very appropriate to be used at the conceptual change stations. The researcher specifically highlighted this issue in her field notes. But, neither Hanna nor Candice mentioned this point in their field assignments. Although they were both well prepared for the stations with a variety of materials, the researcher saw that neither realized that the activities they chose did not clearly represent scientific phenomena.

There were many consistencies between what the preservice teachers reported and what actually happened in their classrooms. All six preservice teachers at the Maple Elementary School took the field assignment very seriously. The researcher specifically 
reported in her field notes that they all were very-well prepared for the stations in terms of the materials they provided, the science logs, the instruction sheets, the books and other additional resources. They brought most of the materials from home. These participants also reported in their reflections how well prepared they were while they were implementing their stations including the conceptual change station. Therefore, there is consistency between their personal reflections and the researcher's field notes in terms of the preparation they all put into the stations.

The participants claimed that their students were really excited about the conceptual change station that they implemented. The researcher's field notes about Sandy and Suzanne's implementation were completely consistent with their reflections. The researcher highlighted in her notes that their students were extremely happy about having the toads in their classrooms in the conceptual change stations on the food chain. The students were cheering and competing with each other to touch the toads. The researcher noted that the idea for the toad activity was similar to an experience in the science methods class where class members observed a toad and watched it eat mealworms. Sandy and Suzanne reported in their reflections that they first experienced the toad activity in their science methods courses and really liked it.

Overall, the researcher believes that the preservice teachers that were observed were objective in their personal reflections when reporting their performance at the stations. The field notes were evidence of the reality of what actually happened in their classroom with their students. 


\section{CHAPTER 5}

\section{Discussion}

This chapter presents interpretation of the findings, implications of the results for teacher education and staff development, and strengths and weaknesses of the study. In addition, ideas for future research and a conclusion of final results are reported. What Understanding Do Preservice and Inservice Teachers Have on Six Earth and Space Science Concepts?

As expected from previous research, the findings of this research indicated that preservice and inservice teachers, without intervention, have limited understanding or incorrect understanding about reasons for seasons, phases of the moon, the rock cycle, reasons for the wind, soil formation, and causes of earthquakes. The research shows that the space science concepts like phases of the moon and reasons for seasons are very difficult and abstract even for adults (Atwood \& Atwood 1996; and Trundle, Atwood, \& Christopher, 2002). The findings of this study are similar to the findings of previous research on preservice teachers (Atwood and Atwood, 1996; Kusnick, 2002; and Rice, 2005) and on inservice teachers (Bulunuz, 2006; Kikas, 2004; and Parker \& Heywood, 1998) in that both student teachers and current teachers have lack of understanding and nonscientific ideas on earth and space science concepts. Following is the discussion of the findings of this research on preservice and inservice teachers' preconceptions on six earth science concepts. 
Reasons for seasons. Distance theory was the most common incorrect understanding about reasons for seasons in this research. This result is consistent with the research on preservice teachers conducted by Atwood and Atwood, (1996) and on inservice teachers by Kikas, (2004); and Parker and Heywood (1998). In addition, most participants in this study mentioned the rotation of the earth around the sun without mentioning the tilted axis of the earth. This common incomplete understanding is consistent with the answers that the preservice teachers gave in the study by Atwood and Atwood, (1996). Unlike the previous studies, the researcher detected a few other nonscientific ideas from the participants' survey answers and that were: "the sun goes around the earth and the sun rotates." In addition, the misinterpretation of the question as "the advantages of having seasons" by several participants in this study is not one of the findings in previous research.

Phases of the moon. The preservice and inservice teachers had a greater variety of initial incorrect understandings about phases of the moon compared to the other concepts in this study. Most of the participants had a common initial understanding and that was "the earth's shadow on the moon causes phases." The findings of the research are consistent with the research on preservice teachers by Callison and Wright (1993) and Trundle et al. (2002); and on inservice teachers by Bulunuz and Jarrett (2006) and Parker and Heywood (1998). The participants in this study had another incorrect initial understanding and that was planets' shadow or alignment of planets in front of the moon causes phases. Parker and Heywood (1998) reported the same nonscientific understanding in their study on inservice teachers. Also, the participants generally reported the earth's rotation [revolution] around the sun but not the moon's revolution 
around the earth. This finding is very similar to the finding of the Trundle et al. (2002). On the other hand, other uncommon answers, such as the moon's orbit around the sun, rotation of the earth around the moon, and the tilt of the sun were not detected in the previous studies.

Rock cycle. Unlike the previous studies on the rock cycle, the researcher detected either incomplete understanding about one or two rock types or lack of understanding on this concept instead of incorrect understanding. In addition, the participants had some initial understanding on sedimentary and metamorphic rocks but not igneous rocks. This finding conflicts with Stofflett's (1994) report that preservice teachers had better understanding on igneous rocks than sedimentary or metamorphic rocks.

Soil formation. Soil formation was another concept about which the preservice and inservice teachers had mostly incomplete understanding rather than incorrect understanding on the pretest. Their answers indicated that they were not thinking of soil as a complex system with various living species (e.g. earthworms, unicellular organisms like bacteria, various bugs, and plants), dead remains of animals and plants, and also nonliving things (e.g. weathered rock, sediments, and minerals). This finding is not consistent with the previous studies on soil formation, which report misconceptions of preservice teachers, university students, and soil scientists about soil formation (Happs, 1984; Hutchinson, 2002; and Dove, 1999). One incorrect understanding of an inservice teacher that was "soil is formed from the earth's ashes" was not found in the studies above. 
Reasons for the wind. The answers of the preservice and inservice teachers on the pretest showed that they had lower initial understanding about reasons for the wind than about the other earth science concepts. The participants had either a lack of understanding or nonscientific ideas about this concept. The most common incorrect understanding of this concept is that wind is caused by tides and storms. The findings of this research are very similar to the findings of the Aron et al. (1994) who argue that the misconceptions teachers hold are very similar to the misconceptions of high school or undergraduate college students.

Causes of earthquakes. Unlike the previous research on misconceptions about earthquakes, the researcher detected partial understanding instead of complete misconceptions among the participants' pretest answers. It was on this concept that the participants had the highest initial rubric scores. Statements from the participants' answers show that many of them used some scientific terminology in their answers such as "plate tectonics," "movement or shifting of plates," or "the activity of the earth's crust;" but, they did not give the detail explanations of these terms. However, in earlier studies, researchers caught various misconceptions about causes of earthquakes among teachers' understanding (King, 2000; and Libarkin, Anderson, Dahl, Beilfuss, \& Boone, 2005). From this angle, the findings of this study are not similar to the studies above. Is There a Difference Between Preservice and Inservice Teachers in Their Understanding of These Concepts?

As it was mentioned earlier, in this analysis the findings show that the assumption of equal variances (Levene's Test) for the concepts of reasons for seasons and phases of the moon were violated $(\mathrm{F}<.05)$. There appeared to be significant differences between 
the rubric scores of inservice and preservice group on the concepts of reasons for seasons and phases of the moon but not other four concepts. However, although the findings indicate significant differences between the two groups on these two concepts, because of the violation of the homogeneity of equal variances, it is impossible to draw that conclusion here. This suggests that inservice teachers do not necessarily learn these concepts while teaching. This is important because all six concepts are currently taught in the elementary school curriculum at various grade levels according to the NSES (National Research Council, 1996), the Benchmarks for Science Literacy (AAAS, 1993), and the recently developed Georgia Performance Standards [GPS] (Georgia Department of Education, 2006) (see Table 1). The findings of this study show that even more experienced teachers hold similar incorrect understandings as preservice teachers. For example, consider the following answers of an inservice teacher, with 23 years of teaching experience, to the questions on three earth science concepts: reasons for seasons: "the earth turns on an axis, moves towards and away from the sun;" phases of the moon: "the moon falls in the shadow of the earth," and the rock cycle: "don't know." What is not known in this study is whether the teachers had greater understanding of the concepts taught at the grade level they taught than the concepts taught at other grade levels. Since teachers often change grade levels, no matter which grade level they teach, elementary school teachers should have scientific understanding on these concepts.

For teachers to have scientific background knowledge of all the many concepts covered in the elementary curriculum would be ideal. However, preservice and inservice teachers often have limited science background. Teachers need to be aware of what they don't know and learn strategies for teaching themselves about concepts they don't 
understand. If teachers are not aware of their incorrect understandings, they can easily pass these nonscientific ideas to students they teach. If they are aware of their limited understandings but do not have strategies for teaching themselves, they may use resources that can be grabbed quickly in their classroom environment, such as teacher handbooks or the Internet to learn about the concepts they do not know. Some of these resources may oversimplify or perpetuate erroneous information. Or teachers with limited understandings may not try to teach themselves, but rather send the children off to Internet sources or books that may not be sufficient for building their understanding. Is Participation in Earth Science Hands-on Learning Stations More Effective in Clarifying Concepts than Reading About These Topics in Textbooks?

Effect of learning method on rubric scores. The finding that preservice teachers showed a significant increase in their posttest 1 rubric scores suggests that the hands-on learning stations and readings from the textbook were effective instructional methods for them to improve their initial understanding on earth and space science concepts. As mentioned earlier, without the instruction, most preservice teachers were very likely to hold alternative conceptions on these concepts. It was concluded that both instructional methods, hands-on learning stations and readings from the textbook, were effective in promoting desirable conceptual change.

The participants realized what they did not know or how little they knew about six earth and space science concepts after they answered the survey questions on the pretest. Therefore, it was possible that taking the pretest not only made participants aware of their lack of understanding but also may have made them receptive to learning about these concepts both through learning stations and readings to improve their initial 
understandings.

The results of this study are consistent with the studies conducted by (Ebert and Elliot, 2002; Gutierrez, Coulter, \& Goodwin, 2002; and McConnell, Steer, \& Owens, 2003). These researchers reported significant improvement on the preservice teachers' conceptual understanding on earth science concepts when they used various hands-on activities and science experiments. In addition, the finding of this study is consistent with many studies focused on the effects of hands-on learning stations on preservice elementary teachers' concept development (Bulunuz \& Jarrett, 2006; Irwin, Nucci, Beckett, 2003; Jones, 1999; and Plourde and Klemm, 2004). Participants working together as active learners is consistent with recommendation of the National Science Education Standards (National Research Council, 1996). The findings from the current study confirm those reported by Jones (1999) and Irwin et al., (2003) that learning stations with hands-on inquiry activities engaged their participants and also developed their conceptual understandings.

Preservice teachers also increased their rubric scores when they learned the concepts through readings form the science textbook. This is not surprising because preservice teachers are familiar with learning concepts from textbooks. In fact, after the implementation of posttest 1 , one preservice teacher talked to the researcher about how well he could understand when he read about concepts from textbooks. In addition, several preservice teachers, who were observed at Maple Elementary School, specifically highlighted that reading teacher textbooks was an effective way for them to improve their conceptual understanding. 
Although the participants increased their rubric scores from pre to posttest both through learning stations and through readings, the findings show that preservice teachers had slightly higher rubric scores when they learned the earth science concepts through hands-on learning stations than readings from the textbook. A beneficial effect of learning stations only approached significance, suggesting that further research is needed.

The findings of the previous study (Bulunuz \& Jarrett, 2006) on four earth and space science concepts as well as the current study show that it is very difficult to teach an entire concept with just a few activities in a short period of time. In addition, developing the most appropriate models especially about the space science concepts of reasons for seasons and phases of the moon that are complex, abstract and difficult to learn is extremely hard for teachers and instructors. Because the previous model that was used for the pilot study for the concept of phases of the moon did not really improve inservice teachers' understanding, the researcher used two other models for the same concept in this study. This result suggests that further research should use other activities and models that were not used in this study for the concepts that were not understood clearly.

Effect of learning method on concept maps. The finding that preservice teachers have similar concept map scores for concepts they learned through readings and stations suggests that no matter how preservice teachers learned earth science concepts, both methods helped them in drawing concept maps with scientific understanding of these concepts. This is consistent with the findings of the previous analysis. Although the findings did not indicate a significant difference between the group concept map scores of the concepts learned via stations and readings, preservice teachers had slightly higher 
mean scores on the concept maps when they learned these concepts through hands-on learning stations. This is consistent with the analysis of the rubric scores, which found that benefits from learning stations approached significance. Markham, Mintzes, and Jones (1994) consider concept mapping an effective way to assess learning from handson science activities. The researcher agrees with Markham et al. that concept maps can be a powerful assessment tool.

Similar to this study, there is evidence that the mapping technique proved an efficient tool to reveal cognitive structure of college students and to show the development of their knowledge in earth science (Gonzalez, 1997). The researcher agrees with Gonzalez in that the quality of training that instructors give to students about concept mapping techniques plays an essential role for students to learn how to draw a concept map.

Does Concept Mapping Help to Clarify Concepts and is the Effect of Concept Mapping Different for Those Who Experienced the Learning Station Activities Compared to Those

\section{Who Read Text Explanations?}

In the previous analysis, concept map scores were used as a dependent variable to determine the effects of method of instruction. However, concept mapping is used not only as an assessment tool but also as an instructional tool. In answering the above question, the concepts about which groups drew concept maps were compared to the concepts for which they did not draw concept maps. According to Novak and Gowin (1984), learning should be meaningful if students "map" key concepts in network forms revealing hierarchy and relationships. Research shows that one can draw a concept map of almost every science concept (McConnell, Steer, \& Owens, 2003). 
The finding that drawing the concept maps had an additive effect in building student understanding no matter how the concepts originally were learned suggests that drawing concept maps has a positive effect on preservice teachers' conceptual understanding of earth science concepts. This finding is consistent with the previous studies that focused on the effectiveness of concept mapping as a conceptual change strategy about the earth science concepts (e.g. igneous rocks, fossils, precipitation, and silicates) of college students (Ault, 1985; Gonzalez, 1997; and McConnell, Steer, \& Owens, 2003).

The findings of this study suggest that the concept mapping activity had various advantages in developing participants' conceptual understanding on science concepts. Collaboration among group members helps participants to scaffold (Vygotsky, 1978) their knowledge on a particular concept by telling something to each other, asking various questions, and discussing different versions of concept maps they draw. For example, in this study, the participants asked one another about earth science terminology, linking words, and examples that they used in their concept maps. They brainstormed together to come up with the most complete concept maps in their groups. Because of these advantages, the concept mapping activity seems to be an appropriate instructional method for young children (Fellows, 1993) as well as for adults. How do the Preservice Teachers Apply Conceptual Change Strategies in Their Field Assignment on Conceptual Change?

The qualitative analysis of the preservice teachers' reflections and the researcher's field notes shows that overall, the preservice teachers successfully implemented hands-on learning stations in their field placements as part of the class requirement. The in-depth 
analyses of two preservice teachers' field assignments and the summary of six other preservice teachers' personal reflections gave a portrait of how they applied hands-on activities at learning stations to change their students' alternative conceptions and improve their initial understanding.

Four critical factors emerged from preservice teachers' statements in their personal reflections that might have affected their overall performance in this field assignment. One of the factors is the degree of support provided by classroom teachers. Amy (highest score) highlighted in her feedback that she was appreciated for her classroom teacher's support during the implementation of the stations in the classroom.

The second factor is the amount of time needed to plan, prepare, and implement the stations. In addition to Amy's strong background knowledge and the preparation she put into the assignment, having had extra time can be considered as another positive contributor to her performance. On the other hand, George (lowest score), encountered classroom impediments such as problematic students and time restriction that could have negatively affected his general performance. In the case of David, the researcher field notes and David's own personal reflections show that he had such serious time restrictions that his students did not even finish rotating through the stations in time. This finding of the study is consistent with the study by Hanuscin, (2003) who found that preservice teachers were hampered by time restriction during the hands-on learning stations implementation.

The third factor is the amount of time needed to implement and analyze the KWL charts. The point that the KWL charts should have been used with students prior to implementation of the stations was apparently not clear to most of the participants. 
Therefore, these preservice teachers tried to learn about their students' initial understanding on the same day as the stations. That did not give them a chance to learn students' preconceptions and design appropriate activities to change incomplete or incorrect understanding. In addition, in spite of the fact that all preservice teachers had some kind of a data on their students' pre and final understanding, they did not really understand how to analyze these data in a systematic way. The researcher does not think that they compared each student's pre and post answers in the KWL charts at the end of the implementation. This would have given them a scientific idea about the effectiveness of their stations on students' conceptual understanding.

The last factor is the level of understanding of conceptual change terminology. It is important to point out that these preservice teachers did not appear to have learned the terminology of conceptual change prior to their science method course. Although the researcher gave instruction about these concepts in one class period and reminded the class of her expectations several times throughout the semester, several key points did not seem to be clear for some of the participants. For example, Hanna used the term "incomplete misconception" instead of "incomplete understanding" in her reflection about her student's initial understanding.

In addition to these factors' influence on the preservice teachers' performance, the personal reflections and researcher field notes indicated yet more issues that merit further discussion. Following are the important points that either were not clear to the participants, or they were not allowed to implement in their field assignment.

For the conceptual change activity, the preservice teachers selected different science concepts. Some of these concepts were very clearly appropriate choices such as: 
Amy: Why do some objects float and others sink? Kayla: Can air take up space?; David: Does air has mass?; and Sandy and Suzanne: What is the food chain? However, Hanna and Candice, who were two of the preservice teachers observed at Maple Elementary School, chose topics as conceptual change topics that were not quite appropriate to be investigated. Although Hanna stated that her activity Let's make play dough! was investigated under the concept of states of matter, the questions she asked to learn students' preconceptions were not clear according to the purpose of the assignment. And, making play dough was a less clear example of "states of matter" than water experiments with freezing and evaporation would have been. Similarly, Candice chose the activity, How soda / coke is made as her conceptual change station. The concepts discussed in class involved understandings of physical phenomena. If Candice had focused on the dissolving of gas in water (making carbonated water), she could have better assessed children's understanding of this phenomenon.

In their personal reflections, preservice teachers showed that they valued the importance of changing incorrect understandings of their students. They stated that they wished they could have had more time for planning, preparing themselves on their stations, implementing other conceptual change strategies and having more chance to talk to their classroom teachers about their students' general ideas about the concepts. The researcher believes that these anecdotal findings from the field assignments are very promising in terms of both the introspective awakenings of the preservice teachers who implemented the assignments in their field placements and for their future students. In summary, these findings suggest that the preservice teachers gained enough additional 
insight from the learning station field assignments to significantly improve students' initial understandings, given future teaching opportunities.

\section{Implications for Teacher Preparation}

This study provides important suggestions for development of teacher candidates in science education. Because the findings of this research show very low initial understanding and a variety of alternative conceptions of preservice teachers regarding earth science concepts, different conceptual change strategies are important for inclusion in science curricula of teacher preparation programs. In order for science methods course instructors to implement conceptual change strategies; first, they need to be knowledgeable about these strategies. Professors, who have expertise in this area, may conduct workshops about implementing various strategies to develop preservice teachers' understanding and change their nonscientific ideas in science.

In the current undergraduate program in which the participants were registered, only two science courses with labs were required for the preservice teachers. It may be helpful that undergraduate students who will be teachers should be required to take more than two science courses in their teacher preparation programs. Two additional courses have recently been mandated at this university.

Science method course instructors need to explore why preservice teachers have a particular understanding of earth science concepts and where that understanding comes from. This approach can provide a basis for challenging alternative conceptions and supporting preservice teachers' conceptual understanding. This process should be seen as part of the continuing professional development of preservice, as well as inservice teachers. Course instructors can alter alternative conceptions by using a range of 
strategies: for example, developing preservice teachers' questioning skills, or asking more open-ended questions (Dove, 1999).

In addition, the idea of "teaching for conceptual change" (Marion, Hewson, Tabachnick, \& Blomker, 1999) in science methods courses should be enhanced in teacher preparation programs. Like the elementary science conceptual change methods courses that were offered by the researchers above, similar science methods courses may be helpful in teaching conceptual change theories, strategies, and methodologies to teacher candidates. If conceptual change pedagogy is included in the preservice teacher science education curriculum, teacher candidates may be more likely to use conceptual change strategies with their own students (Stofflett \& Stefanon, 1996).

This research study shows that preservice teachers' scores were slightly, though not significantly, higher for the concepts they learned through stations than the concepts they learned through readings. Hands-on stations may have marginal benefits for teacher understanding. The findings of the study show that adults can understand the concepts through directly reading from the textbooks. However, hands-on stations model learning in a way that is appropriate for children. According to constructivist theory (Piaget, 1970), young children best build their conceptual understandings through interaction with their environment. Therefore, preservice teachers need to learn how to teach concepts to young children in a hands-on way. Science method course instructors should model (Bandura, 1974) the use of different science manipulatives and materials in hands-on activities. If student teachers learn science in a hands-on way, they may practice the similar approaches in their classrooms. Science instructors must teach concepts with concrete examples and provide additional activities that assist preservice teachers in 
developing an understanding of difficult ideas (McConnell, Steer, Owens, and Knight, 2005) through methods they can apply in the classroom.

\section{Implications for Staff Development}

Unfortunately, teachers do not necessarily learn difficult concepts while teaching. Therefore, extra support is needed for inservice teachers to either learn these concepts in a scientific way or change their incorrect ideas. Workshops, science camps, field trips, and practical demonstrations about abstract concepts may be effective for inservice teachers to improve their conceptual understandings. These staff development activities can not only help improve teachers' content knowledge about particular science concepts, but also can help their professional development. Teachers can also gain positive skills, attitudes, and effective strategies from these training activities that might be useful for their science teaching to students.

This study covered only six earth and space science concepts, just a few of the concepts teachers need to understand. Researchers, educators, and administrators need to teach teachers to be aware of what they do not know and how to teach correct concepts to themselves. Concept mapping could be taught to teachers as a way to make connections between concepts. In concept mapping, teachers can become more aware of the gaps in their knowledge and what they need to learn before teaching. While teachers should be encouraged to use ready resources (that have been pre-checked for validity) in class, such as Internet, teacher handbooks, and hands-on activity books, to teach students, the teachers must be strongly encouraged to teach themselves from reliable, complete resources and to not rely on expedient solutions that might present incorrect concepts. 
Teachers should be encouraged to try out hands-on activities that are appropriate for children and may build their own understanding as well.

The findings of the field assignments in this study suggest that more research is needed on how children best learn concepts. Teachers could conduct action research in this area to learn their students' preconceptions on certain science concepts, implement conceptual change strategies, and test students' knowledge at the end to make sure whether or not instructional methods they practiced were effective. These action research projects can give teachers a clear idea about what their students already know about certain concepts, and how they develop their knowledge after instruction.

\section{Implications of Field Assignment}

Field experiences involving teaching science to children allow preservice teachers to practice what they have learned in their methods class. The findings suggest the guidelines for developing a conceptual change station at the preservice level that can be readily implemented at the inservice level. Beginning teachers who have experienced a field assignment such as the one in the study will have had experience learning how to select an appropriate science concept, assessing student understanding, planning, and managing relevant conceptual change strategies in classrooms. They would likely have a better understanding about which hands-on activity would be the most effective for improving children's understands according to grade level. In addition, the field assignment might give an idea about resistant science misconceptions among students such as "heavy objects sink, light objects float" (Amy).

Classroom teachers who currently teach science through hands-on learning might get an idea about how these approaches can develop students' understanding about a 
particular science concept. They can implement similar science activities according to the grade level they teach. They can challenge alternative conceptions by developing students' skills in various fields, such as using questions during field work and practical demonstrations (Dove, 1999). If inservice teachers would like to implement similar hands-on learning stations in their classrooms to change their students' alternative conceptions, both their students and teachers are likely to benefit from the information teachers can gather on their students' alternative conceptions. For example, a ten-minute activity exploring their students' initial understanding at the beginning of a lesson may reveal ideas, which they had not considered before. Based on students' initial understanding, teachers may re-examine their own understanding and try to improve it. This may give them a chance to present their lesson in a different way next time. With all these activities, teachers may discover that they hold some of the alternative conceptions similar to conceptions of students. As a result, these activities contribute to professional development of teachers.

The field assignment provides a model for science methods course instructors who plan to assign similar course requirements for their preservice teachers. In conclusion, the findings of the two cases and summary of the six preservice teachers' reflections give instructors and researchers a general idea about how preservice teachers can practice the knowledge that they gain in their science methods courses in real classroom situations.

If preservice teachers are required to implement field assignments in their school placements, collaboration between science methods course instructors, cooperating teachers, and preservice teachers might be very helpful to create a common vision of 
what experience preservice teachers should have with students. Science methods course instructors could write letters to classroom mentor teachers with detailed descriptions of the field assignments and specific expectations for preservice teacher accomplishment. This would construct a triangle between the university instructor, the teacher, and the preservice teacher. In this way, classroom teachers' support to preservice teachers might be increased to in terms of giving more time to plan, setting up materials, and implementing stations in classrooms. In addition, if classroom teachers know the details about a preservice teacher's assignment, they could give more time to applying KWL charts to students, getting students' initial understandings, and analyzing students' understandings after they filled out the "L" column of the KWL charts. Universities and schools can both create an experience that will contribute to the development of conceptual understanding of preservice teachers (Marion et al., 1999).

Finally, field experience in science is an important element in preparing preservice elementary teachers for the challenges of teaching science at the elementary level. Early field experiences, like the field assignment that the participants experienced in this study, should provide preservice teachers with meaningful and relevant opportunities to experience success in teaching science to children. The hands-on learning station approach is just one example of a successful strategy that allows preservice teachers to develop their instructional skills in a classroom setting. It can also provide a chance to practice content presented in science methods courses.

\section{Strengths and Weaknesses of the Study}

In the following section, strengths and weaknesses of quantitative part of the study, the qualitative part of the study, and the mixed-methods design will be discussed. 
Quantitative part. The research with the inservice teachers about reasons for seasons, phases of the moon, rock cycle, and causes of earthquakes had been piloted the previous year (Bulunuz \& Jarrett, 2006). The researchers found high reliability on three of the concepts. The inter-rater reliability coefficients of the two new concepts that had not been piloted and the concept that had low reliability coefficient were recalculated in this study and the researcher found high reliability coefficients.

Mean difficulty levels of the concepts to be learned by stations and by readings between the two undergraduate cohorts were equalized at the beginning of the study according to the previous data collected from another preservice cohort. This gave each group a mixture of easier and more difficult concepts to be learned under each method (readings versus learning stations). Another strength is that a counterbalanced design was used so that preservice teachers in the two sections of the course had a chance to learn three concepts through readings and three concepts through hands-on learning stations.

The science textbook that was selected for the reading assignments was clear and comprehensive and did not bias the study against the reading condition. It was chosen because it appeared to be clear and because it covered all six earth and space science concepts with enough scientific information. Not all science textbooks covered all six concepts that were the focus of this study. Also, the researcher chose more than one activity per concept for the learning stations, giving a better chance for the preservice teachers to understand difficult earth science concepts. Two new models of phases of the moon were designed by the dissertation chair and one of the faculty members in science 
education, because the previous model used in the pilot study did not help preservice teachers improve their conceptual understanding.

Because the researcher taught the idea of conceptual change and implemented the instructional methods in both cohorts, this study is strong on internal validity. A strength is that three different instructional methods were used in the study. Two consecutive posttests were helpful in keeping track of the participants' development of conceptual understanding. Group concept map scores were first used as a dependent variable, then as an independent variable, giving the researcher the opportunity to determine the effectiveness of concept mapping as an assessment tool and as an instructional strategy.

There were some limitations of the quantitative section of this study. All three interventions were implemented with the preservice teachers only once. The researcher gave the participants enough time to complete each activity and discuss the activities with their partners; however, the participants had a chance to rotate through the stations only once. So, the total time may not have been enough for some of the participants to reflect on what they learned and return to activities they did not understand.

The same survey was implemented with the participants three times. Because the time period between two administrations was short, some of the students might have remembered and simply repeated their prior answers. It was possible that each of the first two survey administrations worked as interventions themselves and affected the results of the following administrations. Therefore, "testing" (Campbell \& Stanley, 1963) was considered as a threat to the validity of this study.

Two or three activities were chosen per earth science concept in this study. There were many activities in different science activity books related to the same concepts that 
were not selected for the stations. Those activities might have been more helpful for preservice teachers to develop their conceptual understanding and overcome their incorrect understanding.

Another limitation might be related to the accuracy of concept map scores. As concept maps become more complex and the number of links, cross links, and levels increase, the ability to read the hand drawn maps become more difficult (Meagher, 2006). The difficulty resulted from the differences in hand writing quality, space restriction on the manila folders where they drew their maps, and length of link lines separating node topics. The researcher had to re-score some of the concept maps because of the irregular handwriting, unclear hierarchical levels, and crowded appearance of the concept maps. Also, scoring complexity might have affected final score of the groups.

The researcher was the instructor of the science method course where the study was conducted and assisted in instructing the other undergraduate cohort. Researcher involvement might limit generalizability. In addition, this study focused on only six earth science concepts. There are many other concepts in biology, chemistry, and physical sciences about which preservice and inservice teachers might have various range of conceptual understanding. One cannot generalize the findings of this study to the other concepts.

Qualitative part. The strength of the qualitative part of the study is that it provided a window into how preservice teachers practice the knowledge they learn in their science methods course in real classroom environments with students. In addition to reading the preservice teachers' personal reflections, the researcher observed six preservice teachers during their implementation of the stations and gained insights into 
how the assignment was understood and applied with children. The researcher's field observation provided a confirmation of students' perceptions about whether or not they successfully implemented the stations, they managed the students between stations smoothly, their classroom teachers were supportive, their students had behavior problems during the rotation through the stations, they improved their students' understandings, and their other challenges during the implementation.

In addition, the researcher's field notes were very useful for comparing the preservice teachers' personal reflections in the field assignment with the actual situation. The researcher's personal observations and field notes were effective aids for modifying field assignments for future use, such as writing a letter to classroom teachers to give more detailed information about the field assignment, giving additional research articles to an individual preservice teacher or in the class, and highlighting the important points of field assignments before preservice teachers started to implement the stations.

Since the field assignment was the course requirement, the preservice teachers in the researcher's science class took this assignment very seriously. Most of them put great effort into setting up the stations and implemented them in a professional way. Additionally, six preservice teachers who were observed were well prepared for the researcher, and they were comfortable while the researcher was observing them in their classrooms. It is not known what effect there might have been on the quality of the field assignments that the participants were receiving a grade and that they were being observed. 
Mixed-methods design. This investigation used a mixed-methods research design that enabled the researcher to ascertain preservice teachers' knowledge about conceptual understanding, effective methods of facilitating conceptual change, and application of conceptual change strategies with children. The quantitative and qualitative portions were additive in this study.

The contribution of the current study is unique because of the complementary nature of mixed-methods design. Through quantitative and qualitative portions of the research, the researcher had a chance to see the effectiveness of strategies in preparing teachers and the application of the knowledge that preservice teachers transferred from the science methods courses into their school placements. With only the quantitative part of the study, she would not have had an opportunity to see whether or not participants applied their knowledge in the classrooms with students. Likewise, with only the qualitative part of the study, she could not have learned what preservice teachers already knew about six earth and space science concepts and how the preservice teachers learned these concepts in an effective way.

In this study the first four research questions were analyzed quantitatively and the last research question was analyzed qualitatively. A weakness as a mixed methods study is that the quantitative and qualitative parts answered separate research questions. In future research, qualitative data could be collected to figure out how preservice teachers learn earth science concepts better or which conceptual change strategy works better to change their initial understanding. For example, interviews could be conducted with the participants to learn their knowledge about the earth and space science concepts as well as the effectiveness of different instructional methods that were used. Similarly, 
quantitative data could be collected on how preservice teacher apply their knowledge in their classroom with the students, i.e., field assignments and the field notes could be analyzed in a quantitative way. In this way, there would actually be a chance to triangulate both quantitative and qualitative data for each research question.

\section{Future Research}

The field of conceptual change of preservice and inservice teachers' understanding needs further research in many areas. There are other earth and space science concepts that they were not the focus of this study. Because there is a tendency to focus mostly on physical science concepts in this field, future researchers might conduct research on more earth and space science concepts to learn teachers' level of understanding on these concepts.

Researchers agree that only one strategy might not be enough to develop deep changes in both preservice and inservice teachers' conceptual understanding (Sungur, Tekkaya, \& Geban, 2001). Therefore, more studies that test the effectiveness of multiple conceptual change strategies on teachers' understanding might be effective. This study did not look at the long term effects of instructional methods on teachers' understanding. Longitudinal studies are needed to measure the level of preservice teachers' understanding as they transition to classroom teaching.

Another important area of inquiry could be to study specially designed courses similar to "elementary science conceptual change methods courses" designed by Marion, Hewson, Tabachnick, and Blomker in 1999. The researchers might conduct more research on the conceptual understanding of preservice teachers who learn conceptual change theories, strategies and methodologies in these elementary science conceptual 
change methods courses, as well as implementation of conceptual change strategies in field experiences.

A further goal of researchers would be not only determining what preservice teachers already know about certain science concepts, but also investigating their ability to teach these concepts to students in their field placements. While only six preservice teachers were observed in this study, much insight was gained about the application of conceptual change in authentic settings. Studying more preservice teachers would likely yield a broader idea about their ability to teach science concepts effectively in their classrooms.

In this research, Novak and Gowin's (1984) scoring system was used because it is generally accepted as the most common scoring method (Van Zele, Lenaertz, \& Wierne, 2004). However, there are many methods of scoring and identifying the complexity of concept maps left unstudied, e.g., holistic and relational scoring methods (McClure, Sonak, \& Suen, 1999). As these researchers recommended, future research might use other concept mapping scoring methods to get more practical and reliable results instead of Novak and Gowin's scoring method.

Pre instructional concept maps were not employed in this study. After the participants learned the concepts through learning stations and readings, their post instructional concept maps were analyzed. One could look at the differences between participants' pre and post instructional concept maps after certain interventional techniques, using pre and post concept maps to assess the effectiveness of these interventions. 
The number of inservice teachers was very limited in this study compared to the number of preservice teachers because of the current enrollment of students in the separate programs. Future researchers could increase the sample size of inservice teachers and build in years of teaching and grade level taught as independent variables. Also, for inservice teachers, effectiveness of different training strategies such as: workshops, field trips, science museum visits, and directly reading concepts from textbooks could be investigated to see which strategy or combination is most helpful for teachers to develop their knowledge on particular concepts, their attitudes toward teaching these concepts, and their skills in developing appropriate activities to teach these concepts. Although the rubrics for the six earth science concepts were clear and descriptive, scoring of openended questions according to rubrics might not be practical if the sample size is bigger. Therefore, multiple-choice questions might be more practical to evaluate the scores of higher number of participants.

In this study, the participants were required to implement their field assignments in only one classroom placement. However, the same assignment could be required for implementation in both placements throughout the semester to see whether there is a grade level difference in terms of preservice teachers' performance on implementing learning stations.

\section{Conclusions}

The results of this research show that both preservice and inservice teachers have low conceptual understanding of six earth and space science concepts taught in elementary school. Science methods course instructors and researchers may be able to implement different conceptual change strategies either to build new concepts or to 
change incorrect understandings to scientific ones. If university science instructors can be good models for preservice teachers in terms of implementing effective conceptual change strategies with a hands-on approach, preservice teachers can also put similar strategies or ideas into practice with students when they become classroom teachers.

Readings and hands-on learning stations are both successful in building preservice teacher's understanding, through the additional benefits of hands-on experiences approached significance. More time on clearer activities or better-designed models for the difficult space science concepts could make hands-on approach more clearly beneficial.

The concept mapping activity added to the preservice teachers' conceptual understanding, whether the participants originally learned the concepts through readings or through learning stations. Collaborative work of the groups helped the participants exchange their ideas, ask different questions, and discuss the important points during the concept mapping activity. In this study concept mapping was used both as an assessment and an instructional tool.

A field assignment allowed participants to apply the knowledge they learned in the science methods course in their classroom placements. This field assignment gave the researcher (science methods course instructor) a chance to see the effectiveness of the knowledge the preservice teachers gain. Analyses of the field assignments of two illustrative cases presented a portrait of how two very different preservice teachers implemented their conceptual change learning stations with their students. The summary of the qualitative analysis of six preservice teachers' reflections on their conceptual change stations revealed the common answers given to guided reflection questions. In addition, the researcher's field notes about the participants that were observed in the same 
school were helpful in supporting personal reflections on field assignments. The researcher's personal observations and field notes in the classrooms were beneficial for seeing the strengths and the challenges of implementing learning stations with students. This gives the researcher ideas for revising field assignment instructions and modifying the expectations of preservice teachers in future work.

This research contributes to knowledge of weaknesses in conceptual understanding of both preservice and inservice teachers and tests several methods that can be used in science methods courses to increase conceptual understanding. The addition of a qualitative analysis of implementation in the classroom provides insights in how an assignment can be useful in clarifying understanding of how to teach for conceptual change. 


\section{References}

Abell, S., Martini, M., \& George, M. (2001). "That's what scientists have to do": Preservice elementary teachers' conceptions of the nature of science during a moon investigation. International Journal of Science Education, 23(1), 10951109.

American Association for the Advancement of Science (1993). Benchmarks for Science Literacy: Project 2061. New York: Oxford University Press.

Alexopoulou, E., \& Driver, R. (1996). Small-group discussion in physics: peer interaction modes in pairs and fours. Journal of Research in Science Teaching, 33(10), 1099-1114.

Aron, R.H., Francek, M.A., Nelson, B.D., \& Bisard, W.J. (1994). Atmospheric misconceptions. The Science Teacher, 61(1), 31-33.

Atwood, R.K., \& Atwood, V.A. (1996). Preservice elementary teachers' conceptions of the causes of seasons. Journal of Research in Science Teaching, 33, 553-563.

Ault, J. C. (1984). The everyday perspective and exceedingly unobvious meaning. Journal of Geological Education, 32, 89-91.

Ault, C.R. (1985). Concept mapping as a study strategy in earth science. Journal of College Science Teaching, 15(1), 38-44.

Ausubel, D.P. (1962). A subsumption theory of meaningful verbal learning and retention. Journal of General Psychology, 66, 213-224. 
Baldwin, A.L. (1967). Piaget's theory of the developmental process, Theories of Child Development, New York: John Wiley \& Sons, Inc.

Bandura, A. (1974). Behavior theory and the models of man. American Psychologist, December, 859-866

Benacchio, L. (2001). The importance of the moon in teaching astronomy at the primary school. Earth, Moon, and Planets, 85(86), 51-60.

Bereki, D. (2000, Winter). Teaching the rock cycle with ease. The CSTA Journal, 32-34.

Berger, K.S., \& Thompson, R.A. (1996). The Developing Person Through Childhood, New York: Worth Publishers, Inc.

Bisard, W.J., Aron, R. H., Francek, M. A., \& Neslon, B.D. (1994). Assessing selected physical science and earth science misconceptions of middle school through university-preservice teachers. Journal of College Science Teaching, 24, 38-42.

Blake, A. (2001). Developing young children's understanding: An example from earth science. Evaluation and Research in Education, 15(3), 154-163.

Blake, A. (2004). Helping young children to see what is relevant and why: supporting cognitive change in earth science using analogy. International Journal of Science Education, 26 (15), 1855-1873.

Bulunuz, N., Jarrett, O., \& Bulunuz, M. (2005, April). Fifth-grade Turkish elementary school students' conceptions and misconceptions about the fungus kingdom. Paper presented at the annual conference of the National Association for Research in Science Teaching, Dallas, Texas. 
Bulunuz, M., Jarrett, O. S., Bulunuz, N. (2005, April). Undergraduate and masters students' content knowledge about physical properties of air: Do demonstrations and hands-on activities bring about change? Paper presented at the annual meeting of the National Association for Research in Science Teaching, Dallas, TX.

Bulunuz, N., \& Jarrett, O. (2006, February). Basic earth and space science concepts: Building elementary teacher understanding. Paper presented at the annual conference of the Georgia Science Teachers Association, Columbus, Georgia.

Cakir, M., \& Crawford, B. (2001, January). Prospective biology teachers' understanding of genetics concepts. Paper presented at the annual meeting of the Association for the Education of Teachers in Science, Costa Mesa, CA.

Cakir, O.S., Uzuntiryaki, E., \& Geban, O. (2002, April). Contribution of conceptual change texts and concept mapping to students' understanding of acids and bases. Paper presented at the annual meeting of the National Association for Research in Science Teaching, New Orleans, LA.

Callison, P.L., \& Wright, E.L. (1993, April). The effect of teaching strategies using models on preservice elementary teachers' conceptions about earth-sun-moon relationships. Paper presented at annual meeting of the National Association for Research in Science Teaching, Atlanta, Georgia.

Carey, S. (2000). Science education as conceptual change. Journal of Applied Developmental Psychology, 21(1), 13-19. 
Carlsen, D.D., \& Andre, T. (1992).Use of a microcomputer simulation and conceptual hange text to overcome student preconceptions about electric circuits. Journal of Computer-Based Instruction, 19(4), 105-109.

Cetin, G. (2003). The effect of conceptual change instruction on understanding of ecology concepts. Unpublished Doctoral Dissertation, Middle East Technical University, Ankara, Turkey.

Chambers, S. K., \& Andre T. (1997).Gender, prior knowledge, interest, and experience in electricity and conceptual change text manipulations in learning about direct current. Journal of Research in Science Teaching, 34, 107-123.

Chi, M.T.H., Slotta, J.D., \& de Leeuw, N. (1994). From things to processes: A theory of conceptual change for learning science concepts. Learning and Instruction, 4, 27 43.

Clement, J.J., \& Steinberg, M. S. (2002). Step-wise evolution of mental models of electric circuits: A "learning-aloud" case study. Journal of the Learning Sciences, 11(4), 1050-1096.

Colburn, A., \& Henriques, L. (2000). Reaching the reluctant science teacher. Science and Children, 37(8), 46-49.

Costa, M.F. (2003). Hands-on Science. European Commission under the Socrates Project, Retrieved from, http://www.isoc.siu.no/isocii.nsf/projectlist/110157.

Crawford, B.A. (2000). Embracing the essence of inquiry: New roles for science teachers. Journal of Research in Science Teaching, 37 (9), 916-937.

Dahl, J., Anderson, S.W., \& Libarkin, J. (2005). Digging into earth science: Alternative conceptions held by K-12 teachers. Journal of Science Education, 6, 65-68. 
Dai, M.F., \& Capie, W. (1990, April). Misconceptions about the moon held by preservice teachers in Taiwan. Paper presented at the annual meeting of the National Association for Research in Science Teaching, Atlanta, GA.

Dalton, B., \& Morocco, C.C. (1997). Supported inquiry science: Teaching for conceptual change in urban and suburban science classrooms, Journal of Learning Disabilities, 30 (6), 670-684.

Diakidoy, I.N., Kendeou, P., \& Ioannides, C. (2003). Reading about energy: The effects of text structure in science learning and conceptual change. Contemporary Educational Psychology, 28(3), 335-356.

Dove, J. (1996). Student identification of rock types. Journal of Geoscience Education, 44, 266-269.

Dove, J. (1998). Alternative conceptions about the weather. School Science Review, 79(289), 65-69.

Dove, J. (1999). Physical Geography. In M. Biddulph \& G. Butt (Eds.), Theory into practice: Immaculate misconceptions (pp. 15-20). Hong Kong: The Geographical Association.

Driver, R., Guesne, E., \& Tiberghien, A. (1985). Children's ideas in science, Open University Press: Philadelphia.

Driver, R., Leach, J., Miller, R., \& Scott, P. (1996). Young people’s images of science. Philadelphia, PA: Open University Press.

Duit, R. (1994). Research on students' conceptions-developments and trends. In H. Pfundt, \& R. Duit (Eds.), Bibliography: Students' alternative frameworks and science education (pp. xxii-xlii). Kiel, Germany: University of Kiel. 
Duit, R., \& Treagust, D.F. (2003). Conceptual change: A powerful framework for improving science teaching and learning. International Journal of Science Education, 25(6), 671-688.

Ebert, J.R., \& Elliot, N.A. (2002). Mr. Chalkentalk's cupboard- practical lessons for preservice teachers in rock and mineral identification and the management of teaching collections. Journal of Geoscience Education, 50(2), 182-185.

Else, M.J., Ramirez, M.A., \& Clement, J. (2002, January). When are analogies the right tool? A look at the strategic use of analogies in teaching cellular respiration to middle-school students. Paper presented at the annual meeting of the International Conference of the Association for the Education of Teachers in Science, Charlotte, NC.

Ertepinar, H., \& Geban,O. (1996). Effect of instruction supplied with the investigativeoriented laboratory approach on achievement in a science course. Educational Research, 38(3), 333-341.

Eswaran, H., Kupelian, T., Levermann, T., \& Yost, D. (1990). The science of soil. The Science Teacher, 57(5), 50-53.

Fellows, N. (1993, April). Mapping conceptual change in matter and molecules. Paper presented at the Annual Meeting of the American Educational Research Association, Atlanta, GA.

Ford, D. (2003). Sixth graders' conceptions of rocks in their local environments. Journal of Geoscience Education, 51(4), 373-377.

Furlough, V., Taylor, A., \& Watson, S.B. (1997). Hands-in science. Science Scope, 29(7), 16-17. 
Gabel, D. (2003, Winter). Enhancing the conceptual understanding of science. Educational Horizons, 81(2), 70-76.

Gallas, K. (1992, April). Metaphor and analogy in children's science talks. Paper presented at the annual conference of the American Educational Research Association, San Francisco: CA.

Georgia Department of Education. Georgia Performance Standards. Retrieved January 12, 2006 from, http://www.georgiastandards.org/

Gibson, H.L., Bernhard, J., Kropf, A., Ramirez, M.A., \& Van Strat, G. A. (2001, March). Enhancing the science literacy of Preservice teachers through the use of reflective journals. Paper presented at the annual meeting of The National Association for Research in Science Teaching, St. Louis: MO.

Gilbert, J.K., Osborne, R.J., \& Fensham, P.J. (1982).Children's science and its consequences for teaching. Science Education, 66(4), 623-633.

Glynn, S.M. (1991). Explaining science concepts: A teaching-with-Analogies Model. In S.M. Glynn, R.H. Yeany, \& B.K. Britton (Eds.), The Psychology of Learning Science (pp. 219-240). Hillsdale, New Jersey: Lawrence Erlbaum Associates, Publishers.

Gonzalez, F. M. (1997). Evidence of rote learning of science by Spanish university students. School Science \& Mathematics, 97 (8), 419-429.

Gutierrez, M., Coulter, B., \& Goodwin, D.R. (2002). Natural disasters workshop integrating hands-on activities, internet-based data, and GIS. Journal of Geoscience Education, 50(4), 437-443. 
Guzzetti, B.J., Snyder, T.E., Glass, G.V., \& Gamas, W.S. (1993). Promoting conceptual change in science: A comparative meta-analysis of instructional interventions from reading education and science education. Reading Research Quarterly, 28, 117-155.

Guzzetti, B.J. (2000). Learning counter-intuitive science concepts: What have we learned from over a decade of research? Reading and Writing Quarterly, 16, 89-98.

Hanuscin, D. (2003, February). A workshop approach: Instructional strategies for working within the constraints of field experiences in elementary science. Paper presented at the annual meeting of the Association for the Education of Teachers of Science, St. Louis, MO.

Happs, J.C. (1984). Soil genesis and development: views held by New Zealand students. Journal of Geography, 83(4), 177-180.

Happs, J.C. (1985). Regression on learning outcomes: Some examples from the earth sciences. European Journal of Science Education, 7, 431-443.

Haury, D. L., \& Rillero, P. (1994). Perspectives of Hands-On Science Teaching. ERIC Clearinghouse for Science, Mathematics, and Environmental Education, Columbus, $\mathrm{OH}$.

Hawley, D. (2002). Building conceptual understanding in young scientists. Journal of Geoscience Education. 50(4), 363-371.

Henriques, L. (2002). Children's ideas about weather: A review of the literature. School Science and Mathematics, 102(5), 202-215.

Hewson, P.W. (1981). A conceptual change approach to learning science. European Journal of Science Education, 3(4), 383-396. 
Hewson, P.W. (1992, June). Conceptual change in science teaching and teacher education, Paper presented at a meeting of the Research and Curriculum Development in Science Teaching, Madrid, Spain.

Hofstein, A., Navon, O., Kipnis, M., \& Mamlok-Naaman, R. (2005). Developing students' ability to ask more and better questions resulting from inquiry-type chemistry laboratories. Journal of Research in Science Teaching, 42(7), 791-806.

Hutchinson, N. (2002). A matter of opinion; a matter of fact: alternative conceptions in physical geography, Geography Bulletin, Spring, 154-159.

Hynd, C., \& Alvermann, D.E. (1986).The role of refutation text in overcoming difficulty with science concepts. Journal of Reading, 29, 440-446.

Hynd, C., Alvermann, D., \& Qian, G. (1997). Preservice elementary school teachers' conceptual change about projectile motion: Refutation text, demonstration, affective factors, and relevance. Science Education, 81, 1-27.

Hynd, C.R. (2001). Refutational texts and the change process. International Journal of Educational Research, 35, 699-714.

Irwin, L., Nucci, C., \& Beckett, E. C. (2003). Science centers for all: Suggestions on using classroom science centers to engage every learner. Science and Children, 40(5), 35-37.

Iuli, R. J. (2004).Using concept maps as a research tool in science education research. Paper presented at the meeting of the First International Conference on Concept Mapping, Pamplona, Spain.

Jones, I. (1999). A workshop approach: Using learning centers to teach early childhood science. Science and Children, 37(3), 26-31. 
Kelly, J. (2000). Rethinking the elementary science method course: a case for content, pedagogy, and informal science education. International Journal of Science Education, 22(7), 755-777.

Kikas, E. (2003). University students' conceptions of different physical phenomena. Journal of Adult Development, 103, 139- 150.

Kikas, E. (2004). Teachers' conceptions and misconceptions concerning three natural phenomena. Journal of Research in Science Teaching, 41(5), 432-448.

Kim, Y., Germann, P.J., \& Patton, M. (1998, April). Study of concept maps regarding the nature of science by preservice secondary science teachers. Paper presented at the Annual Meeting of the National Science Teachers Association, Las Vegas, NV.

King, C. (2000). The Earth's mantle is solid: Teachers' misconceptions about the earth and plate tectonics. The School Science Review, 82, 57-64.

Kuhn, T.S. (1970). The structure of scientific revolution $\left(2^{\text {nd }}\right.$ ed.). Chicago: University of Chicago Press.

Kusnick, J. (2002). Growing pebbles and conceptual prisms: Understanding the source of student misconceptions about rock formation. Journal of Geoscience Education, $50(1), 31-39$.

Libarkin, J.C., Anderson, S.W., Dahl, J., Beilfuss, M., \& Boone, W. (2005). Qualitative analysis of college students' ideas about the earth: Interviews and open-ended questionnaires. Journal of Geoscience Education, 53(1), 17-26.

Lincoln, Y., \& Guba, E. (1985). Naturalist inquiry. Newbury Park, CA: Sage. 
Marinopoulos, D., \& Stavridou, H. (2002). The influence of a collaborative learning environment on primary students' conceptions about acid rain. Educational Research, 37(1), 18-24.

Marion, R., Hewson, P.W., Tabachnick, R., \& Blomker, K.B. (1999). Teaching for conceptual change in elementary and secondary science methods courses. Science Education, 83, 275-307.

Marques, L., \& Thompson, D. (1997). Misconceptions and conceptual changes concerning continental drift and plate tectonics among Portuguese students aged 16-17. Research in Science and Technological Education, 15 (2), 195-222.

Markham, K.M., Mintzes, J.J., \& Jones, M.G. (1994). The concept map as a research and evaluation tool: Further evidence of validity. Journal of Research in Science Teaching, 31(1), 91-101.

McConnell, D.A., Steer, D.N., \& Owens, K.D. (2003). Assessment and active learning strategies for introductory geology courses. Journal of Geoscience Education, 51(2), 205-216.

McClure, J.R., Sonak, B., \& Suen, H.K. (1999). Concept map of assessment of classroom learning: reliability, validity, and logistical practicality. Journal of Research in Science Teaching, 36, 475-492.

Meagher, T. (2006, April). Analysis of changes in student concept maps from a college introductory environmental biology class, Paper presented at the annual meeting of the National Association for Research in Science Teaching, San Francisco.

Mellado, V. (1998). The classroom practice of preservice teachers and their conceptions of teaching and learning science. Science Education, 82, 197-214. 
Meyer, H., Tabachnick, B.R., Hewson, P.W., Lemberger, J., \& Park, H. (1999). Relationships between prospective elementary teachers' classroom practice and their conceptions of biology and of teaching science. Science Education, 83, 323346.

Mikkila-Erdmann, M. (2001). Improving conceptual change concerning photosynthesis through text design. Learning and Instruction, 11, 241-257.

Mooney, C.G. (2000). Theories of Childhood: An introduction to Dewey, Montessori, Erikson, Piaget, \& Vygotsky, New Jersey: Red leaf Press: Pearson Merrill Prentice Hall.

Moore, R. (2003). Reexamining the field experiences of preservice teachers. Journal of Teacher Education, 54(1), 31-42.

Muthukrishna, N., Carnine, D., Grossen, B., \& Miller, S. (1993). Children's alternative frameworks: Should they be directly addressed in science instruction? Journal of Research in Science Teaching, 30, 233-248.

National Research Council (NRC). (1996). National Science Education Standards. Washington, DC: National Academy Press.

Nelson, B.D., Aron, R.H., \& Francek, M.A. (1992). Clarification of selected isconceptions in physical geography. Journal of Geography, 91, 76-80.

Newton, D.P., \& Newton, L.D. (1995).Using analogy to help young children understand. Educational Studies, 21(3), 379-394.

Niaz, M. (2002). Facilitating conceptual change in students' understanding of electrochemistry. International Journal of Science Education, 24(4), 425-439. 
Novak, J.D., \& Gowin, D.B. (1984). Learning How to Learn (1st ed.). New York: Cambridge University Press.

Novak, J.D. (1998). Learning, Creating, and Using Knowledge, Concept Maps as Facilitative Tools in Schools and Corporations (1st ed.). Mahvah, NJ: Lawrence Erlbaum Associates.

Palmer, D.H. (2001). Factors contributing to attitude exchange amongst preservice elementary teachers. Science Education, 86, 122-138.

Palmer, D.H. (2003). Investigating the relationship between refutational text and conceptual change. Science Education, 87, 663-684.

Papadimitriou, V., \& Londridou, P. (2001). A cross-age study of pupils' conceptions concerning the movement of air masses in the troposphere, Educational Resources Information Center (ERIC) Document number: ED 466368.

Parker, J., \& Heywood, D. (1998). The earth and beyond: developing primary teachers' understanding of basic astronomical events. International Journal of Science Education, 20(5), 503-520.

Parker, J., \& Heywood, D. (2000). Exploring the relationships between subject knowledge and pedagogic content knowledge in primary teachers' learning about forces. International Journal of Science Education, 22 (1), 89-111.

Piaget, J. (1929). The child's conception on the world. London: Routledge and Kegan Paul.

Piaget, J. (1964, March). Development and learning. In R.E. Ripple \& V.N. Rockcastle (Eds.), Piaget rediscovered, a report on the Conference on Cognitive Structures and Curriculum Development. 
Piaget, J. (1951). The child's conception of the world (2 ${ }^{\text {nd }}$ ed.). Rowman \& Littlefield Publishers: Maryland.

Piaget, J. (1970). Piaget's theory, Manual of Child Psychology, In P.H. Mussen (Ed.) Third Edition, Vol. 1, New York: John Wiley \& Sons, Inc.

Pintrich, P.R., Marx, R.W., \& Boyle, R.A. (1993). Beyond cold conceptual change: The role of motivational beliefs and classroom contextual factors in the process of conceptual change. Review of Educational Research, 63, 167-200.

Plourde, L.A. \& Klemm, E.B. (2004). Sounds and sense-abilities: Science for all. College Student Journal, 38(4), 653-660.

Posner, G. J., Strike, G.A., Hewson, P.W., \& Gertzog, W.A. (1982). Accommodation of a scientific conception: Toward a theory of conceptual change. Science Education, $66,211-227$.

Pyle, E. J., \& Akins-Moffatt, J. (1999). The effects of visually-enhanced instructional environments on students' conceptual growth. East Lansing, MI: National Center for Research on Teacher Learning, ERIC Document Reproduction Service No. ED EJ651157.

Radeloff, D. J. (2001). Science discovery centers: Stimulating young children's minds. $A$ Quarterly Newsletter for the Education Community, 13(3), 1-3.

Rice, D.C. (2005). I didn't know oxygen could boil! What preservice and inservice elementary teachers" answers to "simple" science questions reveals about their subject matter knowledge. International Journal of Science education, 27(9), 1059-1082. 
Rider, S. (2002). Perceptions about moon phases. Science Scope, 26(3), 48-51.

Ross, K.E., \& Shuell, T.J. (1990, October). The earthquake information test: Validating an instrument for determining student misconceptions, Paper presented at the annual meeting of the Northeastern Educational Research Association, Ellenville, NY.

Ross, K.E., \& Shuell, T.J. (1993). Children's beliefs about earthquakes, Science Education, 772, 191-205.

Ruiz-Primo, M.A., \& Shavelson, R.J. (1996). Problems and issues in the use of concept maps in science assessment. Journal of Research in Science Teaching, 33, 569600.

Schoon, K.J. (1992). Students' alternative conceptions of earth and space. Journal of Geological Education, 40, 209-214.

Scott, P.H., Asoko, H.M., \& Driver, R.H. (1991, March). Teaching for conceptual change: A review of strategies. In R. Duit, F. Goldberg, \& H. Niederer (Eds.), Research in Physics Learning: Theoretical issues and Empirical Studies, Proceedings of an International Workshop, Section 5, IPN 131, ISBN 3-89088$062-2$.

Spiropoulou, D., Kostopoulos, D., \& Jacovides, C. (1999). Greek children's alternative conceptions on weather and climate. The School Science Review, 81(294), 55-59.

Stahly, L. L., Krockover, G. H., \& Shepardson, D. P. (1999). Third grade students' ideas about the lunar phases. Journal of Research in Science Teaching, 36(2), 59-77.

Stepans, J., \& Kuehn, C. (1985). Children conceptions of weather. Science and Children, 23(1), 44-47. 
Stofflett, R.T. (1993). Preservice elementary teachers' knowledge of rocks and their formation. Journal of Geological Education, 41, 226-230.

Stofflett, R.T. (1994). Conceptual change in elementary school teacher candidate knowledge of rock-cycle processes. Journal of Geological Education, 42, 494500.

Stofflett, R.T. (1994). The accommodation of science pedagogical knowledge: The application of conceptual change constructs to teacher education. Journal of Research in Science Teaching, 31(8), 787-810.

Stofflett, R.T., \& Stoddart, T. (1994). The ability to understand and use conceptual change pedagogy as a function of prior content learning experience. Journal of Research in Science Teaching, 31 (1), 31-51.

Stofflett, R.T., \& Stefanon, L. (1996). Elementary teacher candidates' conceptions of successful conceptual change teaching. Journal of Elementary Science Education, $8(2), 1-20$.

Strauss, A. L., \& Corbin, J. (1990). Basics of qualitative research: Grounded theory procedures and techniques. Newbury Park, Ca: Sage.

Strawitz, B.M., \& Malone, M.R. (1984). The influence of field experiences on stages of concern and attitudes of preservice teachers toward science and science teaching. Journal of Research in Science Teaching, 23(4), 311-320.

Strike, K.A., \& Posner, G. J.(1992). A revisionist theory of conceptual change. In R. Duschl, \& R. Hamilton (Eds.), Philosophy of science, cognitive psychology, and educational theory and practice (pp.147-176). Albany: State University of New York Press. 
Sunal, D.W. (1976). A comparison of two pre-professional programs in the department of Early Childhood Elementary Education, ERIC Document No: ED 139624.

Sunal, D.W. (1980). Effect of field experiences during elementary methods courses on preservice teacher behavior. Journal of Research in Science Teaching, 17(1), 1723.

Sungur, S., Tekkaya, C., \& Geban, O. (2001).The contribution of conceptual change texts accompanied by concept mapping to students' understanding of the human circulatory system. School Science \& Mathematics, 101(2), 91- 102.

Tabachnick, B.R., \& Zeichner, K.M. (1999). Idea and action: action research and the development of conceptual change teaching of science. Science Education, 83, 309-322.

Taylor, N., \& Coll, R. (1997).The use of analogy in the teaching of solubility to preservice primary teachers. Australian Science Teachers Journal, 43(4), 58-65.

Tekkaya, C. (2003). Remediating high school students' misconceptions concerning diffusion and osmosis through concept mapping and conceptual change text. Research in Science and Technological Education, 21, 6-16.

Thiele, R.B., \& Treagust, D.F. (1991, July). Using analogies to aid understanding in secondary chemistry education. Paper presented at the Royal Australian Chemical Institute Conference on Chemical Education, Perth, Western Australia.

Thorley, N., R., \& Stofflett, R.T. (1996). Representation of the conceptual change model in science teacher education. Science Education, 80 (3), 317-339.

Trumper, R. (2000). University students' conceptions of basic astronomy concepts. Physics Education, 35(1), 9-14. 
Trumper, R. (2001). A cross-college age study of science and nonscience students' conceptions of basic astronomy concepts in preservice training for high-school teachers. Journal of Science Education and Technology, 10, 189-195.

Trundle, K. C. (1999). Elementary preservice teachers' conceptual understandings of the cause of moon phases, Unpublished doctoral dissertation, The University of Tennessee, Tennessee.

Trundle, K.C., Atwood, R.K., \& Christopher, J.E. (2002). Preservice elementary teachers' conceptions of moon phases before and after instruction. Journal of Research in Science Teaching, 39, 633-658.

Tsai, C.C. (1999). Overcoming junior high school students' misconceptions about microscopic vies of phase change: A study of an analogy activity. Journal of Science Education and Technology, 8(1), 83-91.

Tyson, L.M., Venville,G.J., \& Harrison, A.G. (1997). A multidimensional framework for interpreting conceptual change events in the classroom. Science Education, 81, 387-404.

Van Zele, E., Lenaertz, J., \& Wierne, W. (2004).Improving the usefulness of concept maps as a research tool for science education. International Journal of Science Education, 26 (9), 1043-1064.

Venville, G., \& Treagust, D.F. (1996).The role of analogies in promoting conceptual change in biology. Instructional Science, 24(4), 295-320.

Vosniadou, S. (1994). Capturing and modeling the process of conceptual change. Learning and Instruction, 4, 45-69. 
Vygotsky, L.S. (1978). Mind in Society, In M. Cole, V. J. Steiner, S. Scribner, \& E. Souberman (Eds.), Cambridge, MA: Harvard University Press.

Wandersee, J.H., Mintzes, J.J., \& Novak, J.D. (1994). Research on alternative conceptions in science, In D.L. Gabel (Ed.), Handbook of Research on Science Teaching and Learning, Macmillan Publishing Company.

Wang, T., \& Andre, T. (1991).Conceptual change text versus traditional text and application questions versus no questions in learning about electricity. Contemporary Educational Psychology, 16, 103-116.

Watanabe, T., McGinnis, J.R., \& McDuffie, A.R. (1997, March). University faculty "modeling" good instruction in mathematics and science courses for prospective middle grades teachers: voices from the MCTP, Paper resented at the annual meeting of the American Educational Research Association, Chicago, Illinois.

Watters, J.J., \& Ginns, I.S. (2000). Developing motivation to teach elementary science: Effect of collaborative and authentic learning practices in preservice education. Journal of Science Teacher Education, 11(4), 277-313.

Weaver, G.C. (1998). Strategies in K-12 science instruction to promote conceptual change. Science Education, 82, 455-472.

Webster, M. (1977). Websters' New Collegiate Dictionary, Massachusetts: G. \& C. Merriam Company: Springfield.

Wichman, A., Gottdenker, J., Jonassen, D., \& Milrad, M. (2003). Developing a framework for conceptual change within scientific inquiry, ICALT Proceedings, Athens. 
Wilson, J.D. (1996). An evaluation of the field experiences of the innovative model for the preparation of elementary teachers for science, mathematics, and technology. Journal of Teacher Education, 47(1), 53-59.

Wood-Robinson, C., Lewis, J., \& Leach, J. (2000).Young people's understanding of the nature of genetic information in the cells of an organism. Educational Research, $35(1), 29-36$.

Yanowitz, K.L. (2001). Using analogies to improve elementary school students' inferential reasoning about scientific concepts. School Science \& Mathematics, 101(3), 133-143.

Yerrick, R.K., Doster, E., Nugent, J.S., Parke, H.M., \& Crawley, F.E. (2003). Social interaction and the use of analogy: An analysis of Preservice teachers' talk during physics inquiry lessons. Journal of Research in Science Teaching, 40(5), 443-463.

Zirbel, E. L. (2004). Framework for conceptual change. Astronomy Education Review, $1(3), 62-76$. 


\section{APPENDICES}

\section{APPENDIX A}

Open-ended survey: "How well do you understand science concepts?"

Try writing simple explanations for the following:

1. Why do we have seasons?

2. Why do we see phases of the moon?

3. Explain the rock cycle.

4. How is soil formed?

5. Why does the wind blow?

6) What causes earthquakes?" 


\section{APPENDIX B}

\section{GRADING MANUAL RUBRIC AND SAMPLE ANSWERS FOR OPEN-ENDED SURVEY}

\section{$3:$ (Integrated with scientific perspective and clear with elaboration)}

$2:$ ( Partially correct or has no elaboration)

$1:$ (No response, incorrect answer or clearly evident misconception)

Q 1: Why do we have seasons?

Rubric

\begin{tabular}{|c|l|}
\hline Scores & \multicolumn{1}{c|}{ Why do we have seasons? } \\
\hline 3 & $\begin{array}{l}\text {-If the response includes two or more of the following ideas: the tilt of the } \\
\text { earth's axis, changes in the part of the earth getting more direct sunlight, and } \\
\text { the tilt of the earth as it revolves around the sun. }\end{array}$ \\
\hline 2 & $\begin{array}{l}\text { - If the response includes a correct idea without elaboration (the amount of the } \\
\text { sun's light concentrated on a particular area) or one correct idea, even if } \\
\text { combined with one that is not clear (because of the tilt and rotation of the } \\
\text { earth). }\end{array}$ \\
\hline 1 & $\begin{array}{l}\text { - No response or if the response showed a clear misconception or did not } \\
\text { explain the concept, e.g. rotation (revolution) of the earth around the sun, the } \\
\text { earth's distance from the sun, our position around the sun, vernal equinox, } \\
\text { time changing, changes in the atmosphere. }\end{array}$ \\
\hline
\end{tabular}

Sample answers

3:

* Because of the tilt of the earth as it revolves around the sun

2:

* Different parts of the earth have heat \& light for different amounts of time.

* The earth revolves around the sun in an oval orbit. The earth's axis is tilted. Greater distance and tilt

* The elliptical path around the sun $\&$ the tilt of the earth on its axis effect the changing seasons.

* Because of the Earth's rotation around the sun-it is an ellipse; so sometimes it is farther away from the sun. Also, because of tilt of Earth's axis

* The position of the sun is relationship to the earth causes fluctuations in the number of hours the earth is exposed-affecting temperature and the angle of exposure.

1:

* So that the environment, plants, animals, wildlife can change, and go through the cycles $\&$ then restart.

* The earth tilts up and down, making the sun shine bright and warmer depending on tilt. 
* Because of the rotation of planets

* Rotation of the earth around the sun can cause temperature changes.

* Because, it is the relation of earth $\&$ the sun

* The seasons change because we are closer to and farther from it.

* The earth moves around the universe and your part of the earth is farther form the sun, it is colder ... when it is closer it is warmer.

* We have seasons to mark the changes in weather. We go from winter to spring to summer to autumn or fall. We have these 4 seasons for the 4 major changes in the weather. Seasons affect our dress, plants, food, etc.

Q 2: Why do we see phases of the moon?

Rubric

\begin{tabular}{|c|l|}
\hline Scores & \multicolumn{1}{|c|}{ Why do we see phases of the moon? } \\
\hline 3 & $\begin{array}{l}\text { - If the response includes both that the phases we see are reflected sunlight } \\
\text { (e.g. the visible reflection of the Sun's light by the Moon and that the amount } \\
\text { of reflected light visible is determined by the orbit of the moon around the } \\
\text { earth (e.g., the position of the Moon on its orbit around the Earth, the angle of } \\
\text { the Moon and the Earth relative to the Sun) }\end{array}$ \\
\hline 2 & $\begin{array}{l}\text { - If the response mentions a correct partial explanation, such as the moon's } \\
\text { revolution around the earth but does not include a full explanation. Given the } \\
\text { common confusion between the words rotate and revolve, credit was given if } \\
\text { the word rotate was used to describe the orbit of the moon around the earth. }\end{array}$ \\
\hline 1 & $\begin{array}{l}\text { - No response or if the response showed a clear misconception or did not } \\
\text { explain the concept. For example, phases are caused by: the Earth's shadow } \\
\text { falling on the Moon, the distance between the Moon and the Earth, the Moon's } \\
\text { position behind the Sun, and the movement of the Moon around the Sun. }\end{array}$ \\
\hline
\end{tabular}

Sample answers

3: No number 3 answer was found in the previous study. Following is what we will look for in a quality answer, a clear understanding of the reason for the phases of the moon:

“The Moon does not produce its own light, but simply reflects the light of the Sun. The phases of the moon are caused because the orbit of the Moon around the Earth will vary the part of the Moon's reflected light that is visible from earth. The angle of the Moon and the Earth relative to the Sun determines the Moon phases."

2:

*Moon rotates around the earth.

*Because of the rotation, the alignment of the sun and the moon. 1:

* Phases of the moon are caused by the blocking of the moon by the sun at certain times of the month.

* The phases are how much light the sun shines on the moon.

* At certain times of the year, the earth's rotation around the sun allows us to see the moon at different angles.

* We see the phases of the moon based on the amount of the sun.

* The blocking is caused by the earth's shadow falling on the moon 
* Rotation of earth shadows

* Because the moon is close to the Earth

* Because of the rotation of the planets

* The sun shines light onto the earth which creates a shadow on the moon, as the moon moves around the earth the shadow changes resulting in the phases.

* Because of the moon's position behind the sun

* The earth and the moon rotate around the sun

Q 3: Explain the rock cycle

Rubric

\begin{tabular}{|c|l|}
\hline Scores & \multicolumn{1}{c|}{ Explain rock cycle } \\
\hline 3 & $\begin{array}{l}\text { If the response includes all three types of rocks (igneous, sedimentary and } \\
\text { metamorphic), their conversion to each other, or their formations (igneous- } \\
\text { melted rock, sedimentary-layers form, and metamorphic-heat \& pressure). }\end{array}$ \\
\hline 2 & $\begin{array}{l}\text { If the response includes information on just one or two types of rock } \\
\text { formation: the rock cycle is formed from sediments, the rock cycle deals with } \\
\text { the heat and years and years of weathering, as the earth ages, various layers of } \\
\text { rock are formed, probably has to do with the change from superheated core } \\
\text { materials pushed upward to the crust. }\end{array}$ \\
\hline 1 & $\begin{array}{l}\text { If the response gives unrelated information, confusing or incorrect } \\
\text { information, or no answer was given. For example: material, pressure, and heat } \\
\text { can cause the formation of rock, rocks are made from minerals, dirt and sand } \\
\text { particles binding together to make one big solid mass, volcanoes produce lava } \\
\text { which melts into rock. }\end{array}$ \\
\hline
\end{tabular}

Sample answers

3: No number 3 answer was found in the previous study. Following is what we looked for in a quality answer, a clear understanding of the cyclical nature of transformations of one rock to another. A drawing such as the diagram below would have yielded a score of 3 although mention of cross links between rock types would have shown more complete understanding. For example, igneous rocks can be converted to metamorphic rocks and metamorphic rocks can be converted to sedimentary rocks.
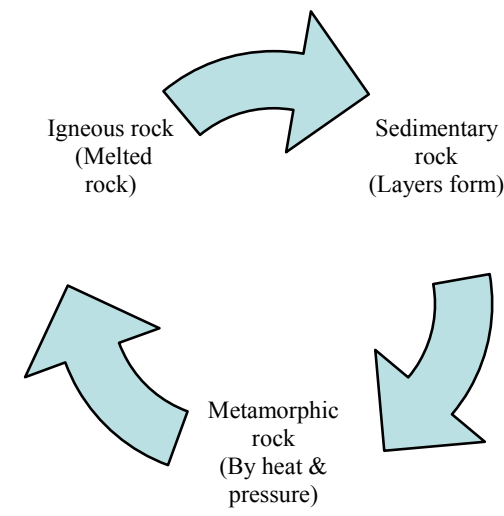
2:

* Minerals form rocks; rocks are weathered into sand \& soil, as soil builds rocks are compressed together to form larger rocks.

* The rock cycle is formed from sediments that receive heat $\&$ pressure $\&$ then harden into a rock.

* Particles harden create rocks - rocks erode into particles

* The rock cycle deals with the heat and years \& years (billions) of weathering.

* As the earth ages, various layers of rocks are formed.

* Probably has to do with the change from superheated core materials pushed upward to the crust.

1:

* Material-Pressure + Heat $=$ Rock

* Water erodes the rocks and they are carried to soil where phosphorus makes new rocks.

* I don't know besides the fact that rocks are made from minerals

* Dirt or sand particles binding together to make one big solid mass.

* Volcanoes produce lava, which melt into rock.

Q 4: How is soil formed?

Rubric

\begin{tabular}{|c|l|}
\hline Scores & \multicolumn{1}{c|}{ How is soil formed? } \\
\hline 3 & $\begin{array}{l}\text { - If the response includes both that soil is formed from organic materials } \\
\text { (decomposition of plants, animals, animal and plant manures, earthworms, } \\
\text { grass, and dead creatures) and from inorganic materials (weathering of rock, } \\
\text { minerals, and sediments) }\end{array}$ \\
\hline 2 & $\begin{array}{l}\text { - If the response includes either organic or inorganic materials but not both } \\
\text { (e.g. recycling of plants and animals; breaking of rock and mineral particles; or } \\
\text { dead creatures). Or answer is vague, referring to decomposition of "various } \\
\text { materials." }\end{array}$ \\
\hline 1 & $\begin{array}{l}\text { - No response or if the response showed a clear misconception or did not } \\
\text { explain the concept. For example: soil is formed from the dirt, water, and sand } \\
\text { particles. }\end{array}$ \\
\hline
\end{tabular}

Sample answers

3:

* By decomposition of plants, animals, and rocks

* From crushed rock, animal manure (decomposed), earthworms, and grass

* Decomposition of plants, animals, minerals, and rocks

2 :

* Through recycling of trees and decomposition

* From rocks breaking apart

* Weathered pieces of rock, sediments, and minerals

* Decomposition of various materials

* By the crushing of rocks and minerals

* By things decomposing they make soil, trees use it, they die it starts over 
* From rock eroding

* Paper and food are processed by animals like worms. Their discretions result in soil.

* Dead plants and animals that are decomposing

* Mountains or rocks erode

1:

* From dirt and water

* From particles of sand

Q 5: Why does the wind blow?

Rubric

\begin{tabular}{|c|l|}
\hline Scores & \multicolumn{1}{c|}{ Why does the wind blow? } \\
\hline 3 & $\begin{array}{l}\text { - If the response includes accurate explanations of both surface winds (e.g. air } \\
\text { moves from high pressure areas to low pressure areas to form local winds, the } \\
\text { temperature differences across the land and the water form winds) and global } \\
\text { winds (global winds occur because of the Earth's rotation). }\end{array}$ \\
\hline 2 & $\begin{array}{l}\text { - If the response includes accurate ideas on either surface winds or global } \\
\text { winds but not both. For example: the movement of air from high pressure areas } \\
\text { to low pressure areas, the Earth's rotation. }\end{array}$ \\
\hline 1 & $\begin{array}{l}\text { - No response or if the response showed a clear misconception or did not } \\
\text { explain the concept (e.g. the winds are caused by ocean, ocean currents, waves, } \\
\text { atmospheric situation, and tides). }\end{array}$ \\
\hline
\end{tabular}

Sample answers

3:

* The movement of air from high pressure areas to low pressure areas and the Earth's rotation.

Following is what we will look for in a quality answer, a clear understanding of the reason for why the wind blows:

"Surface winds are caused by differences in air pressure. Warm air is lighter (has less pressure) and cold air is heavier (has more pressure). Air moves from high pressure to low pressure. High winds (global winds) are caused by the rotation of the Earth from west to east. Because the earth rotates, the winds don't blow northward or southward to the area of lower pressure, but are deflected to the left in the North Hemisphere and to the right in the South Hemisphere."

2:

* Transition from high pressure areas to low pressure areas

* The earth's rotation

1:

* Current and solar winds

* Ocean and waves

* Ocean

* Due to atmospheric situation

* Tides of the ocean 
* The wind is formed from different currents of the ocean

Q 6: What causes earthquakes?

Rubric

\begin{tabular}{|c|l|}
\hline Scores & \multicolumn{1}{c|}{ What causes earthquakes? } \\
\hline 3 & $\begin{array}{l}\text { - If the response includes combinations of ideas giving a clear explanation: } \\
\text { shifting of the earth's crust on the fault line, shift in the tectonic plates creating } \\
\text { on releasing pressure, the plates of the earth colliding and rubbing against each } \\
\text { other, shift in the earth's crust because of the lava inside the earth surface. }\end{array}$ \\
\hline 2 & $\begin{array}{l}\text { - If the response includes a correct term or idea, but lacks full explanation or } \\
\text { gives a too narrow example: plate tectonics, shift in convergent plates, big } \\
\text { plates shift caused by molten rock moving in the middle of the earth, plates } \\
\text { shifting due to volcanoes, new lands form. }\end{array}$ \\
\hline 1 & $\begin{array}{l}\text { - If the response mentions a clearly evident misconception, mentions a phrase } \\
\text { associated with earthquakes but without explanation (e.g. plates in the ocean, } \\
\text { friction, the earth moving), or gives no answer. }\end{array}$ \\
\hline
\end{tabular}

Sample answers

3:

* Shifting of the earth's crust on the fault line.

* The shifting of the tectonic plates along a fault line.

* Shifts in the Earth's crust because of the lava inside the earth surface.

* Shift in the tectonic plates creating on releasing pressure.

* The plates of the earth colliding \& rubbing against each other.

2:

* Tectonic plates (moving of the continents)

* Plate tectonics + pressure

* Plates shifting due to volcanoes, new lands form.

* Heat from the earth moves the plates.

* Shift in convergent plates

* The earth is made up of big plates \& they shift caused by molten rock moving in the middle of the earth.

1:

* Plates in the ocean

* Friction

* The earth moving 


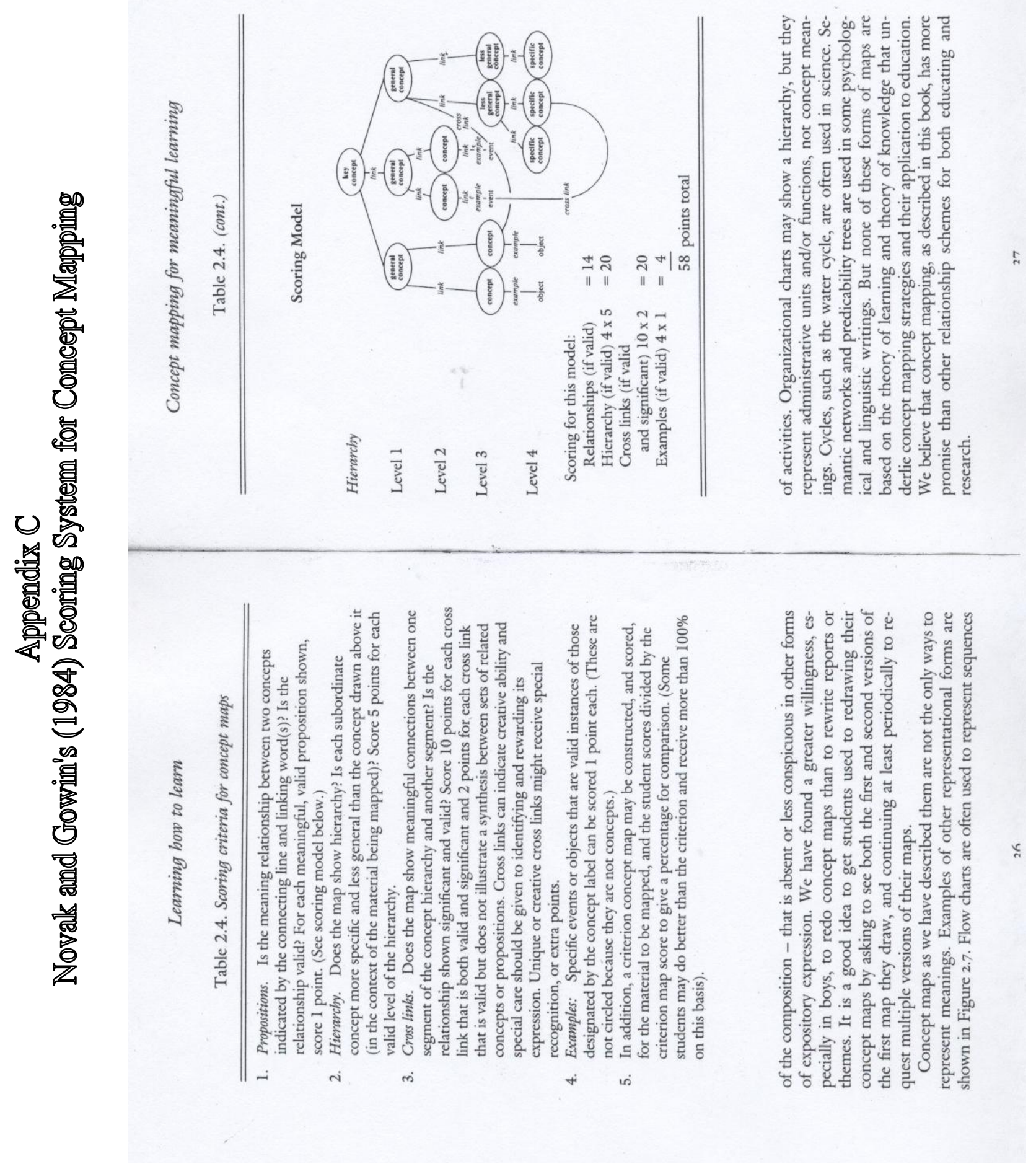




\section{APPENDIX D}

Instructions for Participants to Follow at the Learning Stations

\section{Instructions of the Stations for Cohort 1}

\section{Rock Cycle}

Station 1. Crayon Rock Cycle

Using the pencil sharpener, shave three crayons into the center of an Aluminum (Al) foil square. Record what it looks like.

1. Fold Al foil to a packet and add pressure by standing on it. Open packet, remove a bit of stuff, and tape it onto handout as sedimentary rock.

2. Place packet on the hot plate. Leave until crayons just begin to melt. Take foil from heat with a tweezers, remove a bit of stuff and tape to handout as metamorphic rock. 3. Return packet to hot plate and leave until crayon is completely melted. Observe quickly before "magma" cools. After crayon has completely cooled, tape to handout as igneous rock.

\section{Station 2. Rock Classification}

You will see different types of rocks and related books about them at this station. These rocks are examples of sedimentary, metamorphic, and igneous rocks. By using the materials, try to understand;

- How these three types of rocks form in nature?

- What is the relationship between these rocks?

Find the names of these rocks by using the books.

\section{Reasons for the Wind}

Station 3. a. Movement of Air from a Balloon

1. Take a balloon. Inflate it gently and pinch the mouth of the balloon. How many times did have to blow to inflate it? Think about the air compressed inside the balloon and air molecules outside the balloon? Which has more pressure, the air in the balloon or the air in the room?

2. What will happen if you slightly "unpinch" the balloon's mouth? Try it, aiming the opening toward yourself. Which direction does the air move? What makes the air move from the balloon? What does this have to do with wind?

Hint: Air always travels from the areas that have high pressure to the areas that have low pressure.

b. Inflated Bags

At this station, you will see two plastic bags connected with a tube. One of the bags was inflated before they were connected. If these materials just sit there, what would 
happen to them after a while? What will happen if the air in the bag is put under pressure? Lightly press on the bag and observe what happens. Try to explain what happens.

Hint: Air always travels from the areas that have high pressure to the areas that have low pressure.

Station 4. a. Sinking of Icy-Water

Liquids behave like gases (because they are both fluids). We can provide a model of "why the wind blows" by using water. You will use blue icy water and warm water to illustrate how fluids of different temperatures interact. Put some warm water into the graduated cylinder. By using the dropper, add a squirt of blue icy-water to the warm water. Observe how cold water and the warm water interact. Cold air and warm air interact the same way. Think about why and write in your journal.

b. Prevailing Winds

At this station, you will spin a water globe on a home-made lazy susan and watch what happens to the blue fluid when you stop it. The liquid has a pearly material in it (such as in shampoo) that allows flow to be made visible. Did the fluid stop when the globe stopped turning? What direction does the fluid move? Does it flow toward the poles or away from the poles?

If the Earth did not rotate on its axis, the movement of the air over the Earth (wind) would be simpler. But, the Earth is rotating counter clockwise on its axis and the solid earth and the fluid that surrounds it (atmosphere) moves differently* causing global winds (prevailing winds) around the Earth. Would it take longer to fly toward the east or toward the west?

- You can note this difference by spinning a hard boiled egg (solid) and a raw egg (thick liquid). The hard boiled egg spins much faster than the raw egg.

\section{Causes of Earthquakes}

Station 5. Earthquake Model

When you come to the station:

1. Hook the spring scale to the bungee cord.

2. Ratchet the cord until taut.

3. Each of you should predict how many clicks of the ratchet it will take to move the bricks (cause an earthquake).

4. Check to see how many pounds of tension there are on the scale when the earthquake occurs and measure how far the bricks move.

5. Does this information help you to predict how many clicks until the next earthquake?

[In a real earthquake, pressure builds up because the plates forming the earth's crust can't move smoothly against one another. Friction keeps them from moving smoothly.]

When you are finished, brush off the brick and the sander belt to remove any loose sand. Also pull out the cord for the next person by lifting both metal pieces away from the cogs. 
Station 6. Plate Movements

Use the graham crackers on a paper plate as models of the movement of earth's plates. Draw in your journals.

1. Sliding plates: Slowly slide the two graham cracker halves past each other with their edges scraping against each other in opposite directions.

2. Divergent plates: Slowly pull the two cracker halves away from each other.

3. Convergent plates and subduction: Move the two cracker halves toward each other so that they slowly collide. Carefully, slide the crackers toward each other until they meet. Make the right cracker slowly dive under the left cracker (subduction).

Sliding plates and convergent plates with subduction cause earthquakes.

\section{Instructions of the Stations for Cohort 2}

\section{Reasons for Seasons}

Station 1. Modeling Reasons for Seasons by Using Styrofoam Balls and Flash Light

Figure A: Use a Styrofoam ball with a pencil through it as the axis and a mark around the center as the equator. Find north on the compass and position the ball on a table so that the pencil eraser is tipped slightly from the vertical and pointed toward the north. Place the flashlight about $15 \mathrm{~cm}$ from the opposite side of the ball and observe where the light strikes the ball. Keeping the eraser tipped toward the north, move the ball around the flashlight and turn the flashlight around so it continues to shine on the ball. What do you observe?

Figure B: Shine the light directly at the paper and draw around the light spot (area $\left.A_{1}\right)$. Place the paper at slant and again draw around the light spot $\left(A_{2}\right)$. How are these two activities [Figures A \& B] connected?

Station 2. Using People as Models for Reasons for Seasons

At this station, one person will be the sun and the others will represent the earth.

1. The "sun" will stand at the center.

2. Decide which direction is north. (Either real north or pretend a part of the room is north)

3. The "earth" people will form a circle around the sun, leaning forward, all pointing their heads the same direction. Heads represent the North Pole; leaning represents the tilt of the earth's axis.

4. The "earth" people revolve counter clockwise around the sun while continuing to lean north. It is very awkward but you can do it!

5. As the earth travels around the sun, determine which season in North America the earth represents in each position.

Station 3. How Warm is Slanted vs. Direct Sunlight?

1. Read the temperatures on the two thermometers to make sure they read the same.

2. Then prop up one thermometer in its black case at an angle in the light beam. It will get slanted light. Prop up the other thermometer with some books so the light strikes on it 
directly. The bulbs of the thermometers should be the same distance from the light, 15 $\mathrm{cm}$.

3. Wait five minutes (you can read books), then record the temperatures. Are they the same? If not, why not?

4. Remove the thermometers to prepare for the next group.

\section{Phases of the Moon}

Station 4. Phases of the Moon

Model 1: Look in the black box. The lamp represents the Sun, the bigger ball with the flag represents the earth and the small ball represents the moon. Place the earth in the cup a bit toward a corner of the box so that its axis (stick) points away from the sun.

-One person will hold the moon by its stick and, keeping the "face" of the moon toward the earth, revolve the moon around the earth in a counter clockwise direction, slightly above the earth so the earth does not block the moon.

-Looking down on the earth, imagine how much of the moon you can see every $90^{\circ}$. Notice how the lighted part of the Moon seems to change shape, from a thin line, or crescent, to a full moon then begins to get smaller and smaller until you have no reflected light.

-Rotate the earth counterclockwise on its axis so you can see whether the moon is visible day or night. Can you see a full moon during the day? Why or why not?

Model 2: Because the researcher and the science faculty member could finalize the second model in the last minute, there was not an instruction sheet for that model. The researcher made the necessary explanations for the preservice teachers.

\section{Soil Formation}

Station 5. Soil formation:

You will find two different types of soil (dirt) at this station. One is from near a creek and one is soil from a garden. By using magnifying glasses and microscope, look at these two soil samples, and sort what is in them. What types of bits and pieces do you see in them? Can you find any creatures? Try to find out what the soil made of. What differences do you find between the two soil samples?

Station 6. Rocks in soil

Sometimes pieces of rock are found in soil. One kind of rock (feldspar), weathers chemically and becomes clay. Sometimes rock weathers (wind and/or water) and becomes sand. Sand can be made from many kinds of rock but most of the common sand is quartz. Particles that are larger than clay and smaller then sand are called silt. Make some sand by putting some small rocks in the can and shaking it. You can experiment with the dry can or the wet can. After you have shaken it for five, minutes feel in the bottom of the can to see whether it feels gritty. Remove a bit of grit and examine with a magnifier. 


\section{APPENDIX E}

Team Assignments for Concept Mapping

\section{Cohort 1}

Stations Readings

Rock cycle - phases of the moon

Rock cycle - reasons for seasons

Rock cycle - soil formation

Reason for wind - phases of moon

Reason for wind - reason for seasons

Reason for wind - soil formation

Earthquakes - phases of the moon

Earthquakes - reason for seasons

Earthquakes - soil formation

Cohort 2

Readings Stations

Rock cycle - phases of the moon

Rock cycle - reasons for seasons

Rock cycle - soil formation

Reason for wind - phases of moon

Reason for wind - reason for seasons

Reason for wind - soil formation

Earthquakes - phases of the moon

Earthquakes - reason for seasons

Earthquakes - soil formation 


\section{APPENDIX F}

\section{Assignment from Course Syllabus for Cohort 2}

Science learning station field assignment (lesson plan, management plan, a photo of each station, observers' feedback, reflection, and presentations) (30 points, 5 points of each)

Due April 26 and May 3

In this assignment you will develop at least four hands-on learning stations that will give the children experience with one or more topics and create connections with other subjects. Develop a management plan for moving the children among stations. Use the following lesson plan format to write a lesson plan:

\section{Learning Station Lesson Plan Format}

Rationale: Why you are using these learning stations with your class?

Introduction to learning stations: Introduce the topic of the stations to the class. Go over instructions and management plan. Attach management plan. Tell what the children do if the finish early or if they are not finished when you rotate the children to the next stations

For each learning station include:

Objective(s): What do you expect the children to learn at this station in terms of knowledge, skills, or attitude.

Materials: list all the materials that you will have at the station. Tell whether you will provide them, whether the school has them or whether you get the children to bring materials.

Procedures: Instructions which the children will read or picture instructions for young children. The instructions should make clear whether this is a discovery/exploratory station or whether more direct teaching is involved. At least half of the stations should allow exploration of some type.

Assessment: How will you know what they have learned? Have the children keep journals and/or draw pictures and tell what you would look for in what they wrote. Some stations may need a more structured assessment, such as a chart to be filled out. 
Children can work with learning stations over several days. The learning stations could take the form of discovery boxes. At least four stations must be science related and hands-on.

Closing: How will children share what they have done and learned when they have completed the stations? This could be a scientist meeting as discussed in Science Workshop...

In at least one of the stations, you will include conceptual change activities. Look through the QCC's to determine what science concepts are taught at your grade level. Talk with your cooperating teacher about which concepts have already been taught and how. You can choose a concept that is new or one that has been taught earlier in the year but that still may not be clear to the children. Find out what the children know about the concept (KWL chart).

Talk with your cooperating teachers about the implementation date of your activities. You can implement your stations either on April 17- 18 or the next week April 24- 25. After you decided that, let your instructor know that date. If possible, have your supervisor observe your lesson and give you feedback. If this is not possible, have your cooperating teacher or another student teacher observe you.

Do research on the concept to make sure you understand it and have chosen appropriate conceptual change activities.

Turn in the lesson plan, management plan, a photo of each station, observer's feedback, and reflection (due April 26). In the reflection piece,

- Reflect on the stations in general. What went well and why? What would you do differently and why? What do you think the children learned?

- Describe how you prepared yourself for the conceptual change station and whether there was anything you would do differently.

- On your conceptual change station(s), discuss your choice of concept, what the children knew initially about the concept, your rationale for the station activities, whether you were able to change misconceptions.

Prepare a brief PowerPoint presentation (5 minutes, 6 slides) on your conceptual change station(s). You will be given further instructions on what to include. Present to the class on April 26 or May 3. 


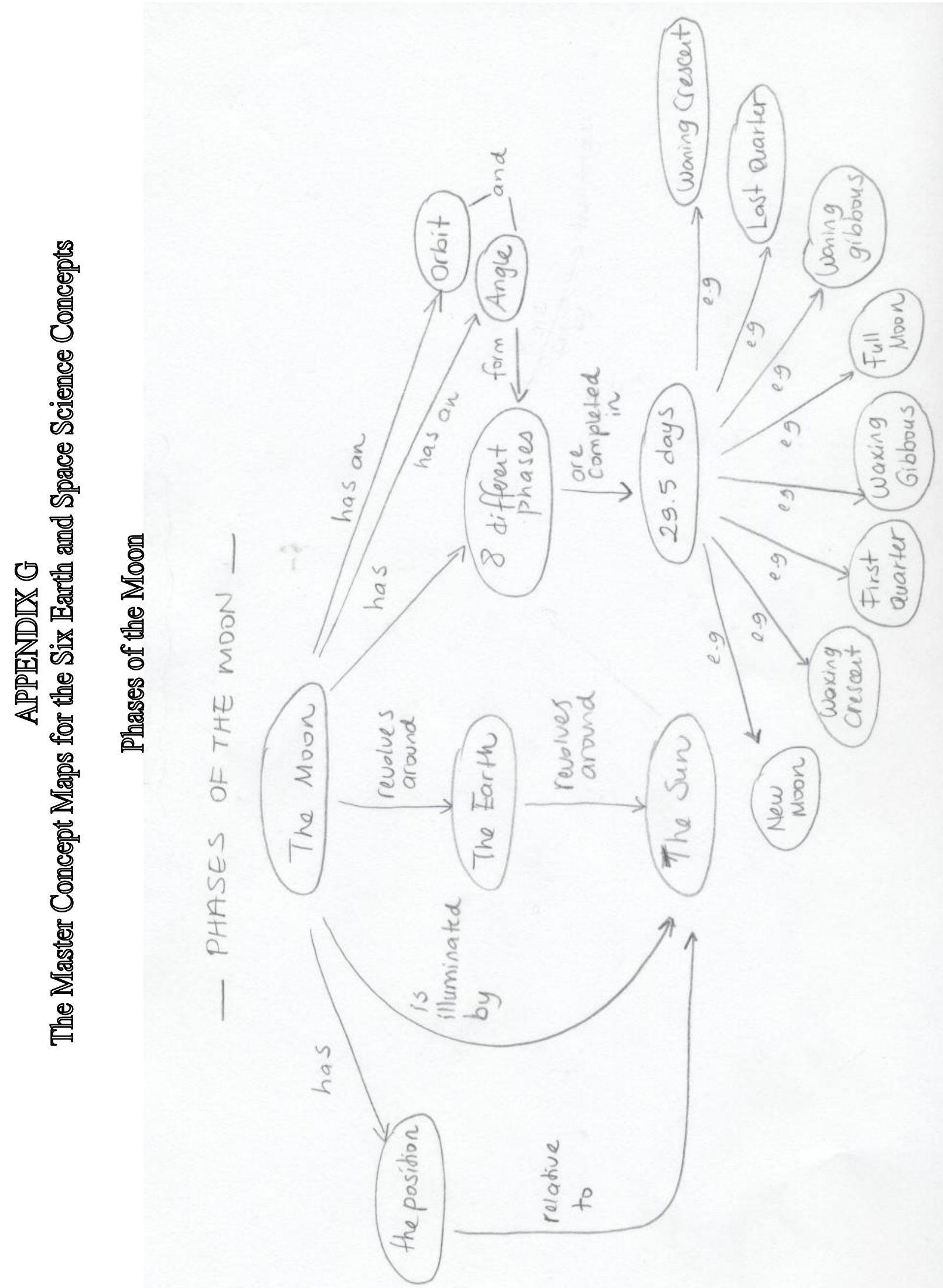




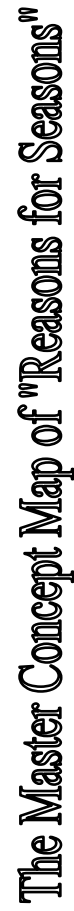

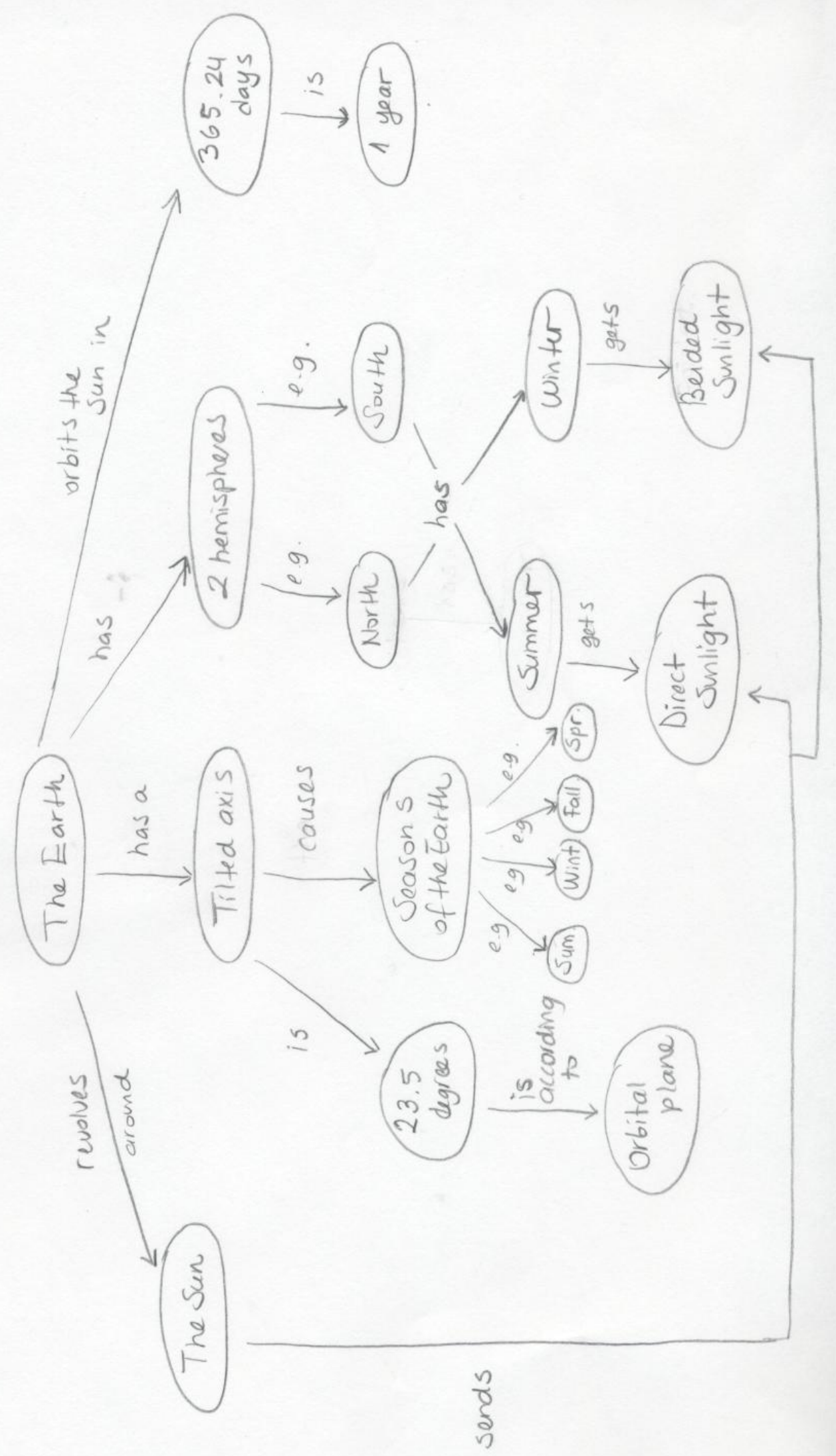



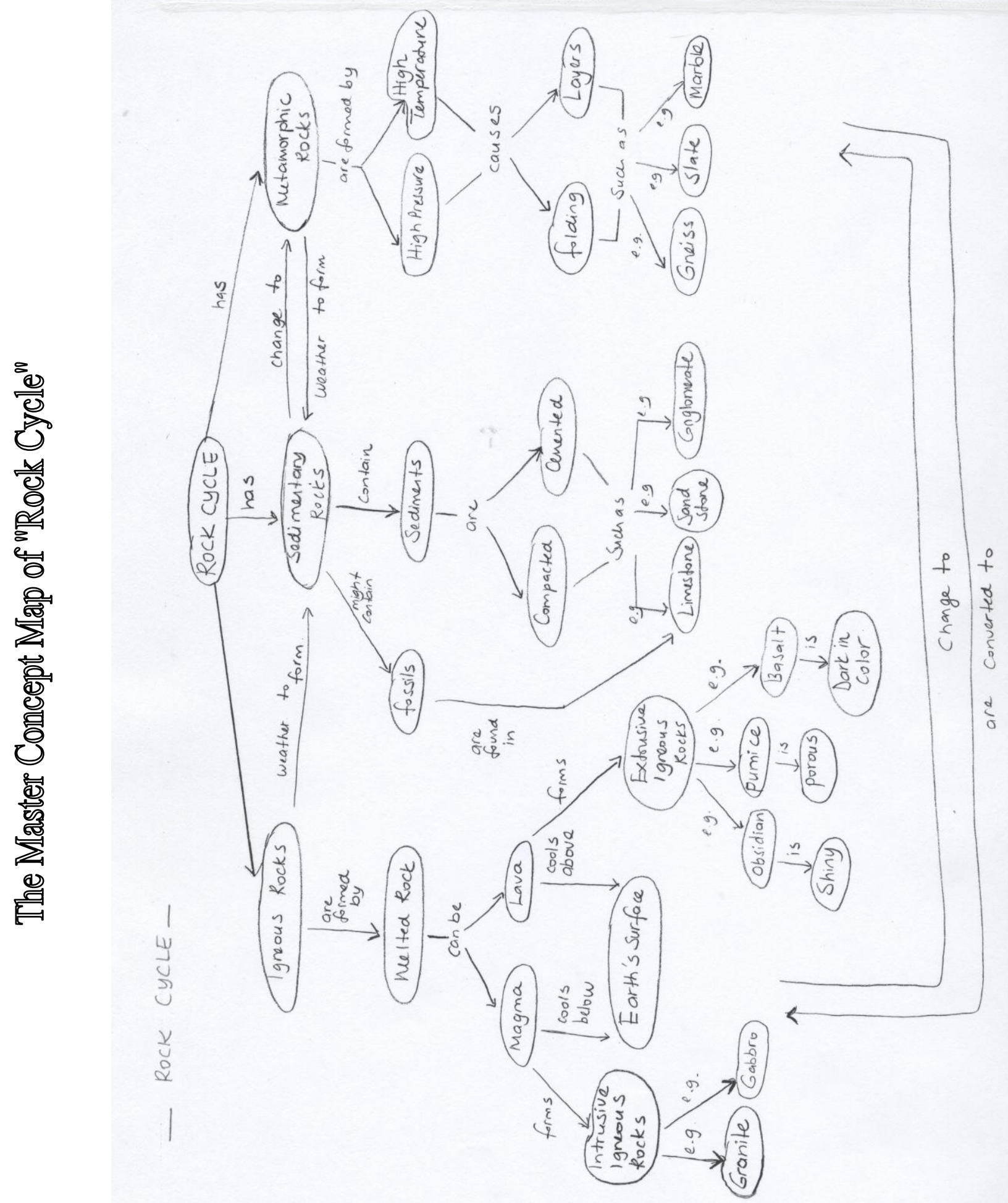

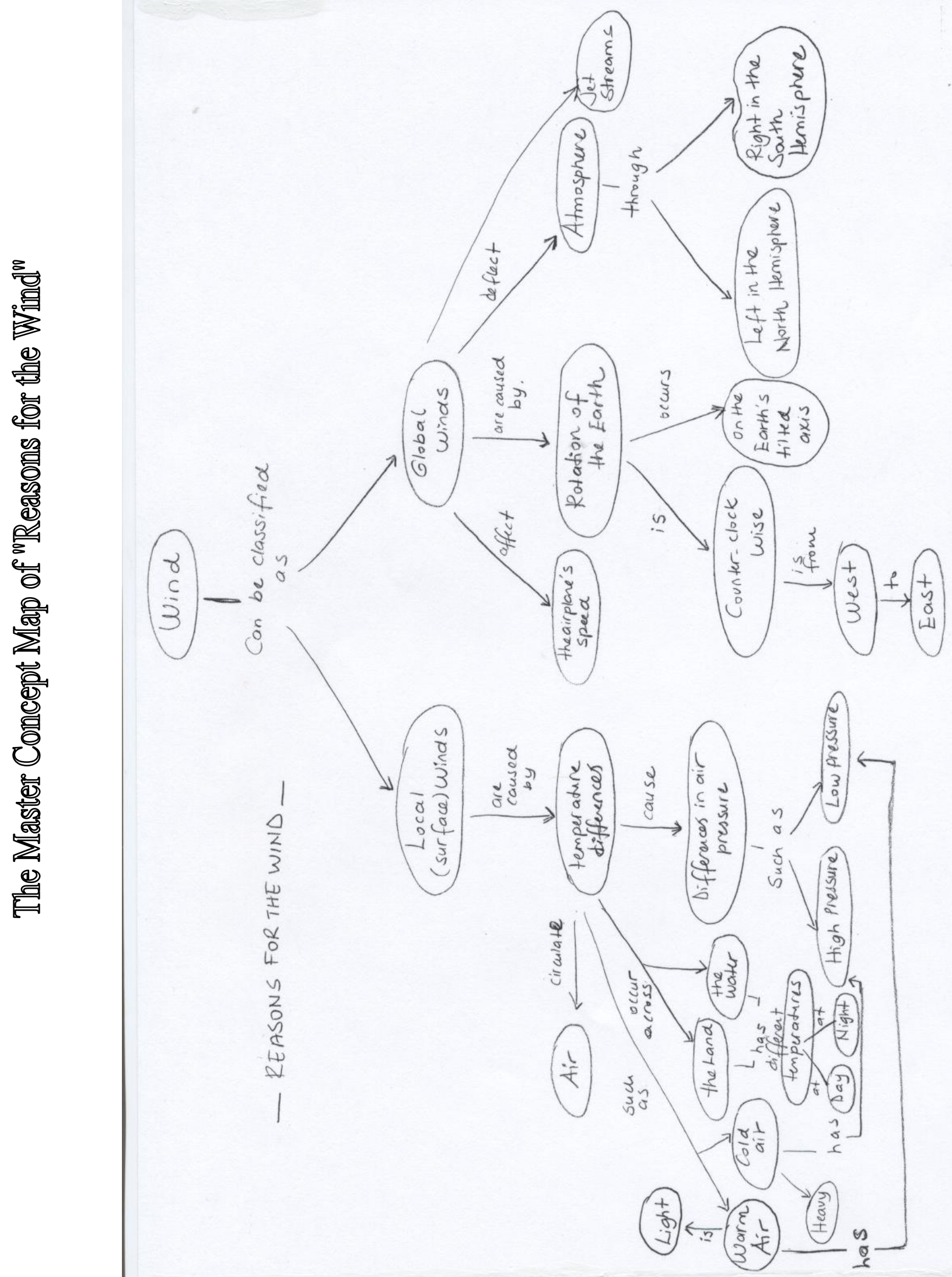

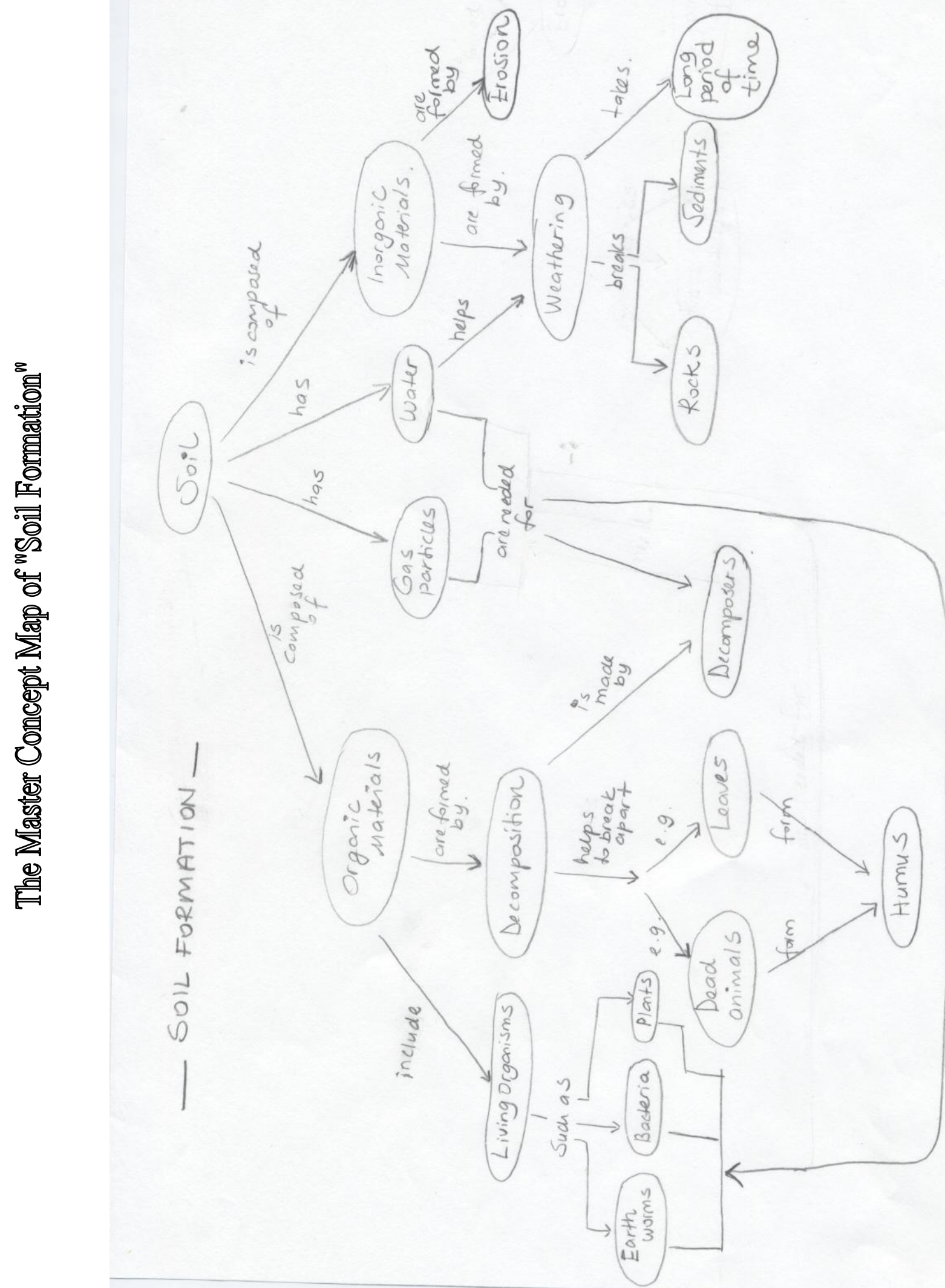

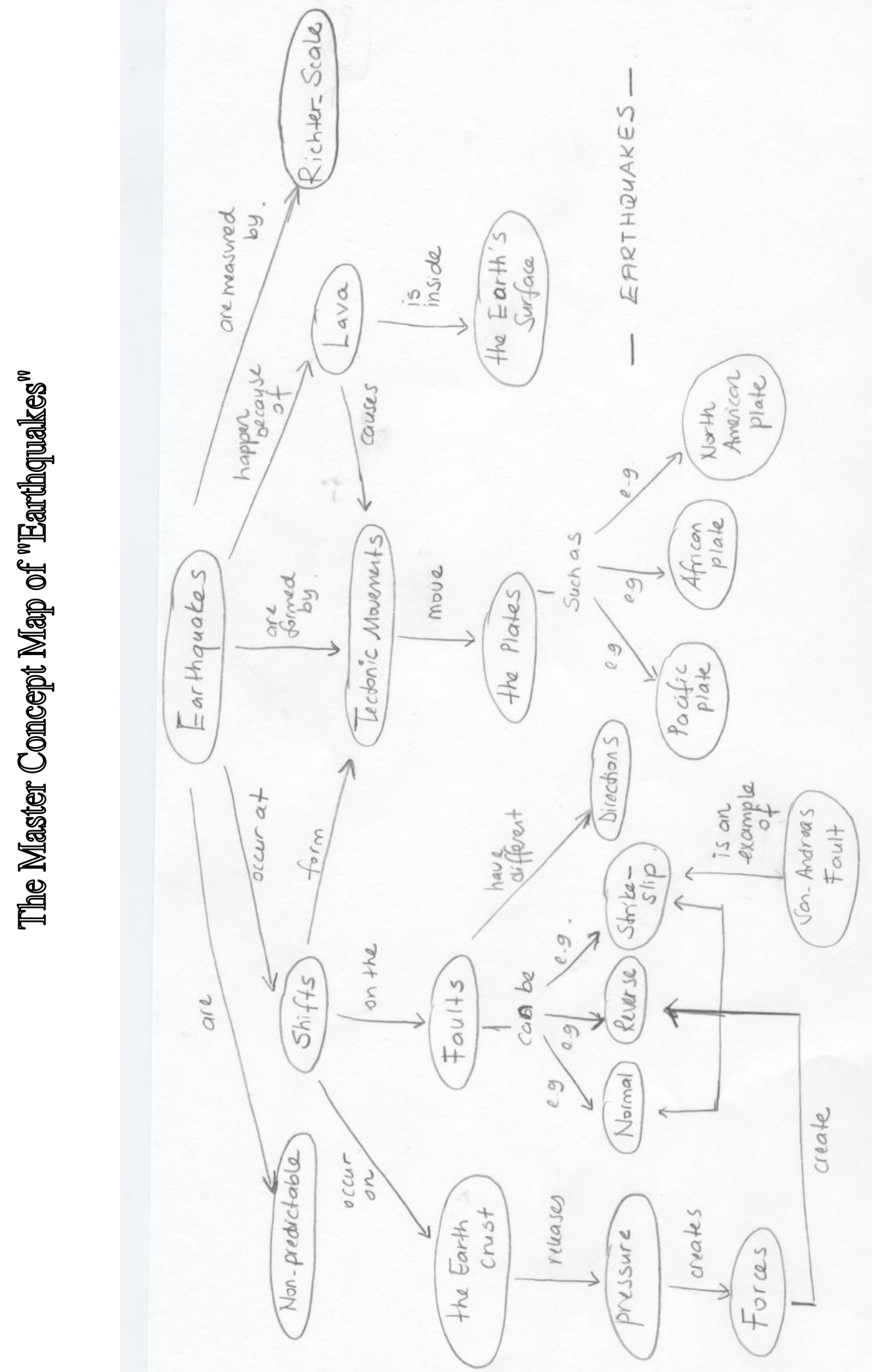


\section{APPENDIX H}

The Calculations of the Master Map Scores of the Six Earth and Space Science Concepts According to Novak and Gowin's (1984) Scoring System

Reasons for Seasons

1. Propositions: $18 \times 1=18$

2. Hierarcy: $4 \times 5=20$

3. Cross-links: $2 \times 10=20$

4. Examples: $6 \times 1=6$

Total score: $\quad 64$

The rock cycle

1. Propositions: $32 \times 1=32$

2. Hierarcy: $6 \times 5=30$

3. Cross-links: $5 \times 10=50$

4. Examples: $11 \times 1=11$

Total score: 123

Soil formation

1. Propositions: $19 \times 1=19$

2. Hierarcy: $5 \times 5=25$

3. Cross-links: $3 \times 10=30$

4. Examples: $5 \times 1=5$

Total score: $\quad 79$
Phases of the moon

1. Propositions: $17 \times 1=17$

2. Hierarcy: $3 \times 5=15$

3. Cross-links: 2 x $10=20$

4. Examples: $\quad 8 \times 1=8$

Total score: $\quad 60$

Reasons for the wind

1. Propositions: $26 \times 1=26$

2. Hierarcy: $\quad 5 \times 5=25$

3. Cross-links: $2 \times 10=20$

4. Examples: $\quad 4 \times 1=4$

Total score: $\quad 75$

Earthquakes

1. Propositions: $19 \times 1=19$

2. Hierarcy: $\quad 4$ x $5=20$

3. Cross-links: $\quad 5 \times 10=50$

4. Examples: $\quad 7 \times 1=7$

Total score: $\quad 96$ 


\section{APPENDIX I}

Three Examples from Group Concept Maps of "Phases of the Moon," "Rock Cycle," and "Earthquakes"

The concept map of "phases of the moon" with a common misconception: "The earth blocks sunlight"

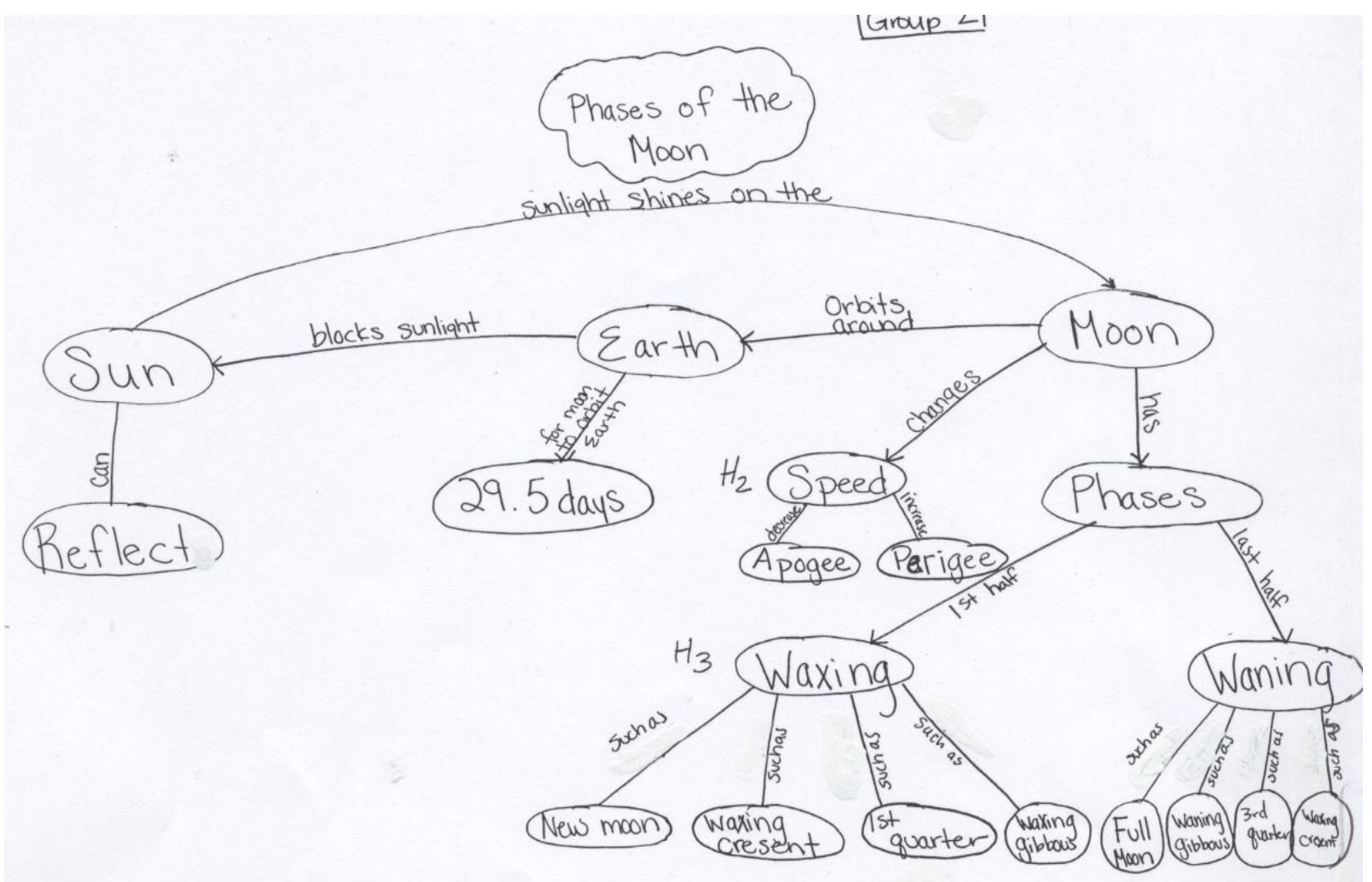


The group concept map of "the rock cycle"

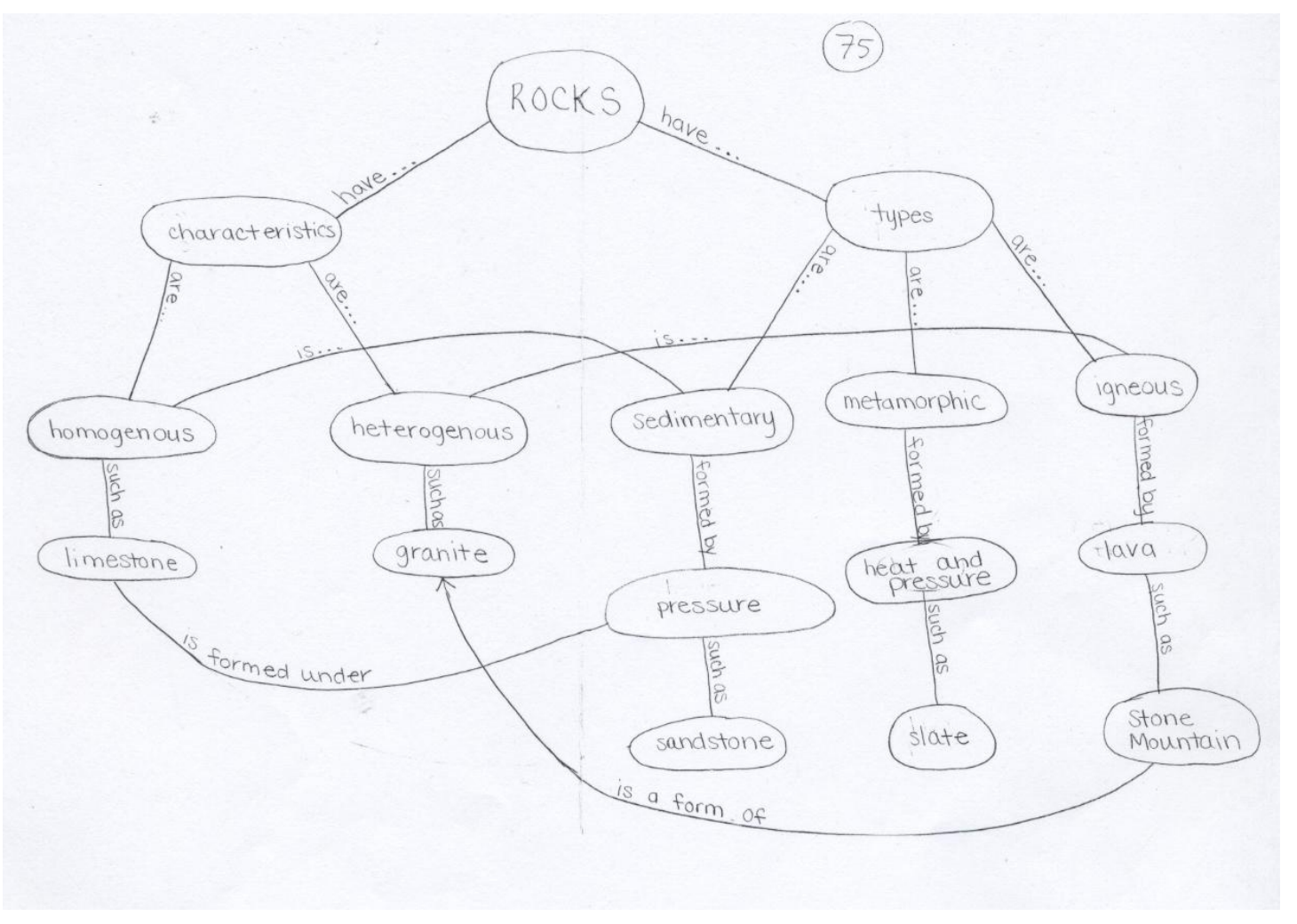



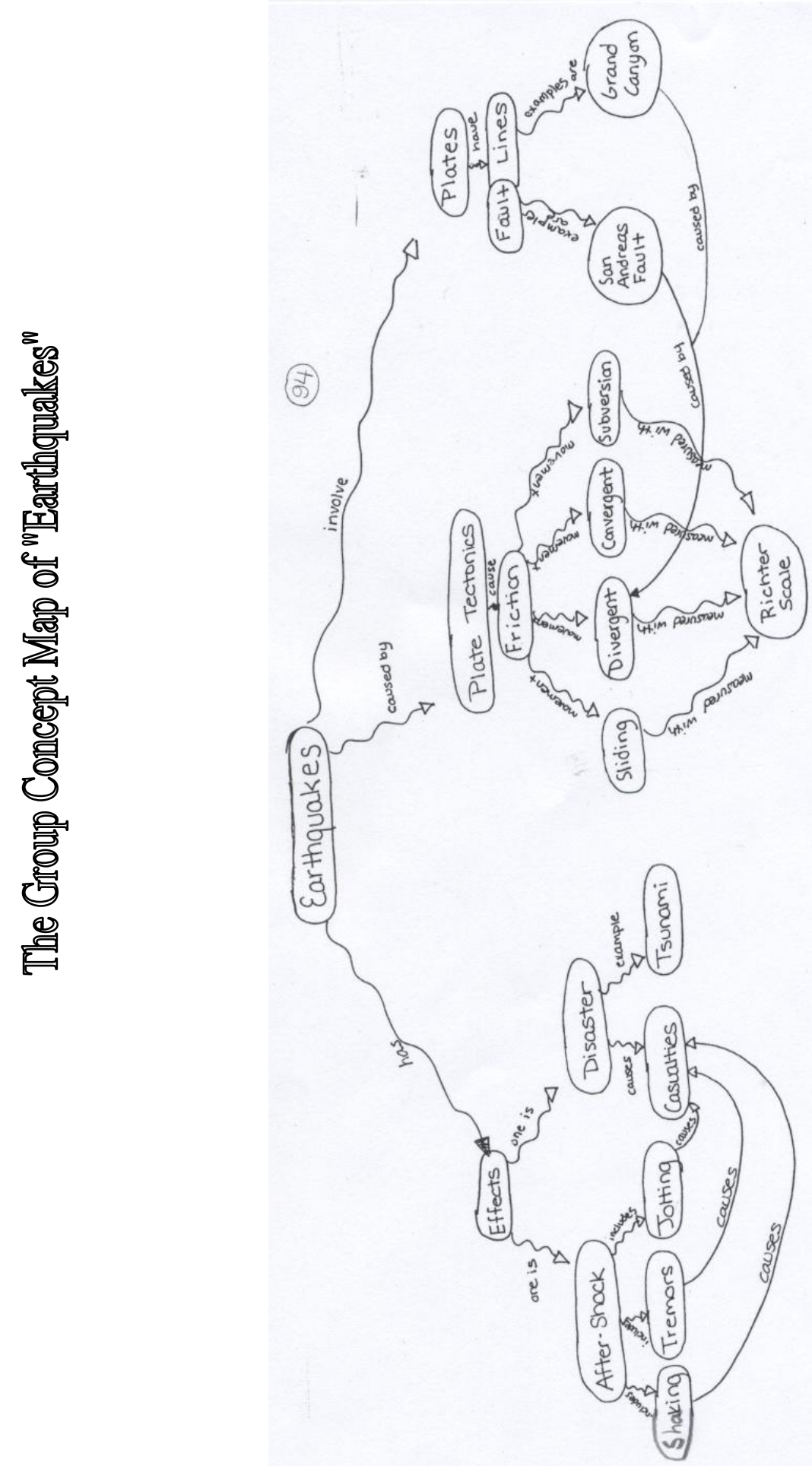


\title{
APPENDIX J Informed Consent Letters
}

\author{
Georgia State University \\ Department of Early Childhood Education \\ Informed Consent A
}

Title:

Understanding of earth and space science concepts: Strategies for concept building in elementary teacher preparation

Principal Investigators: Faculty Supervisor: Olga S. Jarrett

Student Principal Investigator: Nermin Bulunuz

\section{Introduction/Background/Purpose:}

Elementary school teachers need to have a very broad range of scientific knowledge to teach their students. This dissertation study has three parts. The first part identifies the conceptual understandings held by preservice and inservice teachers on six earth and space science concepts: reason for seasons, phases of the moon, reason for wind, rock cycle, how soil is formed, and reason for earthquakes. All of these topics are covered in elementary school on the Georgia Performance Standards. The second and third parts use an undergraduate science methods course to explore ways in which these concepts can be clarified and taught. You are being asked to participate in the first part of the study. In this part, data will be collected from preservice and inservice teachers in three different programs in the ECE department. We are writing to you to request your permission to use your responses to the six open-ended questions. Up to 108 preservice and inservice teachers will participate in this part of the study.

II. Procedures:

You will be asked to answer six open-ended questions on earth and space science. You will not be asked to include any identifying information on the question sheet, except to check your number of years of teaching: one, two to four, or five and more. Completion of the survey will take approximately 10-15 minutes in your normal class period. You will not be included in the rest of the research.

III. Risks:

There are no expected risks to you from participating in this research. If after answering the questions, you are concerned that you are not clear on some of the concepts and want to know more, feel free to contact me, Nermin Bulunuz for ideas for readings and hands-on activities, at ecenbbx@langate.gsu.edu.

IV. Benefits:

The results of this part of the study will help teacher educators decide which earth and space science concepts should be included in teacher education programs. You will benefit by knowing which of these concepts you understand well enough to explain to others. This knowledge could be useful as you transition to the Georgia Performance Standards. 
V. Voluntary Participation and Withdrawal:

Your participation in this research is voluntary. Whether or not you agree to participate in the research through answering the six questions will not affect your grade in this class. Those who do not wish to answer the questions may remain in the classroom and do other work.

VI. Confidentiality:

To insure confidentiality, you will not be identified in any way on the question sheet except by your number of years of teaching. We will keep the collected information in a secure location in Dr. Jarrett's office.

VIII. Contact Persons:

If you have any questions or additional concerns about this study please contact Dr. Olga S. Jarrett (ojarrett@gsu.edu) at (404) 651-2584 or Nermin Bulunuz (ecenbbx@langate.gsu.edu) at (404) 651-2584. If you have any questions or concerns about your rights as a participant in this study, you may contact Susan Vogtner in the Office of Research Integrity at 404- 4630674 or svogtner1@gsu.edu.

IX. Copy of Consent Form to Subject:

We will give you a copy of this consent form to keep.

If you are willing to volunteer for this research, please sign below. 


\author{
Georgia State University \\ Department of Early Childhood Education \\ Informed Consent B
}

Title:

Understanding of earth and space science concepts: Strategies for concept building in elementary teacher preparation

Principal Investigators: Faculty Supervisor: Olga S. Jarrett

Student Principal Investigator: Nermin Bulunuz

\title{
I. Introduction/Background/Purpose:
}

Elementary school teachers need to have a very broad range of scientific knowledge to teach their students. This dissertation study has three parts. The first part identifies the conceptual understandings held by preservice and inservice teachers on six earth and space science concepts: reason for seasons, phases of the moon, reason for wind, rock cycle, how soil is formed, and reason for earthquakes. All of these topics are covered in elementary school on the Georgia Performance Standards. The second part investigates the effectiveness of various methods of clarifying these concepts in an undergraduate science methods course. You are being asked to participate in these two parts of the study. (The third part focuses on implementation in school placements.) In the first part, data will be collected from preservice and inservice teachers in three different programs in the ECE department. In the second part, preservice teachers in both cohorts of ECE 3606 will experience various methods of learning about difficult concepts: reading, activities, and concept mapping. We request permission to use your responses on the six open-ended questions before and after experiencing the various methods as well as your scores on two concept maps. Potentially, the participants in the first part are 108 preservice and inservice teachers and participants in the second part are the 53 undergraduate preservice teachers.

\section{Procedures:}

First, you will be asked to answer six open-ended questions on earth and space science. Answering the questions will take approximately 10-15 minutes in a normal class period. Then, you will receive three different instructional interventions: reading assignments, handson learning stations, and concept mapping. You will be given reading assignments on three concepts as homework and will learn about the other three concepts through hands-on activities. Following instruction on concept mapping, you will work in teams to draw "maps" of two of the concepts. You will answer the six questions two more times after the various interventions. All writing and the participation to the interventions will be done in class in a three week period.

III. Risks:

There are no expected risks to you from participating in this research. Your answers are not graded. If when initially answering the questions, you are concerned that you are not clear on some of the concepts, you have the opportunity to develop clearer understanding.

IV. Benefits:

The results of the first part of the study will help teacher educators decide what earth and space science concepts should be included in teacher education programs. Results from the 
second part will indicate what instructional methods are most effective in clarifying concepts. You will benefit by knowing which concepts you understand well enough to teach and what strategies for clarifying concepts are helpful in building your understanding.

V. Voluntary Participation and Withdrawal:

Answering the open-ended questions and participating in the various instructional interventions are part of the course experience. However, answers to the questions and the concept maps and not graded. They will be scored on rubrics for use in this research. Your participation in this research is voluntary. Whether or not you agree to have your answers and concept maps used in the research will not affect your grades in this class. Withdrawal from the study without adverse consequenœs is possible until all identifying information is removed from the data sheets (see following section). After that, it will impossible to remove data.

VI. Confidentiality:

You will write the last four digits of your social security number rather than your name on the questionnaires and concept maps. Dr. Jarrett will store the data in a secure location in her office and your answers will not be accessible to your instructor. Once the questionnaires are matched, the last four digits will be cut off and a new code number assigned for computer entry purposes. You will not be identified in any way when we present this study or publish its results.

VIII. Contact Persons:

If you have any questions or additional concerns about this study please contact Dr. Olga S. Jarrett (ojarrett@gsu.edu) or Nermin Bulunuz (ecenbbx@langate.gsu.edu) at (404) 651-2584. If you have any questions or concerns about your rights as a participant in this study, you may contact Susan Vogtner in the Office of Research Integrity at 404-463-0674 or svogtner1@gsu.edu.

IX. Copy of Consent Form to Subject:

We will give you a copy of this consent form to keep.

If you are willing to volunteer for this research, please sign below.

Subject

Date

Principal Investigator

Date

2 


\author{
Georgia State University \\ Department of Early Childhood Education \\ Informed Consent C
}

Title:

Understanding of earth and space science concepts: Strategies for concept building in elementary teacher preparation

Principal Investigators: Faculty Supervisor: Olga S. Jarrett

Student Principal Investigator: Nermin Bulunuz

\title{
I. Introduction/Background/Purpose:
}

Elementary school teachers need to have a very broad range of scientific knowledge to teach their students. This dissertation study has three parts. The first part identifies the conceptual understandings held by preservice and inservice teachers on six earth and space science concepts: reason for seasons, phases of the moon, reason for wind, rock cycle, how soil is formed, and reason for earthquakes. All of these topics are covered in elementary school on the Georgia Performance Standards. The second part investigates the effectiveness of various methods of clarifying these concepts in an undergraduate science methods course. In the third part, we would like to know whether what you learned in this science methods class affects how you taught concepts in your field experience as part of your field assignment. Up to 108 preservice and inservice teachers are participants in part one of the study. Twenty-five undergraduates are also included in part two. Because implementing a conceptual change learning station was an assignment in your class only, you are the only group of students (28) who are being asked to participate in all three parts of the study.

\section{Procedures:}

First, you will answer six open-ended questions on earth and space science. Answering the questions will take approximately 10-15 minutes in a normal class period. Then, you will receive three different instructional interventions: reading assignments, hands-on learning stations, and concept mapping. You will be given reading assignments on three concepts as homework and will learn about the other three concepts through hands-on activities. Following instruction on concept mapping, you will work in teams to draw "maps" of two of the concepts. You will answer the six questions two more times after the various interventions. All writing and the participation to the interventions will be done in class in a three week period. For the third part, six of you will be observed by the class instructor who will take field notes while you are implementing your learning stations. You will turn in your learning station assignment, including lesson plans, photographs of your stations (without the children), and your reflection on the stations, including answers to seven questions about the conceptual change station.

III. Risks:

There are no expected risks to you from participating in this research. If when initially answering the questions, you are concerned that you are not clear on some of the concepts, you have the opportunity to develop clearer understanding.

\section{Benefits:}

The results of the first part of the study will help teacher educators decide what earth and space science concepts should be included in teacher education programs. Results from the second part will indicate what instructional methods are most effective in clarifying concepts. The last part will give an idea about how preservice teachers apply the knowledge that they 
gain from the science method course in their field placements. You will benefit by knowing which concepts you understand well enough to teach and what strategies for clarifying concepts are helpful in building your understanding. The field assignment will give you practice in implementing activities designed to clarify concepts.

V. Voluntary Participation and Withdrawal:

Answering the open-ended questions and participating in the various instructional interventions are part of the normal course experience; they will be scored on rubrics for use in this research but will not be graded. However, because one assignment is graded (learning station assignment), you are not asked to sign this Informed Consent Document until your instructor has given you your grade for the course. That way it is impossible for your participation/nonparticipation to affect your grade on that assignment, either positively or negatively. Your participation in this research is voluntary. Those of you who sign this document will have your data included in the research. There will be no negative consequences if you do not want to sign. Should you sign and then wish to withdraw from the study, you can do sowithout adverse consequences. However, once all identifying information is removed from the data sheets (see following section) it will be impossible to remove your data from the research.

VI. Confidentiality:

You will write the last four digits of your social security number rather than your name on the questionnaires and concept maps. After your field assignment has been graded, the relevant lesson plan and reflection will be photocopied and given back to you. You will put the last four digits of your SS\# on the photocopies and return. Dr. Jarrett will store the data in a secure location in her office, and your answers will not be accessible to your instructor. If the Informed Consent Document is signed, Dr. Jarrett will the match questionnaires, cut off the last four digits, assign a new code number for data entry purposes, and return the data to the instructor. You will not be identified in any way when we present or publish this research.

VIII. Contact Persons:

If you have any questions or additional concerns about this study please contact $\mathrm{Dr}$. Olga S. Jarrett (ojarrett@gsu.edu) or Nermin Bulunuz (ecenbbx@langate.gsu.edu) at (404) 651-2584. If you have any questions or concerns about your rights as a participant in this study, you may contact Susan Vogtner in the Office of Research Integrity at 404-463-0674 or svogtner1@gsu.edu.

IX. Copy of Consent Form to Subject:

We will give you a copy of this consent form to keep. If you are willing to volunteer for this research, please sign below. 